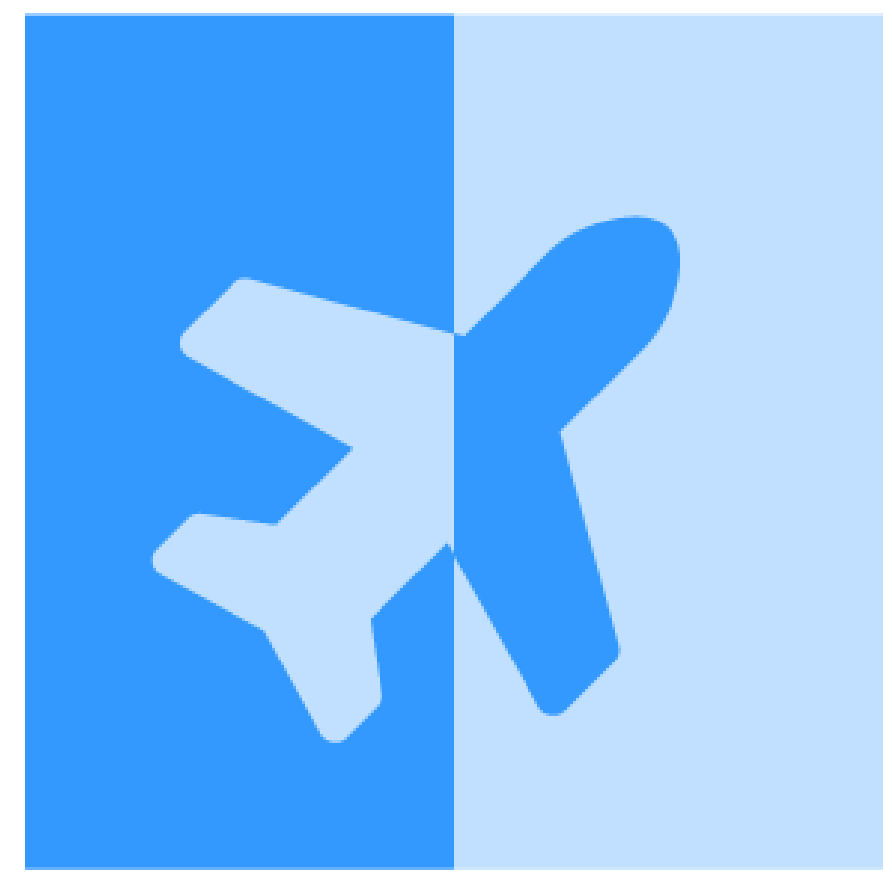

\title{
University-Sponsored Travel at the University of Michigan
}

\section{A Report Developed for and Supported by the \\ U-M President's Commission on Carbon Neutrality}

Revised June 20, 2020

\author{
Creators \\ John Williams, Faculty Co-Lead \\ Ming Xu, Faculty Co-Lead \\ Hyo Sub Choi \\ William Chown \\ Jiangzhou Fu \\ Nate Hua \\ Cathy Lyu \\ Monica Yen
}


Copyright (C) 2021 by the Regents of the University of Michigan

Some rights reserved

\section{(c) (i) $(9)$}

This work is licensed under the Creative Commons Attribution-NonCommercial-NoDerivatives 4.0 International License. To view a copy of this license, visit http://creativecommons.org/licenses/by-nc-nd/4.0/ or send a letter to Creative Commons, PO Box 1866, Mountain View, California, 94042, USA.

Published in the United States of America by Michigan Publishing

DOI: http://doi.org/10.3998/mpub.12095006

ISBN 978-1-60785-691-7 (open access)

This publication is a result of work sponsored by the University of Michigan (U-M) President's Commission on Carbon Neutrality (PCCN) to inform the PCCN's final recommendations to U-M President Mark Schlissel. This publication does not reflect Commission-level recommendations, and should not be interpreted as being recommendations of the PCCN nor carrying its endorsement. 


\section{CONTENTS}

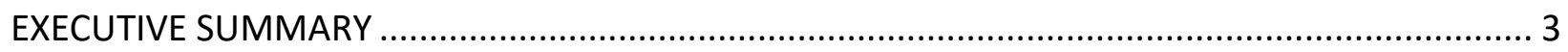

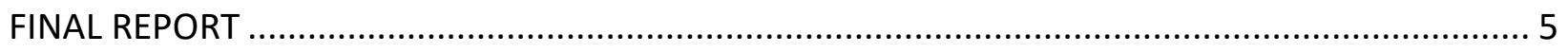

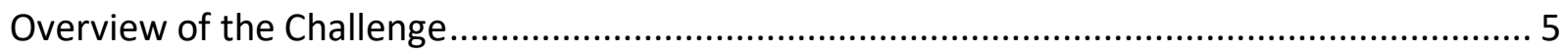

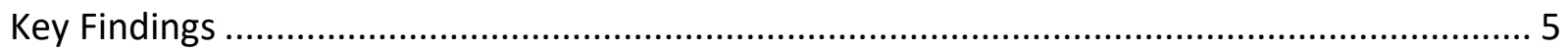

Prioritized Recommendations Summary …….................................................................. 8

Priority \#1 Recommendation: Standardize travel data collection to facilitate carbon footprint calculation and provide feedback to travelers ..................................................................... 12

Priority \#2 Recommendation: Develop mechanisms to assist in reducing the amount of individual travel ............................................................................................................... 13

Priority \#3 Recommendation: Establish a mechanism for travelers on university business to pay a carbon mitigation fee for travel .................................................................................. 14

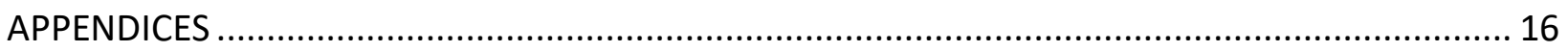

Appendix A: University Air Travel Benchmarking ................................................................ 17

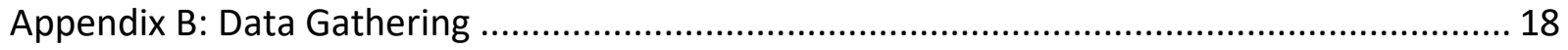

Appendix C: Carbon Accounting Methods, Results, and Discussion ...................................... 19

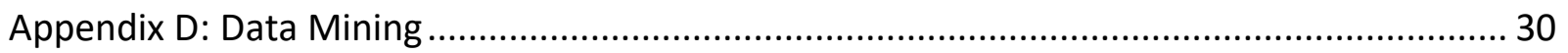

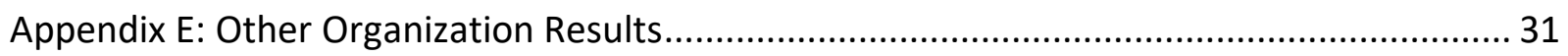

Appendix F: Airline Carbon Offset Prices ......................................................................... 32

Appendix G: Concur and Shared Services Center Receipt Access ............................................ 33

Appendix H: Survey Comparison ...................................................................................... 40

Appendix I: Pilot Travel Survey .......................................................................................... 43

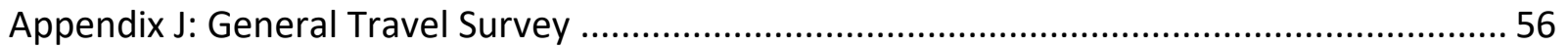

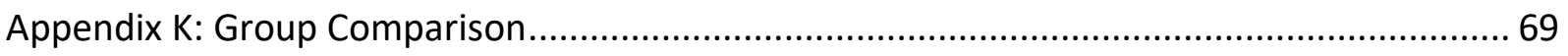

Appendix L: Internet-Assisted Virtual Meetings..................................................................... 71

Appendix M: Air Travel Offsets Established by Other Universities ......................................... 73

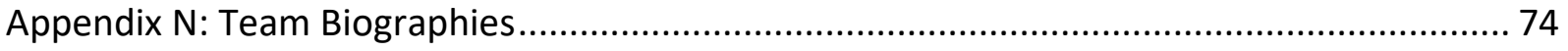

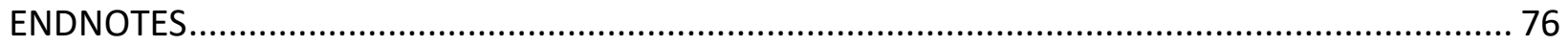




\section{EXECUTIVE SUMMARY}

The mission of the University Travel Internal Analysis Team (IAT) was to quantitate the carbon footprint of university travel and recommend ways to reduce or mitigate this effect. We define university travel as travel by faculty, students, and staff on university business that is paid for using university funds or funds administered by the University of Michigan (U-M) on all three campuses. We did not include student trips between home and school or daily commuting. Our approach to quantitate travel was through reimbursement information and other records from multiple units. Travel data obtained from these sources are reconciled to estimate travel distance of each trip, which is then used to calculate greenhouse gas (GHG) emissions by multiplying by an emission factor for the corresponding travel mode. Using all these sources and scaling up for unavailable information, we estimate U-M's travel carbon footprint at approximately 45,000 metric tons of $\mathrm{CO}_{2}$ equivalents in 2018 . This should be considered a lower limit and points to the need for a more standardized system of recordkeeping that can be readily accessed and provide feedback to the traveler and the department/unit. Overall, this carbon footprint is near the top of that reported by other large universities for travel but is only $7 \%$ of the current reported total of all Ann Arbor campus emissions.

Reducing our travel carbon footprint will require cultural and behavioral shifts and will be difficult as travel is ingrained into academic life. To evaluate this challenge and the willingness to change travel behavior, we surveyed 9,000 travelers obtained from Concur and received over 2,300 replies. The first step is getting U-M faculty, students, and staff to think about whether each travel event is necessary and worthwhile. Some travel is mainly for social and cultural reasons or as a reward for service. Education on the environmental effects of travel may convince people that some travel is not necessary. Modifying the way travel is used as a benchmark of professional success may also help. Finally, some national meetings can be replaced by regional meetings that require no air travel.

Educating the university community on the environmental effects of travel, especially air travel, will encourage individuals to consider whether air travel can be replaced by ground travel. If flying is necessary, understanding why direct flights are less damaging than connecting flights and why business or first class has a larger carbon footprint may help in decision-making. Some air travel can be avoided by internet-assisted virtual meetings. This is especially applicable to short small group meetings such as academic society committee meetings and grant review panels. Most of us have become used to videoconferencing during the COVID-19 pandemic while there had already been some movement in this direction to save money and time. Another opportunity to reduce travel is to convert large annual in-person meetings to an either completely or partially virtual format. While many talks have been replaced by webinars, the challenge is to allow personal interactions in a virtual meeting. We recommend that U-M establish an annual virtual meeting on an area of current social interest to showcase this approach.

Since a significant amount of university travel is deemed essential, we reviewed the use of travel offset fees. Many airlines and a few universities have established their own programs in which a modest fee based on distance traveled goes to support endeavors that reduce net GHG emissions. Our survey indicated that up to $65 \%$ of university travelers would strongly or probably support such a fee if used to reduce GHG emissions on campus or in the local community. Because some individuals both in and outside the University have strong negative views on implementation of a travel mitigation fee, it will require preparation and education as well as consideration of who will pay and how it would be used.

Our three recommendations are to 1) improve travel recordkeeping to make it more easily accessible and to provide feedback to travelers, 2) establish an educational program to reduce 
or replace air travel by other means of communications, and 3) start to work toward establishing a required Travel Mitigation Fee. 


\section{FINAL REPORT}

\section{Overview of the Challenge}

Our team was tasked with quantifying annual greenhouse gas (GHG) emissions from university travel by University of Michigan (U-M) students, faculty, and staff to better illuminate the impacts of various modes of travel on the environment as well as facilitate the creation of the recommendations detailed in this report.

Our first task was to come up with a definition of "university travel" in order to effectively proceed with our work. We decided to include student travel for field work, workshops, or study abroad; student, faculty, and staff travel to meetings or conferences paid for by university sources; athletic travel by students, faculty, and staff; travel to perform music or theatre paid for by U-M sources; travel by outside experts such as visiting faculty or speakers invited by U-M; and travel by new hires to come to U-M at all three campuses (Ann Arbor, Flint, and Dearborn). We did not consider travel to non-university locations paid for by other institutions such as grant review panels or other universities, travel by students from or to home unless paid for by the University, vacation travel, or commuting to be university travel. While we may consider travel to interviews for medical residency or to job interviews as university travel, we did not include such travel in our analyses because it is self-funded and therefore difficult to get records of. Based on the defined system boundary, we analyzed the carbon footprint of university travel for the calendar year 2018.

U-M is a large institution with travel frequently undertaken by students, faculty, and staff alike. There has been considerable concern in recent years for organizations such as research universities to have a system for quantifying their carbon footprints to facilitate climate change mitigation measures. Other universities have analyzed their air travel carbon footprint with most between 25,000 and 45,000 metric tons of $\mathrm{CO}_{2}$ equivalent per year $\left(\mathrm{tCO}_{2} \mathrm{e} / \mathrm{yr}\right.$ ) (see Appendices $A$ and $E$ ). Our analyses yield similar results, highlighting the significant impacts university travel has on total GHG emissions.

\section{Key Findings}

\section{Carbon footprint of university travel}

We estimate the total university travel carbon footprint to be $\sim 45,000$ metric tons $(\mathrm{t})$ in 2018 based on GHG emission factor data from the Environmental Protection Agency (EPA) (Figure 1). Another estimation using an alternative emission factor yielded only a $4 \%$ difference. For a robust breakdown of our methods, please see Appendix $C$. This carbon footprint does not include a radiative forcing factor, which would double the effect of air travel if applied. We did not include it as there is not a general agreement on its value.

The estimated carbon footprint of university travel is $~ 7 \%$ of the U-M scope 1 and scope 2 GHG emissions reported in the PCCN work plan overview from May of 2019. It's important to note that our estimated amount of GHG emissions does not include radiative forcing and maintains uncertainty due to travel data extrapolation, therefore resulting in our estimate being a lower bound on university travel emissions. These uncertainties were addressed in a sensitivity and scenario analysis that can be found in Appendix C. Additionally, we find that air travel is the mode of travel with the most impact, representing $\sim 90 \%$ of the total travel emissions in each model. Car travel was the second most impactful mode of travel, representing $\sim 10 \%$, making emissions from train and bus negligible. Furthermore, air travel was found to be the most frequent mode of travel, representing $\sim 80 \%$ of all unique trips taken in 2018 . Given this, we isolated the most frequent air travel trips originating from Detroit Metropolitan Wayne County 
Airport, gaining insight into popular destinations that can be used to help identify appropriate travel solutions. For further discussion on these results, please see Appendix C.

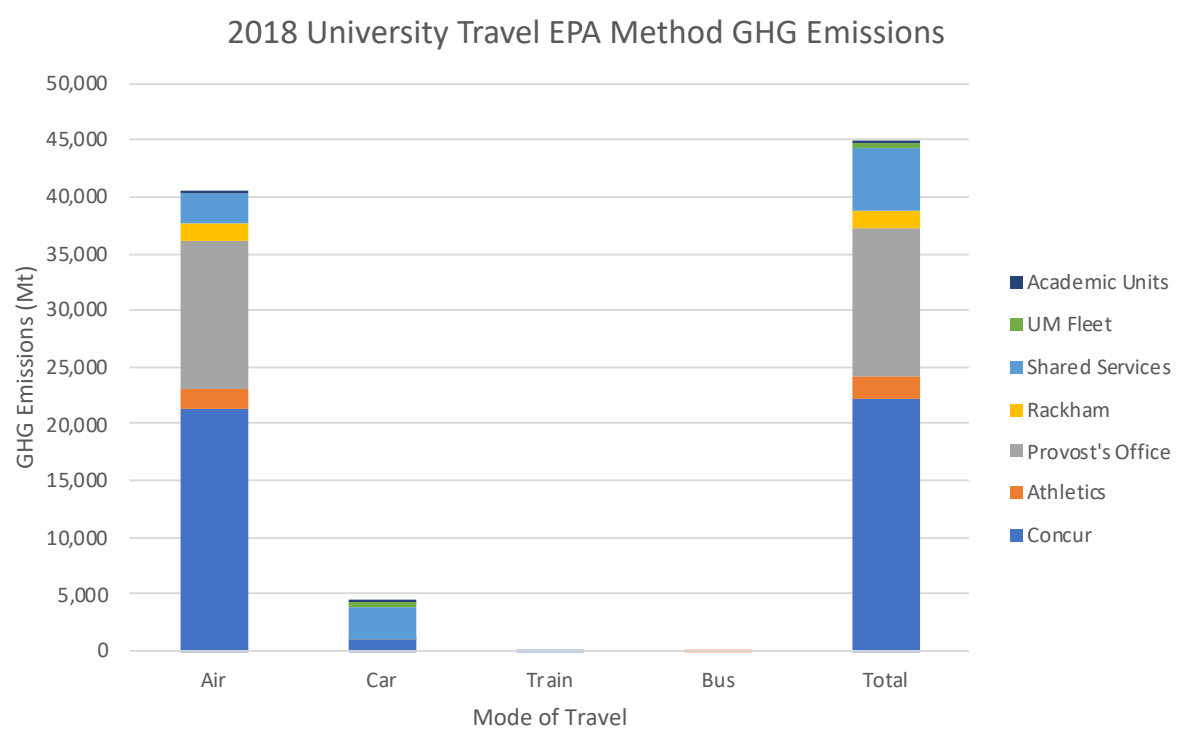

Figure 1. GHG emissions in 2018, modeled using EPA emission factors, from university travel by data source and mode of travel.

\section{Travel survey}

To understand better why and how individuals were traveling on university business, we conducted a survey completed by over 2,300 individuals who traveled in FY2019 as identified by Concur. The most abundant groups in order were staff, faculty, and students. We also assessed their knowledge and attitudes toward travel and willingness to reduce or mitigate their air travel emissions. The survey was deemed to be exempt by the Medical Center IRB. The complete survey and number of answers is given in Appendix $\mathrm{J}$, and reference to the survey is made at various points in the text. Prior to the general survey, we carried out a pilot survey of all members of the Department of Molecular \& Integrative Physiology. The most abundant respondents there, in order, were students, faculty, and staff. Those data are given in Appendix $\mathrm{I}$, and a comparison of the two surveys is in Appendix $\mathrm{H}$. A number of questions were asked regarding alternatives to air travel, which accounts for the majority of the travel carbon footprint.

The most important finding of our survey is about opinions on alternatives to air travel, including videoconferencing and ground transportation (Figure 2). Our results show that most of the faculty members and staff have used videoconferencing, and $60 \%$ of faculty members and staff regard videoconferencing as easy to use. About $80 \%$ of respondents are willing to choose ground transportation instead of air travel when the distance is less than 300 miles in order to reduce $\mathrm{GHG}$ emissions.

We asked a battery of questions regarding the setup of a travel fee to mitigate GHG emissions due to university travel (Figure 3). Our survey data shows that the majority of people (more than $65 \%$ ) support the travel fee even though conditions vary. However, if a travel fee were included in the increased cost of the ticket, the smallest number of respondents, only $25 \%$, would definitely support it.

Furthermore, we also made different group comparisons. Our statistical testing shows that people who know more about GHG emissions tend to accept alternatives to air travel and also are more willing to support the travel fee (Appendix K). This may give us insight for further actions and campaigns to reduce and mitigate air travel emissions. 

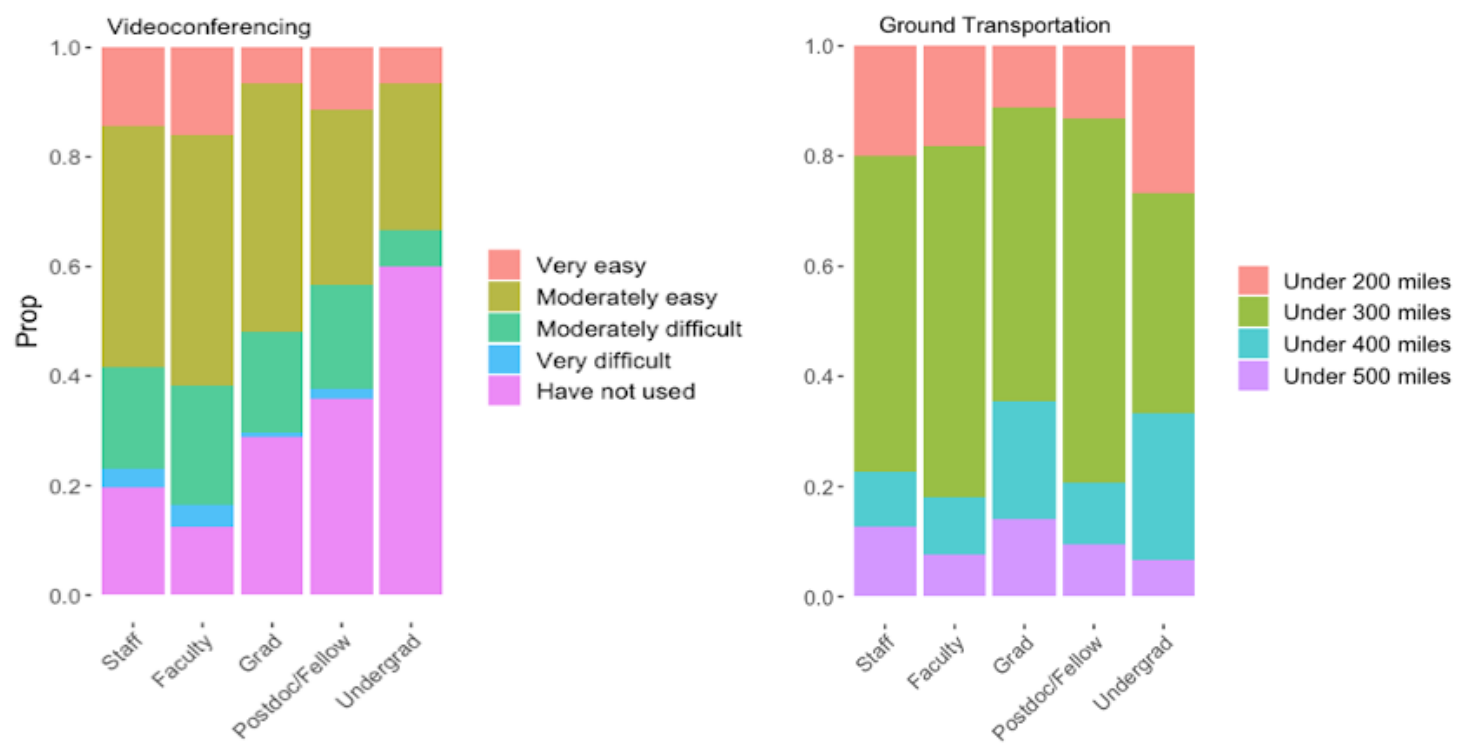

Figure 2. Attitudes on alternatives for university travel.

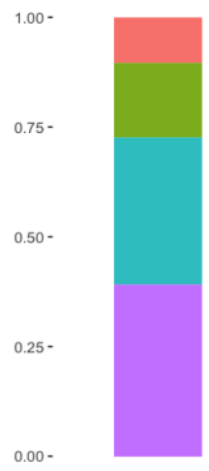

024

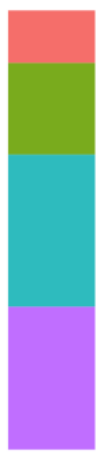

Q25

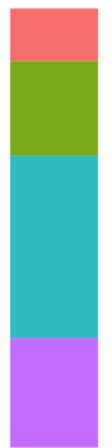

Q26

\begin{tabular}{cl}
\hline Question & $\begin{array}{l}\text { How much would you } \\
\text { support a travel fee if...? }\end{array}$ \\
\hline Q24 & $\begin{array}{l}\text { If the travel fee were paid } \\
\text { for by the funds supporting } \\
\text { the travel }\end{array}$ \\
Q25 & $\begin{array}{l}\text { If it were paid for by the } \\
\text { Unit or Department home } \\
\text { of the traveler } \\
\text { If the travel fee were } \\
\text { included in the increased } \\
\text { cost of the ticket? }\end{array}$ \\
\hline
\end{tabular}

Figure 3. Attitudes on travel fee.

\section{Carbon Footprint and Accounting}

For each trip in our accounting boundary, data on transportation mode, distance traveled, and number of people who traveled are required for quantifying the carbon footprint of university travel. Some of these data are directly reported or can easily be determined, such as transportation mode and number of people who traveled in each trip, whereas distance traveled often needs to be inferred based on other information, such as trip origin and destination. We found that these data are reported to and recorded by various units on the three campuses in a highly decentralized way (see Figure 4). Most of the data are from Concur and Shared Services Center (SSC) when travel reimbursements or travel expenses directly paid by U-M are processed. In addition, there are other travel expenses that are not processed through either Concur or SSC, such as some chartered trips by the Athletics Department. The majority of these data are unfortunately embedded in receipt files (PDF or images) that need to be extracted using computer programs. 


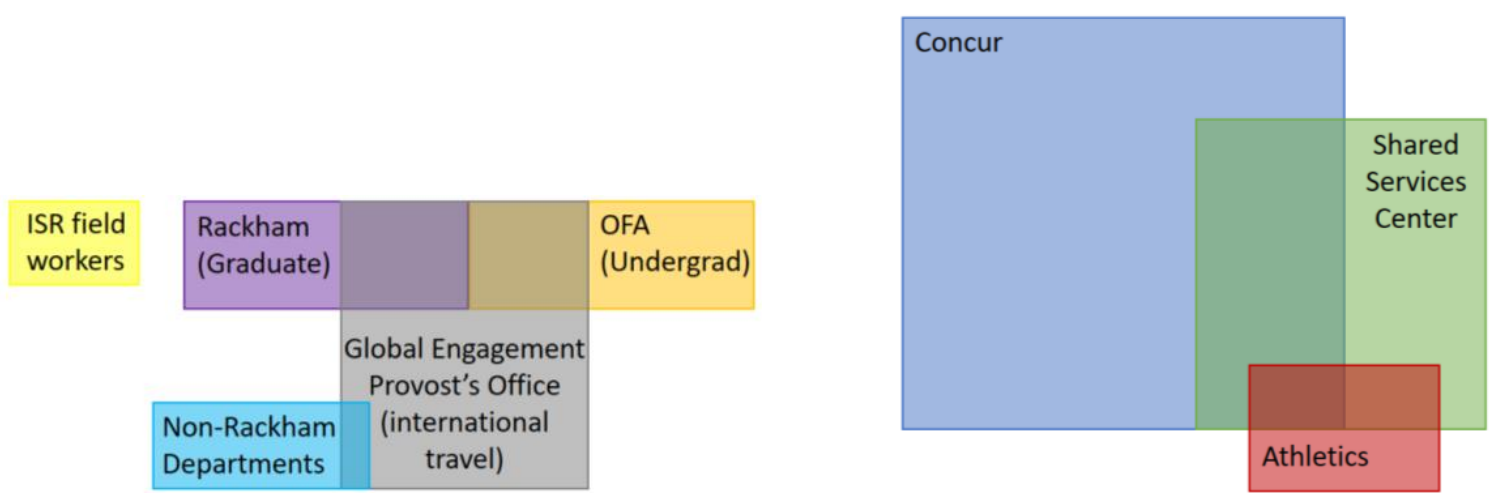

Figure 4. Sources of travel data from various units at U-M. Size of blocks roughly represents the number of trips based on estimation. Units with additional travel data at UM-Flint and UM-Dearborn are not shown.

To estimate the carbon footprint of university travel, we first calculate travel distance for each trip in 2018 recorded in various datasets that are available to us. Next, we estimate the GHG emissions of each trip by multiplying the travel distance by an emission factor of the corresponding travel mode. Since our travel data are not complete, we extrapolate the carbon footprint of all university travels in 2018 by linearly scaling up the results calculated based on the available data.

Two main challenges exist for carbon footprint accounting for university travel. First, university travel data are recorded by various units on campus in a highly decentralized and unstandardized way. Getting access to these data from multiple sources was challenging. Second, processing these travel data in various formats is another challenge. We developed Python scripts for each data source by its format to calculate the travel distance (great circle distances [GCD] for air travel) between origins and destinations. The majority of the travel data are embedded in PDF or image files of expense reports. We also had to develop image recognition scripts in Python to extract travel information from those files, for which many issues remain unresolved due to difference in file type and image quality.

More information about our carbon footprint accounting methods and results can be found in Appendices B, C, and D.

\section{Prioritized Recommendations Summary}

\section{Standardize travel data collection and provide feedback to travelers on travel carbon footprint}

A standardized system should be developed at U-M to collect necessary information on all university travels to establish baseline of miles traveled, number of travel segments, and the travel carbon footprint to monitor the reduction progress. The system should also be able to provide feedback to travelers on the carbon footprint of each trip to facilitate behavioral changes to reduce travel and reduce travel carbon footprint.

\section{Develop mechanisms to assist in reducing the amount of individual travel}

In order to reduce the amount of university travel and its carbon footprint, individuals, including faculty, staff, and students, need to be assisted in limiting their own travel, especially air travel. We need to develop a culture in which everyone considering travel thinks about whether the travel is necessary, its positive benefits, and its negative effects on the planet. Faculty and staff especially should develop goals to reduce their air travel and use other means of travel and communication. In the past, travel has sometimes been used to reward individuals, and this practice needs to change. Promotion and tenure committees should evaluate the quality of 
national and especially international presentations rather than their quantity. Providing feedback on the carbon footprint of planned travel through a web tool and at time of booking or reimbursement should assist in this as will presentations in news media and at departmental meetings. This coverage can include the fact that direct flights are better for the environment than connecting flights as direct flights use less fuel.

\section{Mitigate air travel by use of ground transport}

A second way to reduce travel is to promote the use of ground transportation and regional meetings accessible by ground transport, such as train, intercity bus, or high-mileage hybrid cars. In addition to assisting travelers with deciding if travel is necessary, an effort should be made to assist switching from air to ground transportation. The top domestic destinations for U$\mathrm{M}$ travelers are Washington, DC, New York City, and Chicago. Much travel to Washington, DC, is for in-person review panels and committees that can be replaced by videoconferencing, and

travel to Chicago can be by train rather than air. To minimize the effect of ground transport, U-M should provide access to high-mileage cars and make their use free or low cost when this travel replaces air travel or if two or more passengers use the same vehicle. We recommend encouraging the use of ground transportation for trips under 300 miles. Eighty-one percent of the survey participants are willing to use ground transportation for distances under 300 miles to reduce GHG emissions. These distances would cover locations such as Chicago, Indianapolis, Pittsburgh, and Toronto that constitute $6.8 \%$ of the university travel that we have analyzed and will reduce travel $\mathrm{GHG}$ emissions by $5 \%$ if most of this air travel were replaced by ground transportation.

\section{Mitigate travel by videoconferencing}

We suggest that a significant portion of university travel could be replaced with videoconferencing. Videoconferencing platforms have been steadily gaining traction over the last decade, and due to the recent COVID-19 outbreak, their use has surged. We propose that U-M promote the use of videoconferencing via several methods. First, each department/unit should provide videoconferencing facilities to their members and have someone who can maintain the facilities and help students and faculty use videoconferencing. Second, public lectures and seminars should be streamed and archived. And third, U-M should host an annual virtual conference on a topic of national importance in order to increase the visibility and comfort level of using videoconferencing.

From our survey, we found that one of the most important challenges to increasing videoconferencing use is basic familiarity. If students and faculty do not know that videoconferencing is an option, they will never use it. When asked about survey participants' previous use of videoconferencing, "Have not used" was the largest category at $38 \%$. Importantly, this survey was completed shortly before COVID-19 became widespread and social distancing began; many classes and other meetings have been held on videoconferencing platforms for several months now. We expect that if the same question were to be asked after COVID-19, we would find a significantly greater comfort level with videoconferencing.

The primary downside to virtual meetings is that personal connections are easier to make in person, when people can physically interact with one another; a good handshake, for example, can help to increase confidence and trust. However, much of university travel is well suited to virtual meetings. In the survey, participants were open to videoconferencing for several forms of university travel, including grant review panels, society committee meetings, and networking with colleagues. They were least willing to use videoconferencing for presenting at large meetings. Again, we expect that the increased familiarity with and use of videoconferencing platforms due to COVID-19 have increased the willingness of U-M faculty, staff, and students to consider videoconferencing in place of air travel for any of the scenarios shown in Figure 5. 
Situations to Consider Videoconferencing in Place of Traveling by Air

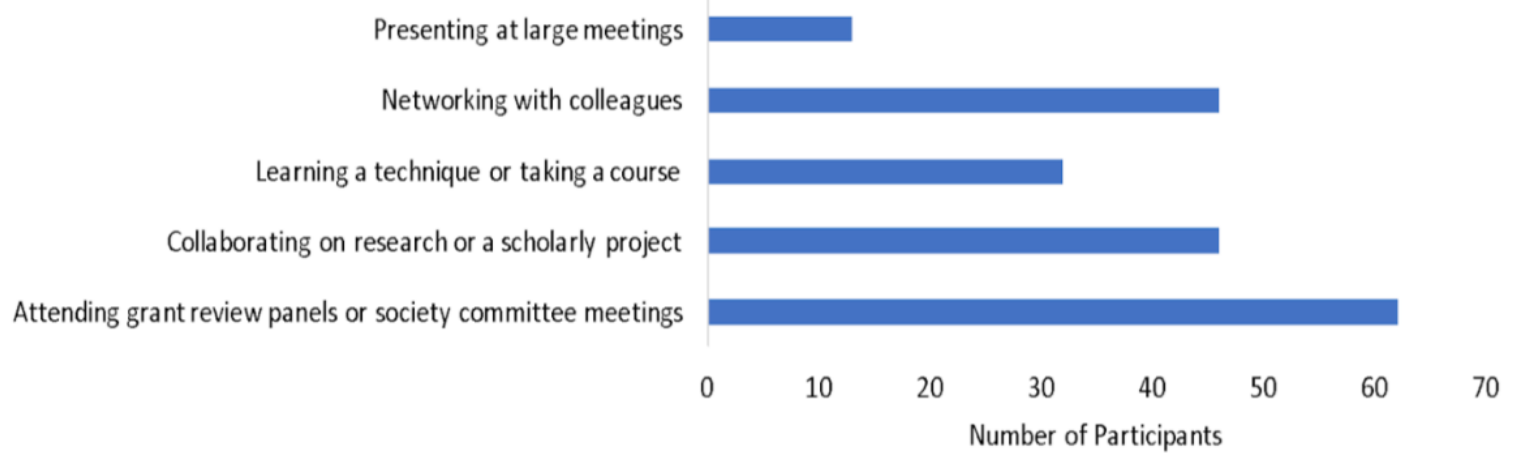

Figure 5. Situations to consider videoconferencing in place of traveling by air.

The type and quantity of videoconferencing facilities would vary by department; some buildings, such as the Duderstadt Center, already have extensive videoconferencing facilities. The cost of videoconferencing facilities and equipment has a wide range, depending on factors such as how many people would be using them for different meetings, how many people would be on a single meeting, and how long the facility should last. Installation prices can range from free to around $\$ 50,000$ as well as include a monthly subscription fee that is usually less than $\$ 100$.

However, even if students, faculty, and staff are willing to use videoconferencing, the best facilities are useless if the meetings do not offer a videoconferencing option in the first place. That is why U-M should lead by example and stream and archive public lectures, seminars, and potentially other types of events. The library and other venues should also host workshops on how to run a virtual meeting that could cover both hardware and techniques.

To promote video meetings, we recommend that U-M hosts an annual virtual conference under the Michigan brand on a topic of national importance to promote videoconferencing as a viable substitute for in-person meetings and events. With the right topic and speakers, such a conference has the potential to be highly popular.

Overall, we expect videoconferencing to potentially reduce travel-related GHG emissions by as much as $10 \%$ over the next five years. Further substitution of videoconferencing for travel probably depends on technological advances and society understanding that reducing climate change requires major lifestyle changes. It is also important to note that the usefulness of virtual meetings depends only partly upon the willingness of U-M faculty, staff, and students to utilize videoconferencing; the meeting host must also be willing to arrange a virtual meeting option. Fortunately, such options have become fairly commonplace as environmental (and, more recently, COVID-19) concerns have increased. It is also important to realize that there are energy costs to manufacture and use videoconferencing. It will increase the use of electricity, but since electricity can easily be quantitated and generated without fossil fuels, this increase can be mitigated. For further information, see Appendix J.

\section{Mitigate essential air travel by carbon offsets}

Because long-distance travel by air is often essential, but also emits considerable GHGs, we feel that travelers should be informed of the amount of GHG emissions produced and the cost to mitigate this production. We propose that U-M work toward initiating an air travel mitigation fee to offset the carbon footprint of all university travel. Using a social cost of $\$ 50$ per $\mathrm{tCO}_{2} \mathrm{e}$, the travel fee would vary depending on distance and other factors. Table 1 shows the GHG emissions calculated at the myclimate website 
(https://co2.myclimate.org/en/flight calculators/new), which uses a forcing factor of 1.9 for factors other than $\mathrm{CO}_{2}$ alone, and the resulting travel fee. If the other calculators were used, which do not include a forcing factor, the travel fee would be only half as much.

Table 1. Social cost of flying to selected destinations

\begin{tabular}{|c|c|c|}
\hline Round Trip Detroit to & $\underline{\mathrm{tCO}_{2}} \mathrm{e}$ & Travel Fee \\
\hline Boston & $\overline{0.43}$ & $\$ 22$ \\
\hline Los Angeles & 1.01 & $\$ 55$ \\
\hline Paris, France & 2.10 & $\$ 105$ \\
\hline Tokyo, Japan & 3.40 & $\$ 170$ \\
\hline
\end{tabular}

The travel fee would be paid by the funds supporting the travel, the traveler's discretionary funds, or the traveler's department, in that order. This program could establish several uses for the funds, which might include a local sequestration project. If funds are used for an external project outside the United States, that project should be certified. In our survey of 2,360 U-M travelers, $52 \%$ would definitely or probably support a travel fee, but $46 \%$ would probably or definitely not support the fee. This significant negative response and a number of individual comments indicate that a broad educational campaign should be provided before imposing the travel fee. There is little indication that individuals opposed to the travel fee feel that the cost of environmental damage is not real, but rather they feel it is not fair for the traveler to have to pay and that it might reduce the ability to fly for some. This supports the contention that we need an educational campaign to encourage U-M faculty, staff, and students considering travel to 1) evaluate whether the travel is worthwhile, 2) substitute ground for air travel or hold a virtual rather than face-to-face meeting, or 3 ) mitigate air travel by means of a travel offset. In support of this, a recent study found that travelers were more willing to include a mitigation fee in the cost of travel if it were framed as an "offset" and would have positive effects on the environment. ${ }^{1}$

There are a number of companies that act as brokers for carbon offsets and identify and validate projects in less-developed parts of the world. Some sell directly to consumers and others connect to airlines. The better ones use $90 \%$ of their funds for projects and have thirdparty verification from independent organizations. Individual projects include simple cook stoves to reduce fuel and air pollution, sustaining forests, and biogas production. Many airlines have their own programs with a partner (Appendix F). These programs often underestimate carbon production and may underestimate carbon production costs. ${ }^{2}$ Because individuals will choose different airlines, the costs between travelers may differ, and because they are voluntary, U-M would have no control over the process. For these reasons, this report recommends a single calculator tied to reimbursement. Another factor is that many environmental writers have called air travel offsets a con job that fails to deliver real measurable reductions. Not everyone is so negative, and for individual travelers, these programs at least introduce the idea that you can offset the environmental costs of air travel.

Several universities have already instituted various forms of a travel fee (see Appendix M). Most of these funds are used to reduce external energy needs in the surrounding area or on campus. Most often their costs are low, possibly to generate acceptance, and some exempt certain types of travel, such as student, athletic, or sometimes grant-funded travel. Respondents in our survey of travelers at U-M were most supportive of on-campus or off-campus but local projects to generate clean power and least supportive of planting trees in the Amazon basin. 


\section{Priority \#1 Recommendation: Standardize travel data collection to facilitate carbon footprint calculation and provide feedback to travelers}

A centralized system should be developed to collect all necessary information for calculating travel paid for by university sources. Since Concur already hosts most of U-M's travel data including Flint and Dearborn campuses, we recommend all other sources of travel data to be integrated with Concur. Also, the system should automatically provide carbon footprint information to the traveler.

GHG emission reduction potential. Such a centralized system itself does not directly reduce emissions but will provide baseline data to evaluate emission reduction potential and monitoring capability to track emission reduction progress for university travel.

Financial costs and savings. The financial costs of implementing such a system will depend on several factors, including Concur's pricing, the structural aspects of the system that affect how many people oversee the creation and maintenance of the system, and the availability of departments or groups to undertake the project. The savings such a system would bring are likely to be considerable, as not having a standardized procedure to quantify GHG emissions has led to travel unfettered by environmental impact considerations, resulting in longer flights, car, train, and bus routes.

Metrics and tracking. The metrics used to keep track of travel would primarily be the amount of $\mathrm{GHG}$ emissions per trip measured in $\mathrm{tCO}_{2} \mathrm{e}$. This metric will be calculated by an internal calculator that should be developed down the line.

Organizational structure considerations. The system that is established will require information such as travel date, departure location, arrival location, and mode of travel (air, train, car, or bus). Since Concur already hosts most U-M's travel data, we recommend all other sources of travel data to be integrated with Concur. Such a system for keeping track of travel data should include centralized data storage/entry in the Concur system.

Campus culture and individual accountability considerations. Convincing units at U-M that do not use Concur and have alternative travel accounting systems to adopt a different method of keeping track of travel may be difficult without a campaign to broadcast the benefits of a centralized system of travel accounting. This consideration may contribute to the financial cost consideration mentioned above. Individual accountability will be enhanced with the second part of this recommendation. Providing carbon footprint information to each traveler will bring environmental impact of travel to bear on decision-making regarding university travel.

Equity and justice considerations. The system should be accessible to students, faculty, and staff alike. Demographic data are not relevant and should therefore not be collected.

Scalability, transferability, and external engagement. The system we are recommending should require regular engagement with Concur staff and staff members from other units in charge of procurement and reimbursement. Since Concur is already being used for universitysponsored travel for faculty/staff, we do not expect any difficulty in scaling the system up to include students. Additional departments at the University using the system will put more load on the system, but that is not expected to be a problem either.

Timeline for implementation. Creating a committee or assigning a group to oversee the creation of the system may take a couple months. Assistance with the campaign to change campus culture may extend the timeline to six months. The creation of the system may take another six or more months.

Unknowns, gaps, and potential implementation challenges. Our recommendation is based on our limited understanding of university administrative structure and resources available. 
Some of the details of the recommendation may not apply to the real situation. But creating a system that can regularly collect necessary travel data to calculate carbon footprint and provide feedback to travelers remains necessary and urgent.

Critical next steps to catalyze work. As mentioned in our timeline, the most critical next step is to organize a committee to oversee the creation of the travel accounting system.

\section{Priority \#2 Recommendation: Develop mechanisms to assist in reducing the amount of individual travel}

In order to reduce the amount of university travel and its carbon footprint, individuals including faculty, staff, and students need to be assisted in reducing their own travel, especially air travel. We need to develop a culture in which everyone considering travel thinks about whether the travel is necessary, its benefits, and its negative effects on the planet. In the past, travel has been used to reward individuals, which needs to change. Regional meetings accessible by ground should be promoted as a substitute for some national meetings. In addition to assisting travelers with deciding if travel is necessary, an effort should be made to assist switches from air to ground transportation. To minimize the effect of ground transport, U-M should provide high-mileage cars and make their use free or low cost when it replaces air travel or if two or more passengers use the same vehicle. A third way of reducing travel is to provide facilities and assistance for videoconferencing on campus. Each department/unit should provide one or more rooms equipped for videoconferencing for its members. All departments/units should stream and archive their seminars and public lectures. To promote video meetings, U-M should hold an annual low-cost virtual conference in an area of national importance. The Duderstadt Center can be a resource for this. Faculty can also be given a reward of discretionary funds each time they participate in a video meeting that otherwise would require travel.

Carbon emission reduction potential. It should be possible to initially reduce overall air travel by $20 \%$ over five years, with $10 \%$ by abstaining or switching to ground travel and $10 \%$ by replacing travel with videoconferencing. Given our current travel carbon footprint of $\sim 45,000$ $\mathrm{tCO}_{2} \mathrm{e} / \mathrm{yr}$, this would be a reduction in $9,000 \mathrm{tCO}_{2} \mathrm{e} / \mathrm{yr}$. Further reduction may be possible, and we may also inspire individuals to reduce their non-work-related travel.

Financial costs and savings. The main new ongoing cost would be the salary for the individual charged with implementing these programs. This could be the same person who implements Priorities 1 and 3 and the overall cost might be $\$ 130,000$ per year. The other cost would be for establishing new videoconferencing hubs for small groups in 10 buildings. This could be done for $\$ 50,000$. The ongoing cost is estimated at $\$ 13$ per $\mathrm{tCO}_{2} \mathrm{e}$.

Metrics and tracking. The main metric would be the number of air travel trips taken and air trips averted by use of ground transportation or videoconferencing.

Organizational structure considerations. We recommend that the University establish a guideline for when to use videoconferencing or ground transportation instead of air travel. We recommend this guideline be created and regulated by the Office of Sustainability.

Campus culture and individual accountability. To gain acceptance for this program there would need to be a change in campus culture. This change could be promoted by stories in The Michigan Daily and The University Record and presentations to departments or faculties. Deans and promotion committees should be convinced that travel should not be used as a promotion metric. Individuals and departments/units should be given an annual accounting of their travel and its footprint at the same time as the Annual Report is prepared.

Equity and justice considerations. No individual should be asked to pay for the use of 
videoconferencing. We recommend the videoconferencing rooms be set up in a way to promote diversity, inclusion, and equity and consider accessibility for all U-M faculty, staff, and students. Similarly, it will also be necessary for U-M to make exceptions for ground transportation for those who may be unable to use alternative modes of travel for accessibility reasons.

Timeline for implementation. This program will take some time to ramp up. In the first year, videoconferencing facilities should be added, and educational material on the climatic impact of flying should be prepared. It may be easier to convert staff and administrative meetings to virtual than faculty and student meetings.

Unknowns, gaps, and potential implementation challenges. These changes will require behavioral changes, which are difficult to predict.

Critical next steps to catalyze work. Recruit a person to oversee the programs.

\section{Priority \#3 Recommendation: Establish a mechanism for travelers on university business to pay a carbon mitigation fee for travel}

A carbon mitigation fee could be limited to air travel or also include ground travel, which accounts for a small fraction of the travel carbon footprint. The fee would be calculated either at the time of ticket purchase or reimbursement and would be charged to the funds supporting the travel or the traveler's department or unit. The money paid would go into a Travel Mitigation Fund, if desired to keep separate, or pooled into a broader Energy Reduction Fund in a manner that the overall travel component could be calculated. In either case, the money would be used for energy conservation, sequestration, or generation of clean power in the University or surrounding area. This travel mitigation fee would be integrated with the Priority \#1 recommendation.

Carbon emission reduction potential. Our estimate of the University's travel footprint and the possible $20 \%$ reductions as seen in the Priority \#2 recommendation leaves $36,000 \mathrm{tCO}_{2} \mathrm{e} / \mathrm{yr}$ to be offset by the travel mitigation.

Financial costs and saving. If the social cost of GHG emissions is set at $\$ 50$ per $\mathrm{tCO}_{2} \mathrm{e}$, the aggregate cost for the travel mitigation would be $\$ 1,800,000$ per year. This would be supported by a variety of sources including departments/units. The main central cost to run the program would be for a person to oversee the collection, accounting, and use of the funds. This could be combined with the oversight of the travel system once it is in place.

Organizational and structural considerations. We recommend that the person responsible for monitoring travel and the mitigation fee program be part of the Office of Sustainability. We also recommend that a Travel Advisory Committee of faculty, students, and staff be established to advise the program.

Campus culture and individual accountability. Same as for Priority \#2 recommendation.

Equity and justice considerations. No individual should be asked to pay the mitigation fee from their personal funds. All departments/units would need to establish a mechanism to pay the fee if funds supporting the travel cannot pay. Because athletes often travel in groups and the travel is supported by the Athletic Program, we recommend that all athletic travel be covered centrally.

Scalability, transferability, and external engagement. This program could start with UM-Ann Arbor, then spread to the other campuses and possibly other state-funded universities. Individuals outside the University could be provided the opportunity to calculate their travel carbon footprint and make a voluntary contribution through airlines or other mechanisms. 
Timeline for implementation. It will take some time to get mechanisms and procedures in place for travel purchase, reimbursement, and information feedback to the traveler. The mitigation fee program could start one year after its announcement. This will allow time for publicity and educational material as described for Priority \#2 recommendation. The fee could be voluntary for the first year of implementation.

Unknowns, gaps, and potential implementation challenges. The major unknown is the length of time it will take to establish a more detailed system for collecting travel data.

Critical next steps to catalyze work. Approve and announce the decision to include university travel as part of the University's carbon footprint and the establishment of a carbon travel fee. The subsequent step would be to recruit a person to oversee the program.

\section{Timetable for Carbon Neutrality for University Travel}

University travel, as is true for most scope 3 emissions, is dependent on individual choices made within and outside the University. Moreover, the University's research, education, and service roles extend beyond the campus to the state and the world as well and are essential to its mission. Hence, travel can be reduced but not abolished and to reach carbon neutrality must involve carbon offsets. This seems appropriate since the choice of air travel incurs an environmental cost beyond that covered by the ticket price.

Toward the end of our work with air travel, it became clear that we need to explicitly track the mileage traveled and probably the number of flight segments as well as the carbon footprint. These numbers were generated to obtain the carbon footprint and for 2018 were 142,677,047 miles and 62,288 unique segments for air travel. The importance of this is that the efficiency of commercial flying has been increasing at $2 \%$ per year but has been overtaken by an increased number of flights globally, which has led to a $32 \%$ increase in $\mathrm{CO}_{2}$ emissions over the last five years. ${ }^{14}$ Thus, if the University of Michigan can prevent an increase in miles traveled, we can obtain a decrease in the carbon footprint of at least $10 \%$ over the next 10 years. This combined with a decrease in travel by choice (10\%) and replacement of air by ground travel $(5 \%)$ and virtual meetings (10\%) makes the goal of reducing the travel footprint $35 \%$ by 2030 seem reasonable.

The effect of COVID-19 on travel, especially by air, overtook us in March 2020. Because of the health and economic effects and the University's response, university travel is almost zero. Some travel will return as the University reopens, but this is unlikely to be more than partial until a vaccine is developed. COVID-19 has shown that air travel is not as essential as we thought previously, and because of its effect on climate change, the University may want to develop more stringent goals to prevent faculty and staff travel from returning to its pre-COVID-19 level. Do we need to send a large contingent to a football bowl game? Do we even need bowl games unless they are for a national championship? Administrative limitation of air travel would have to come from the central Administration and be modeled by School and College administrators, but if pursued vigorously, this could reduce total air travel by $50 \%$ while maintaining our core missions.

By 2050 , it is possible that some air travel will use a low-carbon energy source, such as electricity, biofuels, or synthetic jet fuel. However, to get to a zero carbon footprint for travel, offsets will be needed. This means that the sources that fund travel will pay a fee to reduce GHG production additively and permanently and in a verifiable manner on or off campus. In this report, we propose the establishment of an Air Travel Mitigation (ATM) Fee and Fund. We do not recommend that the University use its own funds to pay this fee in its entirety because it would initially be a large amount (around \$2 million/year). Even more importantly, in paying the 
entire fee, the University would reduce the incentive for individuals to learn to limit travel and be responsible for determining when travel is essential. However, the University could make a statement and serve as a model if it agreed to pay the ATM fee for purposes such as international student educational travel. The Athletic Department will ultimately have to pay the ATM fee for athletic travel, which could be phased in. This could lead to another $15 \%-25 \%$ reduction in the travel carbon footprint by 2030 . The biggest initial issue is that some sources of travel funds, such as federal grants, cannot currently be used to pay the ATM fee. Some of this may change over time, but this cannot be included in planning. If travel offsets are used, it should be possible to reduce the University's travel carbon footprint $50 \%$ by 2030 and achieve carbon neutrality by 2040 or 2050.

\section{Next Steps}

The most critical near-term action items U-M should take to catalyze progress on this topic are:

- Organize a committee with representation from UM-Flint and UM-Dearborn to oversee the creation of a centralized travel accounting system with carbon footprint assessment capabilities and the ability to provide feedback to travelers and departments.

- Contact necessary external stakeholders, including Concur and carbon offset providers.

- Approve and announce the decision to include university travel as part of U-M's carbon footprint.

- Begin the educational process on the effects of travel on climate change.

- Begin planning for the initiation of an Air Travel Mitigation Fee and Fund.

\section{APPENDICES}

A: UNIVERSITY AIR TRAVEL BENCHMARKING

B: DATA GATHERING

C: CARBON ACCOUNTING METHODS, RESULTS, AND DISCUSSION

D: DATA MINING

E: OTHER ORGANIZATION RESULTS

F: AIRLINE CARBON OFFSET PRICES

G: CONCUR AND SHARED SERVICES CENTER RECEIPT ACCESS

$H$ : SURVEY COMPARISON

I: PILOT TRAVEL SURVEY

J: GENERAL TRAVEL SURVEY

K: GROUP COMPARISON

L: INTERNET-ASSISTED VIRTUAL MEETINGS

M: AIR TRAVEL OFFSETS ESTABLISHED BY OTHER UNIVERSITIES

N: TEAM BIOGRAPHIES 
Appendix A: University Air Travel Benchmarking

Air Travel GHG Emissions by other North American Universities

\begin{tabular}{|c|c|c|c|c|}
\hline School & Enrollment* $^{*}$ & $\underline{\text { Air Travel } \mathrm{tCO}_{2}} \underline{\mathrm{e}}$ & \% Campus total & How Calculated \\
\hline Arizona State U & 55,552 & $45,000(2018)$ & $?$ & No details given \\
\hline $\begin{array}{l}\text { Cornell } \\
\text { (Ithaca) }\end{array}$ & 23,600 & $23,727(2018)$ & $10 \%$ & No details given \\
\hline Ohio State U & 45,087 & $45,262(2017)$ & $9 \%$ & No details given \\
\hline $\begin{array}{l}\text { U British } \\
\text { Columbia }\end{array}$ & 54,863 & $\begin{array}{l}26,333- \\
31,685 \\
(2016)\end{array}$ & $63-73 \%$ & $\begin{array}{l}\text { Central Booking, } \\
\text { Concur, and a } \\
\text { Survey }\end{array}$ \\
\hline $\begin{array}{l}\text { U Maryland } \\
\text { (College Park) }\end{array}$ & 41,200 & $47,801(2017)$ & $25 \%$ & No details given \\
\hline U Montreal & 45,630 & $40,193(2018)$ & $39 \%$ & $\begin{array}{l}\text { SIMAP from } \\
\text { sample } \\
\text { of travel data }\end{array}$ \\
\hline U Washington & 44,786 & $17,800(2014)$ & $11 \%$ & Est from $\$$ spent \\
\hline
\end{tabular}

* Enrollment is taken from current website and most are total but some are FTE.

Cornell and Maryland do not include data from their medical schools which are considered a different campus. 


\section{Appendix B: Data Gathering}

List of units and contacts for travel data at U-M:

- Procurement Services, Services \& Performance Support (Concur)

- Travel and Expense Processing, Shared Services Center

- Accounts Payable, Shared Services Center

- Athletic Department

- Global Engagement Team, Provost's Office

- Rackham Graduate School

- Office of Financial Aid

- Institute for Social Research

- Colleges/Schools/Departments

- Alliance for the Arts in Research Universities (a2ru)

- School for Environment and Sustainability

- Ross School of Business

External contacts:

- VP, Concur Labs 
Appendix C,

University Travel Internal Analysis Team Final Report

\section{Appendix C: Carbon Accounting Methods, Results, and Discussion}

\section{Methods}

We utilized two methods for our university travel GHG emissions accounting, both of which utilize emission factors, Great Circle Distances (GCDs), and ground vehicle miles. The first method (EPA method) relied on $\mathrm{CO}_{2}, \mathrm{CH}_{4}$, and $\mathrm{N}_{2} \mathrm{O}$ emission factors from the EPA. ${ }^{3}$ Ground vehicle emission factors were based on data from the EPA's Inventory of U.S. Greenhouse Gas Emissions and Sinks: 1990-2015 and the Federal Highway Administration Highway Statistics 2015. Car and bus emission factors were standardized to vehicle miles while train emission factors were standardized to passenger-miles. Air travel emission factors, standardized to passenger-miles, were based on 2017 Guidelines to Defra/DECC's GHG Conversion Factors for Company Reporting. These air travel emission factors were segmented based on travel distance, with different factors for trips $<300$ miles, trips between 300 and 2,300 miles, and trips $>2,300$ miles. Additionally, the most recent global warming potentials (GWPs) were used to convert all emissions to $\mathrm{GHG}$ units of $\mathrm{tCO}_{2} \mathrm{e}$. The second method (SIMAP method) relied on $\mathrm{CO}_{2}, \mathrm{CH}_{4}$, and $\mathrm{N}_{2} \mathrm{O}$ emission factors from SIMAP. ${ }^{4}$ SIMAP is a GHG accounting tool designed by the University of New Hampshire and commonly used by other organizations. Its ground vehicle emission factors, standardized to vehicle miles, are based on U.S. Department of Transportation fleet emission factors and fuel economies. Its air travel emission factors, standardized to passenger-miles, were calculated using the EPA's National Emission Inventory for combustion factors and passenger-mile data from the U.S. Bureau of Transportation Statistics.

Two other methods which leveraged online emissions calculating tools, the ICAO Carbon Emissions Calculator and the myclimate $\mathrm{CO}_{2}$ Calculator, were explored for quantifying air travel emissions but ultimately did not meet the demands of our data. Both of these methods involved automating origin and destination pairs through an Application Programming Interface (API) to extract emissions results from a calculator tool. The underlying formulas for the ICAO Carbon Emissions Calculator ${ }^{5}$ and the myclimate $\mathrm{CO}_{2}$ Calculator $^{6}$ are shown in Figures $\mathrm{C} 1$ and $\mathrm{C} 2$ respectively. While these tools appear to be more robust, our attempts to utilize each online tool produced non-comprehensive results. The ICAO Carbon Emissions Calculator was able to be scraped, but due to the lack of a significant amount of origin and destination pairs built into the ICAO Carbon Emissions Calculator, the tool was unable to represent our data. The myclimate $\mathrm{CO}_{2}$ Calculator has a built-in radiative forcing multiplier that is not easily removed without knowing all other parameters used in their formula. Since we excluded radiative forcing effects from our scope, the myclimate $\mathrm{CO}_{2}$ Calculator did not meet our requirements. Radiative forcing is a direct measure of the Earth's energy imbalance. GHGs are a major mechanism of radiative forcing as they prevent energy from leaving Earth's atmosphere. Air travel is commonly associated with radiative forcing since airplanes emit GHGs directly in the upper atmosphere. While we recognize this, we also recognize that the radiative forcing multiplier-ranging from between 1.2 to $4.7^{7}$-is uncertain. In future work, the ICAO Carbon Emissions Calculator and myclimate $\mathrm{CO}_{2}$ Calculator could potentially be applied to U-M's data if disaggregated to recreate each calculating tools' formula. 
All travel GHG emission factors between the EPA and SIMAP methods were compared. Air travel $\mathrm{CO}_{2}$ emission factors between EPA, SIMAP, the ICAO Carbon Emissions Calculator, and the myclimate $\mathrm{CO}_{2}$ Calculator were also compared. Only $\mathrm{CO}_{2}$ emission factors were compared for air travel since the ICAO Carbon Emissions Calculator and the myclimate $\mathrm{CO}_{2}$ Calculator only output $\mathrm{CO}_{2}$ emissions and not $\mathrm{CH}_{4}$ or $\mathrm{N}_{2} \mathrm{O}$. The air travel emission factors for EPA and SIMAP were calculated based on all analyzed data while the ICAO Carbon Emissions Calculator and the myclimate $\mathrm{CO}_{2}$ Calculator were calculated using output emissions from a sample size of six cities of varying GCD from Detroit (Pittsburgh, Chicago, Washington DC, San Francisco, London, and Beijing). Linear regressions were performed on this sample dataset to calculate the ICAO Carbon Emissions Calculator and the myclimate $\mathrm{CO}_{2}$ Calculator air travel $\mathrm{CO}_{2}$ emission factors.

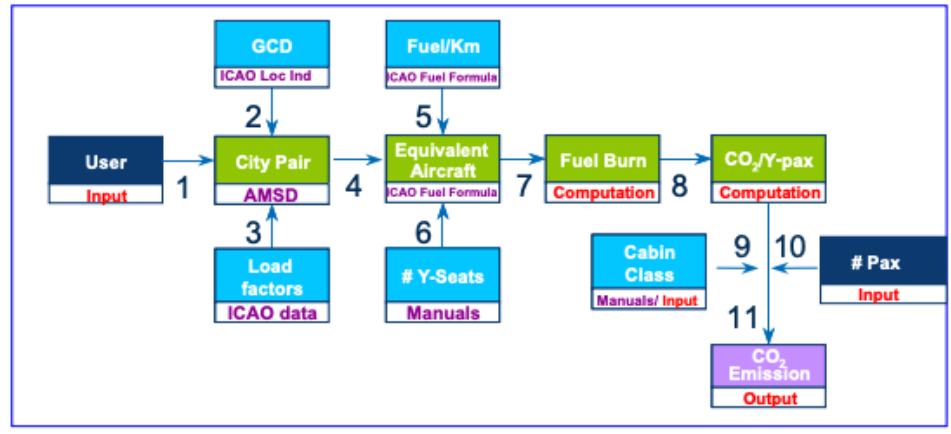

Figure C1. The calculation procedure used by the ICAO Carbon Emissions Calculator tool.

$$
E=\frac{a x^{2}+b x+c}{S * P L F} *(1-C F) * C W *(E F * M+P)+\mathrm{AF} * \mathrm{x}+\mathrm{A}
$$

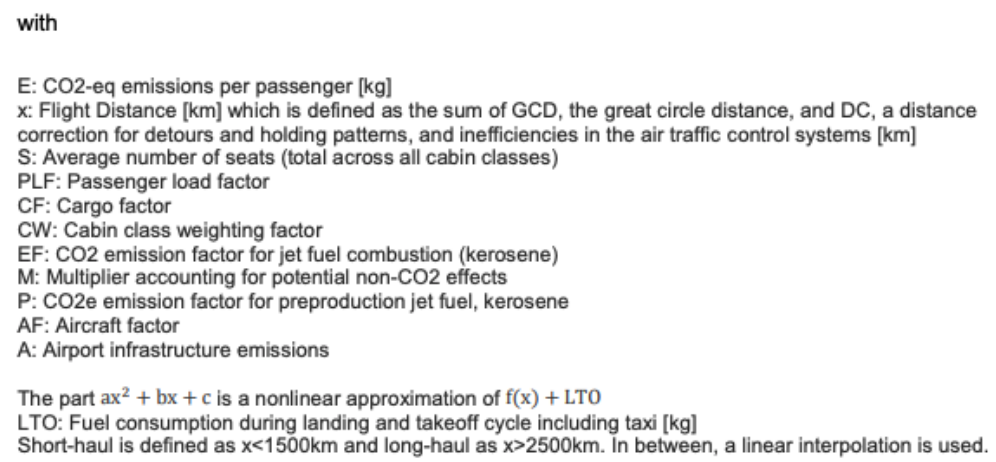

Figure C2. The formula used by the myclimate $\mathrm{CO}_{2}$ Calculator tool.

Identifying Frequently Traveled to Destinations from Detroit Metropolitan Wayne County Airport Using origin and destination data from all of the datasets provided to us, we were able to identify the most frequented destinations from the Detroit Metropolitan Wayne County Airport. The motivation behind doing this was to gain insight on popular destinations so that we could identify trends in travel from Detroit Metropolitan Wayne County Airport and support work which explores rationale behind these trips and potential alternatives. 
Appendix C, University Travel Internal Analysis Team Final Report

\section{Emissions Calculation}

For all datasets except Shared Services, determining air travel emissions relied on the calculation of GCDs between origin and destination pairs using the script described in Appendix D. We then assumed that each origin and destination pair represented the travel of one traveler and applied passenger-mile emission factors from each method to these GCDs following Equation C1. Treatment of the Shared Services dataset is discussed in a subsequent section.

\section{Equation C1. Generic formula used for calculating air travel GHG emissions from GCDs.}

$$
\begin{aligned}
& \text { Air Travel GHGs }(\mathrm{kg} \mathrm{CO} 2 \mathrm{e}) \\
& =G C D(\text { miles }) * \# \text { of travelers } * \text { Air Travel } \mathrm{CO}_{2} E F\left(\frac{\mathrm{kg} \mathrm{CO}}{\text { passenger }- \text { mile }}\right) \\
& +G C D(\text { miles }) * \# \text { of travelers } * \text { Air Travel } \mathrm{CH}_{4} \mathrm{EF}\left(\frac{\mathrm{kg} \mathrm{CH} \mathrm{H}_{4}}{\text { passenger }- \text { mile }}\right) \\
& * \frac{28 \mathrm{kgCO} \mathrm{C}_{2} e}{1 \mathrm{kgCH}}+\mathrm{GCD}(\text { miles }) * \# \text { of travelers } \\
& \text { * Air Travel } \mathrm{N}_{2} \mathrm{O} \text { EF }\left(\frac{\mathrm{kg} \mathrm{N}_{2} \mathrm{O}}{\text { passenger }- \text { mile }}\right) * \frac{265 \mathrm{kgCO}_{2} e}{1 \mathrm{~kg} \mathrm{~N} \mathrm{~N}_{2} \mathrm{O}}
\end{aligned}
$$

In order to account for ground travel emissions (i.e., car, train, and bus), total vehicle miles were extracted from all datasets except for Shared Services, of which treatment for is discussed later. Total vehicle miles were reported in all datasets except Athletics. The Athletics data came in the form of receipts for chartered cars and buses. Origin and destinations for unique trips in this dataset were manually extracted and vehicle miles were calculated using Google Maps. In each method, GHG emissions were calculated using emission factors standardized to vehicle miles for cars (Equation $\mathrm{C} 2$ ). The number of passengers was assumed not to matter since the vehicle was utilized by U-M personnel, therefore requiring all of the vehicle's emissions be attributed to UM. In the EPA method, all train trips were assumed to be on intercity rail trains and utilized passenger-mile standardized emission factors for such. The SIMAP method applied generalized train emission factors, also standardized to passenger-miles, to all trips. Equation C3 shows the generic formula for calculating GHG emissions associated with train travel for both methods. All of the bus travel data provided to us was from Athletics and involved private chartering. As such, emission factors applied bus miles were standardized to vehicle miles since U-M is responsible for all of the bus's emissions (Equation C4). In future work, if individual bus travel is reported, emission factors standardized to passenger-miles will need to be used for those trips.

Equation C2. Generic formula used for calculating car travel GHG emissions from vehicle-miles.

Car Travel GHGs $\left(\mathrm{kg} \mathrm{CO}_{2} \mathrm{e}\right)$

$$
\begin{aligned}
& =\text { Distance traveled (miles) } * \text { Car Travel } \mathrm{CO}_{2} \mathrm{EF}\left(\frac{\mathrm{kgCO}_{2} e}{\text { vehicle }- \text { mile }}\right) \\
& + \text { Distance traveled (miles) } * \text { Car Travel } \mathrm{CH}_{4} \mathrm{EF}\left(\frac{\mathrm{kg} \mathrm{CH}}{\text { vehicle }- \text { mile }}\right) * \frac{28 \mathrm{~kg} \mathrm{CO}_{2} e}{1 \mathrm{~kg} \mathrm{C \textrm {H } _ { 4 }}} \\
& + \text { Distance traveled (miles) } * \text { Car Travel } \mathrm{N}_{2} \mathrm{O} \mathrm{EF}\left(\frac{\mathrm{kg} \mathrm{N} \mathrm{N}_{2} \mathrm{O}}{\text { vehicle }- \text { mile }}\right) * \frac{265 \mathrm{kgCO}_{2} e}{1 \mathrm{~kg} \mathrm{~N}_{2} \mathrm{O}}
\end{aligned}
$$


Equation C3. Generic formula used for calculating train travel GHG emissions from distance traveled and occupancy.

Train Travel GHGs $(\mathrm{kg} \mathrm{CO} 2 \mathrm{e})$

$$
\begin{aligned}
& =\text { Distance traveled (miles) *\# of travelers } \\
& * \text { Train Travel } \mathrm{CO}_{2} \mathrm{EF}\left(\frac{\mathrm{kg} \mathrm{CO} \mathrm{O}_{2}}{\text { passenger }- \text { mile }}\right)+\text { Distance traveled (miles) } \\
& * \text { \# of travelers } * \text { Train Travel } \mathrm{CH}_{4} \mathrm{EF}\left(\frac{\mathrm{kg} \mathrm{CH} \mathrm{H}_{4}}{\text { passenger }- \text { mile }}\right) * \frac{28 \mathrm{~kg} \mathrm{CO}_{2} e}{1 \mathrm{kgCH} \mathrm{CH}_{4}} \\
& + \text { Distance traveled (miles) } * \# \text { of travelers } \\
& * \text { Train Travel } \mathrm{N}_{2} \mathrm{O} \mathrm{EF}\left(\frac{\mathrm{kg} \mathrm{N} \mathrm{N}_{2} \mathrm{O}}{\text { passenger }- \text { mile }}\right) * \frac{265 \mathrm{~kg} \mathrm{CO}_{2} e}{1 \mathrm{~kg} \mathrm{~N}_{2} \mathrm{O}}
\end{aligned}
$$

Equation C4. Generic formula used for calculating bus travel GHG emissions from vehicle-miles.

Bus Travel GHGs $\left(\mathrm{kg} \mathrm{CO}_{2} \mathrm{e}\right)$

$$
\begin{aligned}
& =\text { Distance traveled (miles) } * \text { Bus Travel } \mathrm{CO}_{2} \mathrm{EF}\left(\frac{\mathrm{kgCO}_{2} e}{\text { vehicle }- \text { mile }}\right) \\
& + \text { Distance traveled (miles) } * \text { Bus Travel } \mathrm{CH}_{4} \mathrm{EF}\left(\frac{\mathrm{kgCH}}{\text { vehicle }- \text { mile }}\right) * \frac{28 \mathrm{kgCO}_{2} e}{1 \mathrm{kgCH}_{4}} \\
& + \text { Distance traveled (miles) } * \text { Bus Travel } \mathrm{N}_{2} \mathrm{O} \mathrm{EF}\left(\frac{\mathrm{kg} \mathrm{N} \mathrm{N}_{2} \mathrm{O}}{\text { vehicle }- \text { mile }}\right) * \frac{265 \mathrm{kgCO}_{2} e}{1 \mathrm{~kg} \mathrm{~N}_{2} \mathrm{O}}
\end{aligned}
$$

\section{Scaling Concur Data and Emissions}

In meeting with members from UM's procurement office (Jeanette Frost and Chip Reese), we were informed that the Concur data provided to us in spreadsheet form only represented $\sim 30 \%$ of the travel data and $\sim 28,000$ unique trips stored in Concur. It is important to note that this $\sim 30 \%$ value from procurement was a generous estimate. It is likely that the amount of data we were provided in the Concur spreadsheet represents less than $30 \%$. The remaining data in Concur is stored as receipts. Receipts can be accessed individually but is a manual task and considering the sheer volume of unique trips stored via this method is near impossible. The procurement office contacted Concur to see if they could provide these receipts, but the price to do so was $\$ 18,000$. Given this large amount of difficult to obtain data, we instead estimated the amount of travel data and emissions in the Concur database by utilizing a scaling factor. Since we had $\sim 30 \%$ of the data from Concur, we simply used a scaling factor of 0.3 to estimate the number of unique trips in and GHG emissions from the Concur database. It should be noted that a sensitivity analysis is recommended to be applied to this scaling factor due to aforementioned uncertainty in the $\sim 30 \%$ value. Reducing the scaling factor would necessarily linearly increase the total amount of emissions from Concur. An additional scaling factor was used for train trips and GHG emissions. Because of data gaps in the spreadsheet data from Concur, only 86 of the 401 trips had distance traveled data. As such, we scaled unique train trips and GHG emissions further by a factor of 0.214 (86/401). See Appendix $G$ for directions to access Concur receipts.

\section{Estimating Shared Services Emissions}

As previously mentioned, data from Shared Services were processed differently than data from other sources. Travel data are stored in Shared Services as vouchers (receipts). Like with Concur, vouchers can be accessed individually using unique voucher IDs, but the number of 
unique travel related voucher IDs in 2018 was $\sim 39,000$. In order to get an estimate on the air and ground travel GHG emissions from trips stored in Shared Services, the number of unique vouchers associated with air travel and ground travel were first identified based on account description. 7,055 air travel vouchers and 21,170 ground travel vouchers were identified. Each voucher was assumed to represent a single unique trip. Then using the GHG emissions results from our analysis on all other databases in both the EPA and SIMAP methods, we determined emission factors for both air and ground travel standardized to unique trips ( $\mathrm{tCO}_{2} \mathrm{e} /$ unique trip). These emission factors were then applied to the identified unique air and ground travel trips from Shared Services. See Appendix F for directions to access Shared Services vouchers/receipts.

\section{Results and Discussion}

Table C1 compares GHG emission factors from EPA and SIMAP. We see that car and air travel emission factors are very similar $(<5 \%)$ while emission factors for train and bus differ by greater than $15 \%$. These similarities and differences show that estimates of the university travel GHG footprint can vary depending on the method chosen for analysis. Further, it shows that emission factors based on different input factors can vary. While all these input data sources are empirical, organization and manipulation of these inputs can lead to different outcomes.

Table C1. Comparison of emission factors between EPA and SIMAP for various modes of travel.

\begin{tabular}{|c|c|c|c|c|c|c|c|}
\hline \multicolumn{4}{|c|}{} & & & \multicolumn{3}{c|}{ Air (kg GHG/PM) } \\
\hline Method & $\begin{array}{c}\text { Car (kg } \\
\text { GHG/VM) }\end{array}$ & $\begin{array}{c}\text { Train (kg } \\
\text { GHG/PM) }\end{array}$ & $\begin{array}{c}\text { Bus (kg } \\
\text { GHG/VM) }\end{array}$ & $<300 \mathrm{mi}$ & $\begin{array}{c}>=300 \& \\
<=2300 \mathrm{mi}\end{array}$ & $>2300 \mathrm{mi}$ & $\begin{array}{c}\text { Average } \\
\text { from Data }\end{array}$ \\
\hline EPA & 0.346 & 0.141 & 2.908 & 0.227 & 0.137 & 0.167 & 0.160 \\
\hline SIMAP & 0.360 & 0.119 & 3.713 & - & - & - & 0.164 \\
\hline \hline$\%$ Difference & $4 \%$ & $-16 \%$ & $28 \%$ & - & - & - & $2 \%$ \\
\hline
\end{tabular}

Table C2 compares the air travel $\mathrm{CO}_{2}$ emission factors from EPA and SIMAP to those from the ICAO Carbon Emissions Calculator and myclimate's $\mathrm{CO}_{2}$ Calculator. We find large differences between the ICAO and myclimate emission factor relative to the EPA emission factor. The ICAO emission factor is $72 \%$ smaller than EPA's. This difference is significant. A possible explanation is that across the range of GCDs that the linear regression for the ICAO emission outputs was performed on, a linear relationship does not exist. Across the range of GCDs, it actually looks like emission outputs follow a logarithmic curve. Given this, to obtain an accurate comparison of air travel $\mathrm{CO}_{2}$ emission factor between the ICAO Carbon Emissions Calculator and EPA method, the ICAO Carbon Emissions Calculator must be used on all available data as was done for the EPA method. We also observe that the myclimate $\mathrm{CO}_{2}$ Calculator emission factor is $62 \%$ greater than that of the EPA's. This large difference is likely due to the inclusion of a radiative forcing multiplier of 2 in the myclimate emissions formula. 
Table C2. Comparison of air travel $\mathrm{CO}_{2}$ emission factors between EPA, SIMAP, the ICAO Carbon Emissions Calculator, and the myclimate $\mathrm{CO}_{2}$ Calculator.

\begin{tabular}{|c|c|c|}
\hline \multicolumn{3}{|c|}{ Carbon Accounting Air Travel Emission Factor Differences } \\
\hline Method & Air (kg CO $/$ PM) & \% Difference (relative to EPA) \\
\hline EPA & 0.159 & $0 \%$ \\
\hline SIMAP & 0.162 & $2 \%$ \\
\hline ICAO & 0.045 & $-72 \%$ \\
\hline myclimate & 0.258 & $62 \%$ \\
\hline
\end{tabular}

In analyzing frequent air travel destinations from Detroit Metropolitan Wayne County Airport, we identified 45 cities traveled to over 100 times in 2018. Of these 45 cities, 18 were international and 27 were domestic. Washington DC was overall the most frequented destination and Paris was the most frequented international destination. These descriptive statistics are shown in Tables C3-C5. From this information, proceedings should seek to identify why these destinations are the most frequented. If the reasonings are known, targeted strategies can be devised to provide travel alternatives.

Our GHG emissions analysis of university travel (including the scaled Concur data and estimate of GHG emissions from Shared Services) found that university travel accounts for $\sim 45,000 \mathrm{t}$ of GHG emissions. Results from our EPA method returned 44,879 $\mathrm{t}$ (Figure C3) and results from our SIMAP method returned 46,647 $\mathrm{t}$ (Figure C4), just a 4\% difference. Tables C6 and C7 tabulate these results. In both methods, emissions from air travel dominated, representing $\sim 90 \%$ of total GHG emissions. Within air travel, Concur ( 50\%), Vice Provost $(\sim 29 \%)$, and Shared Services $(\sim 12 \%)$ were the largest contributing data sources. Car travel accounted for nearly all of the remaining GHG emissions $(\sim 10 \%)$, making emissions from train and bus travel nearly negligible. For context, the University's scope 1 and scope $2 \mathrm{GHG}$ emissions are estimated to be $\sim 631,000 \mathrm{t},{ }^{8}$ making our estimated GHG footprint of university travel $\sim 7 \%$ of this value. 
Table C3. Air travel destination cities with over 100 travel events with Detroit Metropolitan Wayne County Airport as the origin in 2018.

\begin{tabular}{|c|c|c|c|}
\hline Destination City & Domestic or International & Frequency & $\%$ \\
\hline Washington DC & Domestic & 1,282 & $10.3 \%$ \\
\hline New York & Domestic & 722 & $5.8 \%$ \\
\hline Chicago & Domestic & 695 & $5.6 \%$ \\
\hline Atlanta & Domestic & 616 & $5.0 \%$ \\
\hline Boston & Domestic & 593 & $4.8 \%$ \\
\hline Paris & International & 451 & $3.6 \%$ \\
\hline San Francisco & Domestic & 446 & $3.6 \%$ \\
\hline Los Angeles & Domestic & 403 & $3.2 \%$ \\
\hline Philadelphia & Domestic & 358 & $2.9 \%$ \\
\hline Denver & Domestic & 324 & $2.6 \%$ \\
\hline Amsterdam & International & 290 & $2.3 \%$ \\
\hline Newark & Domestic & 284 & $2.3 \%$ \\
\hline Toronto & International & 281 & $2.3 \%$ \\
\hline Orlando & Domestic & 272 & $2.2 \%$ \\
\hline San Diego & Domestic & 272 & $2.2 \%$ \\
\hline London & International & 265 & $2.1 \%$ \\
\hline Barcelona & International & 256 & $2.1 \%$ \\
\hline Phoenix & Domestic & 253 & $2.0 \%$ \\
\hline Seattle & Domestic & 253 & $2.0 \%$ \\
\hline Minneapolis/St Paul & Domestic & 249 & $2.0 \%$ \\
\hline Beijing & International & 240 & $1.9 \%$ \\
\hline New Orleans & Domestic & 228 & $1.8 \%$ \\
\hline Shanghai & International & 220 & $1.8 \%$ \\
\hline Dallas & Domestic & 215 & $1.7 \%$ \\
\hline Tel Aviv & International & 194 & $1.6 \%$ \\
\hline Berlin & International & 193 & $1.6 \%$ \\
\hline Rome & International & 189 & $1.5 \%$ \\
\hline Houston & Domestic & 186 & $1.5 \%$ \\
\hline Florence & International & 182 & $1.5 \%$ \\
\hline Montreal & International & 161 & $1.3 \%$ \\
\hline Salt Lake City & Domestic & 158 & $1.3 \%$ \\
\hline Seoul & International & 146 & $1.2 \%$ \\
\hline Nashville & Domestic & 143 & $1.1 \%$ \\
\hline Las Vegas & Domestic & 138 & $1.1 \%$ \\
\hline Madrid & International & 126 & $1.0 \%$ \\
\hline Prague & International & 124 & $1.0 \%$ \\
\hline Pittsburgh & Domestic & 123 & $1.0 \%$ \\
\hline Copenhagen & International & 123 & $1.0 \%$ \\
\hline Austin & Domestic & 122 & $1.0 \%$ \\
\hline Tokyo & International & 120 & $1.0 \%$ \\
\hline Madison & Domestic & 119 & $1.0 \%$ \\
\hline Raleigh/Durham & Domestic & 115 & $0.9 \%$ \\
\hline Charlotte & Domestic & 109 & $0.9 \%$ \\
\hline Sydney & International & 102 & $0.8 \%$ \\
\hline Portland & International & 100 & $0.8 \%$ \\
\hline Total & - & 12,441 & $100 \%$ \\
\hline
\end{tabular}


Appendix C, University Travel Internal Analysis Team Final Report

Table C4. The top seven most traveled to domestic destination cities from Detroit Metropolitan Wayne County Airport in 2018.

\begin{tabular}{|c|c|}
\hline \multicolumn{2}{|c|}{ Most Frequented Domestic Destinations } \\
\hline Destination City & Frequency \\
\hline Washington DC & 1282 \\
\hline New York & 722 \\
\hline Chicago & 695 \\
\hline Atlanta & 616 \\
\hline Boston & 593 \\
\hline San Francisco & 446 \\
\hline Los Angeles & 403 \\
\hline
\end{tabular}

Table C5. The top seven most traveled to international destination cities from Detroit Metropolitan Wayne County Airport in 2018.

\begin{tabular}{|c|c|}
\hline $\begin{array}{l}\text { Most Frequented In } \\
\text { Destination City }\end{array}$ & $\begin{array}{l}\text { Destinatio } \\
\text { Frequency }\end{array}$ \\
\hline Paris & 451 \\
\hline Amsterdam & 290 \\
\hline Toronto & 281 \\
\hline London & 265 \\
\hline Barcelona & 256 \\
\hline Beijing & 240 \\
\hline Shanghai & 220 \\
\hline
\end{tabular}


Appendix C, University Travel Internal Analysis Team Final Report

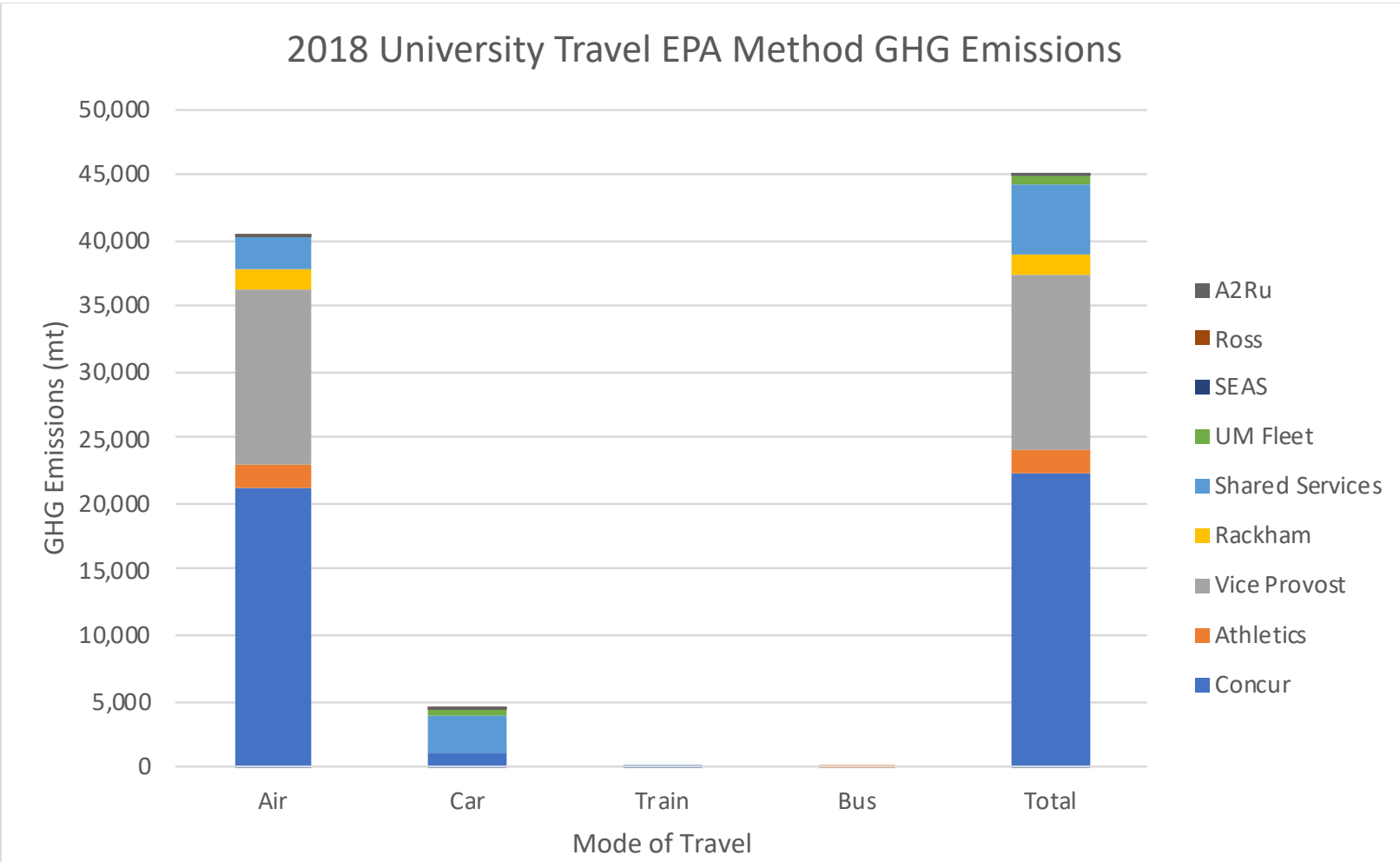

Figure C3. University travel GHG emissions, accounted using the EPA method, in 2018. Emissions are separated by mode of travel and data source.

Table C6. Tabulated results of university travel GHG emissions in 2018 using the EPA method. Emissions are separated by mode of travel and data source.

\begin{tabular}{|c|c|c|c|c|c|c|c|c|c|c|}
\hline \multirow[t]{2}{*}{ Mode of Travel } & \multicolumn{10}{|c|}{ Data Source } \\
\hline & Concur & Athletics & Vice Provost & Rackham & Shared Services & UM Fleet & SEAS & Ross & A2Ru & Total \\
\hline Air & 21,280 & 1,736 & 13,159 & 1,556 & 2,592 & $\quad 0$ & 15 & 10 & 20 & 40,367 \\
\hline Car & 965 & 1 & 0 & 0 & 2,866 & 538 & 5 & 1 & 2 & 4,379 \\
\hline Train & 51 & 0 & 0 & 0 & 0 & 0 & 0 & 0 & 0 & 51 \\
\hline Bus & 0 & 81 & 0 & 0 & 0 & 0 & 0 & 0 & 0 & 81 \\
\hline Total & 22,297 & 1,819 & 13,159 & 1,556 & 5,458 & 538 & 20 & 11 & 22 & 444,879 \\
\hline Estimated Value & & & & & & & & & & \\
\hline
\end{tabular}


Appendix C, University Travel Internal Analysis Team Final Report

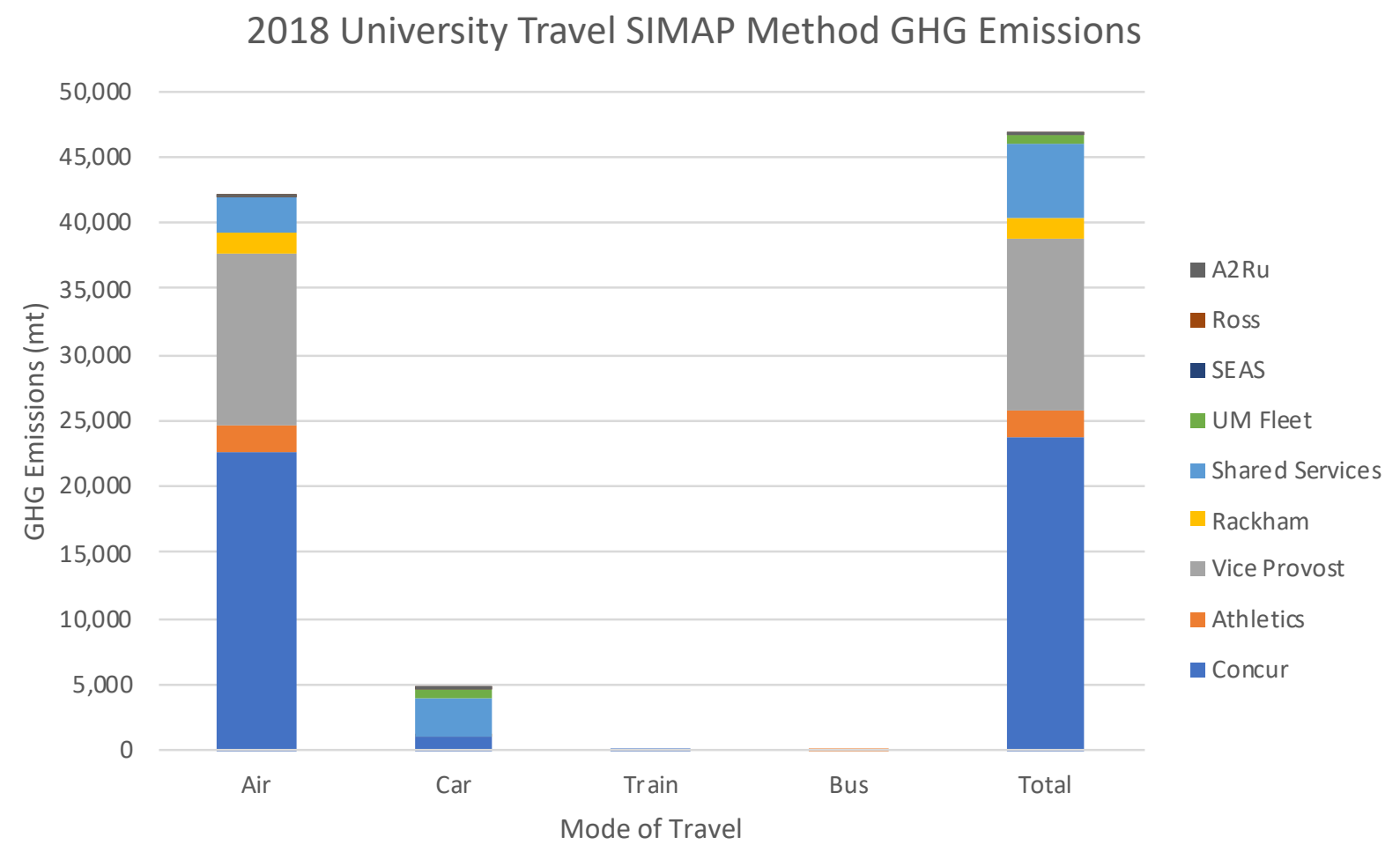

Figure C4. University travel GHG emissions, accounted using the SIMAP method, in 2018. Emissions are separated by mode of travel and data source.

Table C7. Tabulated results of university travel GHG emissions in 2018 using the SIMAP method. Emissions are separated by mode of travel and data source.

\begin{tabular}{|c|c|c|c|c|c|c|c|c|c|}
\hline \multirow[t]{2}{*}{ Mode of Travel } & \multicolumn{9}{|c|}{ Data Source } \\
\hline & Concur & Athletics & Vice Provost & Rackham & Shared Servic UM Fleet & SEAS & Ross & A2Ru & Total \\
\hline Air & 22,656 & 1,968 & 12,932 & 1,634 & 2,648 & 16 & 12 & 22 & 41,886 \\
\hline Car & 1,004 & 2 & 0 & 0 & 3,040 & 5 & 1 & 2 & 4,613 \\
\hline Train & 43 & 0 & 0 & 0 & 0 & 0 & 0 & 0 & 43 \\
\hline Bus & 0 & 104 & 0 & 0 & 0 & 0 & 0 & 0 & 104 \\
\hline Total & 23,703 & 2,073 & 12,932 & 1,634 & 5,688 & 21 & 12 & 24 & 46,647 \\
\hline
\end{tabular}

Estimated Value

It should again be noted that radiative forcing was not considered in our emissions analysis. If radiative forcing was indeed considered for all travel emissions, the estimated $\sim 45,000$ t of university travel GHG emissions would increase to anywhere between $\sim 54,000 \mathrm{t}$ and $\sim 212,000 \mathrm{t}$ ( 9-34\% of U-M scope 1 and scope 2 GHG emissions) using multipliers of 1.2 and 4.7 respectively. If radiative forcing was considered just for air travel GHG emissions, the estimated amount of university travel GHG emissions would increase to anywhere between $\sim 53,000 \mathrm{t}$ and $\sim 197,000 \mathrm{t}$ ( $~ 8-31 \%$ of U-M scope 1 and scope 2 GHG emissions). These considerations can be seen in Table C8.

Exploring some sensitivity in our analysis relative to the scaling factor used for Concur travel data shows that our $\sim 45,000$ t of GHGs for university travel is likely an underestimate. Since 
procurement said that the Concur spreadsheet data we were given represents up to $\sim 30 \%$ of all of the travel data in Concur, we explored what the GHG output would be if this spreadsheet data represented only $\sim 10 \%$ of the travel data in Concur. Using a 0.1 scaling factor for our analyzed Concur data, we returned a value of $\sim 90,000$ t of GHGs for university travel (14\% of U-M scope 1 and scope 2 GHG emissions). Considering this $\sim 90,000 \mathrm{t}$ of $\mathrm{GHG}$ estimate for radiative forcing, all university travel GHG emissions could increase to anywhere between $\sim 108,000 \mathrm{t}$ and $423,000 \mathrm{t}(\sim 17-67 \%$ of U-M scope 1 and scope 2 GHG emissions). These considerations can be seen in Table C8. Considering only the air travel GHG emissions in this $\sim 90,000$ t GHG estimate for radiative forcing, the amount of university travel GHG emissions could increase to anywhere between $\sim 100,000 \mathrm{t}$ and $\sim 390,000 \mathrm{t}(\sim 16-62 \%$ of U-M scope 1 and scope $2 \mathrm{GHG}$ emissions).

Table C8. Sensitivity of the 2018 university travel GHG estimate under various radiative forcing and Concur scaling factor scenarios.

\begin{tabular}{|c|c|c|c|c|}
\hline Scenario & Description & $\begin{array}{l}\text { Approximate GHG } \\
\text { emissions (mt) }\end{array}$ & $\begin{array}{l}\% \text { Difference } \\
\text { from Base }\end{array}$ & $\begin{array}{l}\text { \% of U-M Scope } 1 \text { and } \\
\text { Scope } 2 \text { GHG Emissions }\end{array}$ \\
\hline Base & $\begin{array}{l}\text { Concur scaling factor of } 0.3 \text { and no } \\
\text { radiative forcing multiplier }\end{array}$ & 45,000 & $0 \%$ & $7 \%$ \\
\hline Base + Low Radiative Forcing & $\begin{array}{l}\text { Concur scaling factor of } 0.3 \text { and } 1.2 \\
\text { radiative forcing multiplier }\end{array}$ & 54,000 & $20 \%$ & $9 \%$ \\
\hline Base + High Radiative Forcing & $\begin{array}{l}\text { Concur scaling factor of } 0.3 \text { and } 4.7 \\
\text { radiative forcing multiplier }\end{array}$ & 212,000 & $371 \%$ & $34 \%$ \\
\hline 0.1 Concur Scale & $\begin{array}{l}\text { Concur scaling factor of } 0.1 \text { and no } \\
\text { radiative forcing multiplier }\end{array}$ & 90,000 & $100 \%$ & $14 \%$ \\
\hline 0.1 Concur Scale + Low Radiative Forcing & $\begin{array}{l}\text { Concur scaling factor of } 0.1 \text { and } 1.2 \\
\text { radiative forcing multiplier }\end{array}$ & 108,000 & $140 \%$ & $17 \%$ \\
\hline 0.1 Concur Scale + High Radiative Forcing & $\begin{array}{l}\text { Concur scaling factor of } 0.1 \text { and } 4.7 \\
\text { radiative forcing multiplier }\end{array}$ & 423,000 & $840 \%$ & $67 \%$ \\
\hline
\end{tabular}

Our estimates of travel GHG emissions from Shared Services returned values of 2,592 t from air travel and 2,866 trom ground travel for a total of 5,458 t. Moving forward, we recommend that another method of estimation be used for travel GHG emissions from Shared Services. One proposal is to use a cost-based approximation method. In this method, the economic value of each travel voucher in Shared Services would be converted to GHG emissions using a GHG/\$ factor. This $\mathrm{GHG} / \$$ factor could be extracted from the spreadsheet travel data from Concur. Using this approximation has its own shortcomings as an economic proxy can be volatile and is subject to market conditions. This could lead to inconsistencies across time and also doesn't necessarily address the differences in emission factors across trip distances. 
Appendix D, University Travel Internal Analysis Team Final Report

\section{Appendix D: Data Mining}

- Great Circle Distance (GCD)

- There are two major input formats of university travel data: airport codes and airport cities. For each input format, the script is customized to fit input format and recycled to be used on similar datasets.

- The dataset with origins and destinations as airport codes is transformed to appropriate format and each entry requires searches for longitude and latitude in a manually-established corpus. The last step is to compute GCD by geographic formula.

- For datasets' origins and destinations as airport cities, similarly, the dataset is read and organized in proper format and each data pair is searched for its longitude and latitude in a manually-constructed dictionary. Finally, the GCD is computed by geographic formula.

- There is an alternate method of calculating origins and destinations with cities. The latitude and longitude information is loaded in from the "basic" World Cities data source found here: https://simplemaps.com/data/world-cities. This is suitable for calculating GCD of international trips.

- ICAO API

- The ICAO web-scraping can be applied to our domestic travel datasets. The ICAO is a well-established website with reliable great circle distance and carbon emission information when inputting origins and destination cities. The script automates the process in generating corresponding results information. Please note that Selenium requires a web driver like ChromeDriver to be installed.

- PDF Information

$\circ$ PDF receipt is another format storing the information we need. We use the combination of Optical Character Recognition (OCR) and regular expression to extract origins and destinations information.

- Python scripts

- All these data mining tasks were implemented in Python. Python scripts are available upon request. 
Appendix E,

University Travel Internal Analysis Team Final Report

\section{Appendix E: Other Organization Results}

A study done at the University of Washington (UW) revealed that the university's carbon footprint from air travel accounted for an estimated $11 \%$ of emissions. The goal of the study was to track air travel more accurately, uncover faculty and staff attitudes around flying, and recommend ways to implement an emissions reduction. Travel data was obtained from the UW Travel office; other travel data was extrapolated from cost. Also, surveys were sent to identified travelers. Trips were sorted into short, medium, and long bins. Overall, the data for FY 2014 showed 136 million miles flown and $23,811 \mathrm{tCO}_{2} \mathrm{e}$ produced. The most frequent traveling department was Global Health. The survey showed that many high frequency flyers were willing to travel less and would be happy to switch to videoconferencing or ground transportation when possible. $53 \%$ of faculty, however, had never used videoconferencing. Any change in flying habits would have to come from the top with university leaders creating the desired culture. ${ }^{9}$

In a Swiss study, the carbon footprint of air travel from 2014 to 2016 by researchers from the École Polytechnique Fédérale de Lausanne (EPFL) was quantified and analyzed. The air travel was discovered to be responsible for $27 \%$ of EPFL's total $\mathrm{CO}_{2}$ emissions. Trips were both continental and intercontinental. Travel was unequally distributed. Professors had carbon footprints ten times larger than students and five times greater than postdocs. $10 \%$ of individuals who traveled the most accounted for $58 \%$ of GHG emissions. Relatively simple measures such as flying economy class, substituting short flights with train rides, and avoiding layovers were found to have the potential to reduce emissions by $36 \%{ }^{10}$

A study investigating the carbon footprint of the Norwegian University of Technology and Science in Trondheim, which has 20,000 students and 5,500 employees, found it to be 92,000 $\mathrm{tCO}_{2}$ for 2009 (including scope 3). This translates to $4.6 \mathrm{tCO}_{2}$ per student. Energy (19\%), buildings (19\%), travel (16\%), and equipment (19\%) were the biggest components. The Medical School was highest in terms of emissions from faculty. ${ }^{11}$

Data was collected by survey at the University of Montreal with a $\sim 9 \%$ response rate. Out of 815 responses, 703 were kept (professors, postdocs, graduate and undergraduate students). Data for student international travel and athletic travel obtained administratively were also included. Carbon footprints were calculated using University of New Hampshire's SIMAP platform and emission factors were from EPA. Results showed that most trips were short within Quebec while international trips were mostly to US and Europe and accounted for most (70-80\%) of the distance traveled. Purposes for traveling are shown with most for conferences, seminars or workshops (lumped) and secondly for field work or collaborative research. Cars were used for $43 \%$ of trips and plane for $35 \%$. The per capita footprint was $2.97 \mathrm{tCO}_{2}$. Professors had a per capita of $10.8 \mathrm{t}$ and international students 3.85 metric tons. Overall, students and sports teams accounted for $23,049 \mathrm{tCO}_{2}$ with $84 \%$ due to air travel. Individuals surveyed expressed interest in using video conferencing more and having easier access on campus. Overall, academic mobility contributed $37 \%$ of the total university footprint, but they don't give details on the denominator. They do not report total travel $\mathrm{CO}_{2}$, but we estimate it to be 38,000 metric tons using their data. ${ }^{12}$ 
Appendix F, University Travel Internal Analysis Team Final Report

\section{Appendix F: Airline Carbon Offset Prices}

Table F. Airline Carbon Offset Rates ${ }^{13}$

\begin{tabular}{|c|c|c|c|}
\hline Airline & $\begin{array}{c}\text { Partner } \\
\text { Organization }\end{array}$ & Project Type & Rate Per 1,000 Miles \\
\hline $\begin{array}{l}\text { Alaska } \\
\text { Airlines }\end{array}$ & Carbonfund.org & Unspecified & $\$ 1.70$ \\
\hline Delta & $\begin{array}{l}\text { The Nature } \\
\text { Conservancy }\end{array}$ & Land use & $\$ 2.09$ \\
\hline JetBlue & Carbonfund.org & Methane destruction & $\$ 1.70$ \\
\hline United & $\begin{array}{l}\text { Conservation } \\
\text { International }\end{array}$ & Various & $\$ 1.49$ \\
\hline Air Canada & Less Emissions & Unspecified & $\begin{array}{l}\$ 3.68 \text { international offsets, } \$ 2.86 \\
\text { domestic offsets }\end{array}$ \\
\hline $\begin{array}{l}\text { Air New } \\
\text { Zealand }\end{array}$ & ClimateCare & $\begin{array}{l}\text { Energy efficiency, land } \\
\text { use, renewable energy }\end{array}$ & $\$ 1.69$ \\
\hline Austrian & Climate Austria & $\begin{array}{l}\text { Energy efficiency, land } \\
\text { use, renewable energy }\end{array}$ & $\$ 4.63$ \\
\hline $\begin{array}{l}\text { Brussels } \\
\text { Airlines }\end{array}$ & CO2logic & Energy efficiency & $\begin{array}{l}\$ 2.57 \text { economy, } \$ 5.59 \text { business, } \\
\$ 8.45 \text { first }\end{array}$ \\
\hline $\begin{array}{l}\text { Cathay } \\
\text { Pacific }\end{array}$ & none & $\begin{array}{l}\text { Energy efficiency, } \\
\text { renewable energy }\end{array}$ & $\begin{array}{l}\$ 0.34 \text { economy, } \$ 0.43 \text { premium } \\
\text { economy, } \$ 0.52 \text { business, } \$ 0.68 \text { first }\end{array}$ \\
\hline China Airlines & ClimateCare & Unspecified & $\begin{array}{l}\$ 1.25 \text { economy, } \$ 2.50 \\
\text { business/upper }\end{array}$ \\
\hline EVA Air & ClimateCare & Unspecified & $\begin{array}{l}\$ 1.00 \text { economy, } \$ 2.00 \\
\text { business/upper }\end{array}$ \\
\hline $\begin{array}{l}\text { Japan Airlines } \\
\text { (JAL) }\end{array}$ & Myclimate & Various & $\begin{array}{l}\text { From } \$ 7.05 \text { economy, } \$ 13.76 \\
\text { business, } \$ 21.46 \text { first }\end{array}$ \\
\hline Lufthansa & Myclimate & $\begin{array}{l}\text { Energy efficiency, } \\
\text { renewable energy }\end{array}$ & $\begin{array}{l}\$ 2.21 \text { economy, } \$ 3.11 \text { premium } \\
\text { economy, } \$ 4.80 \text { business, } \$ 7.14 \text { first }\end{array}$ \\
\hline Qantas & none & Land use & $\$ 1.68$ \\
\hline
\end{tabular}




\section{Appendix G: Concur and Shared Services Center Receipt Access}

Perceptive Content is the document imaging/database software that Shared Services uses to store travel receipts (and other reimbursement receipts)

\section{Obtaining permission to access perceptive content:}

Before you log into Perceptive Content, you need the role of "FN View AP Voucher." This will give open and search privilege for documents in the FN AP Voucher Drawer. To request this access, please go to OARS - https://access.its.umich.edu/. It is recommended to work with your Unit Liaison.

- Points of contact (ITS): Zac Broughman (zacbro@umich.edu) or Brittany Lee Stewart (bwegman@umich.edu)

\section{Accessing document images:}

1. Go to Wolverine Access

(https://wolverineaccess.umich.edu/f/u24l1s13/normal/render.uP)

a. Go to "Faculty \& Staff" tab

b. Select "Document Imaging" under "University Business" box (see image below)

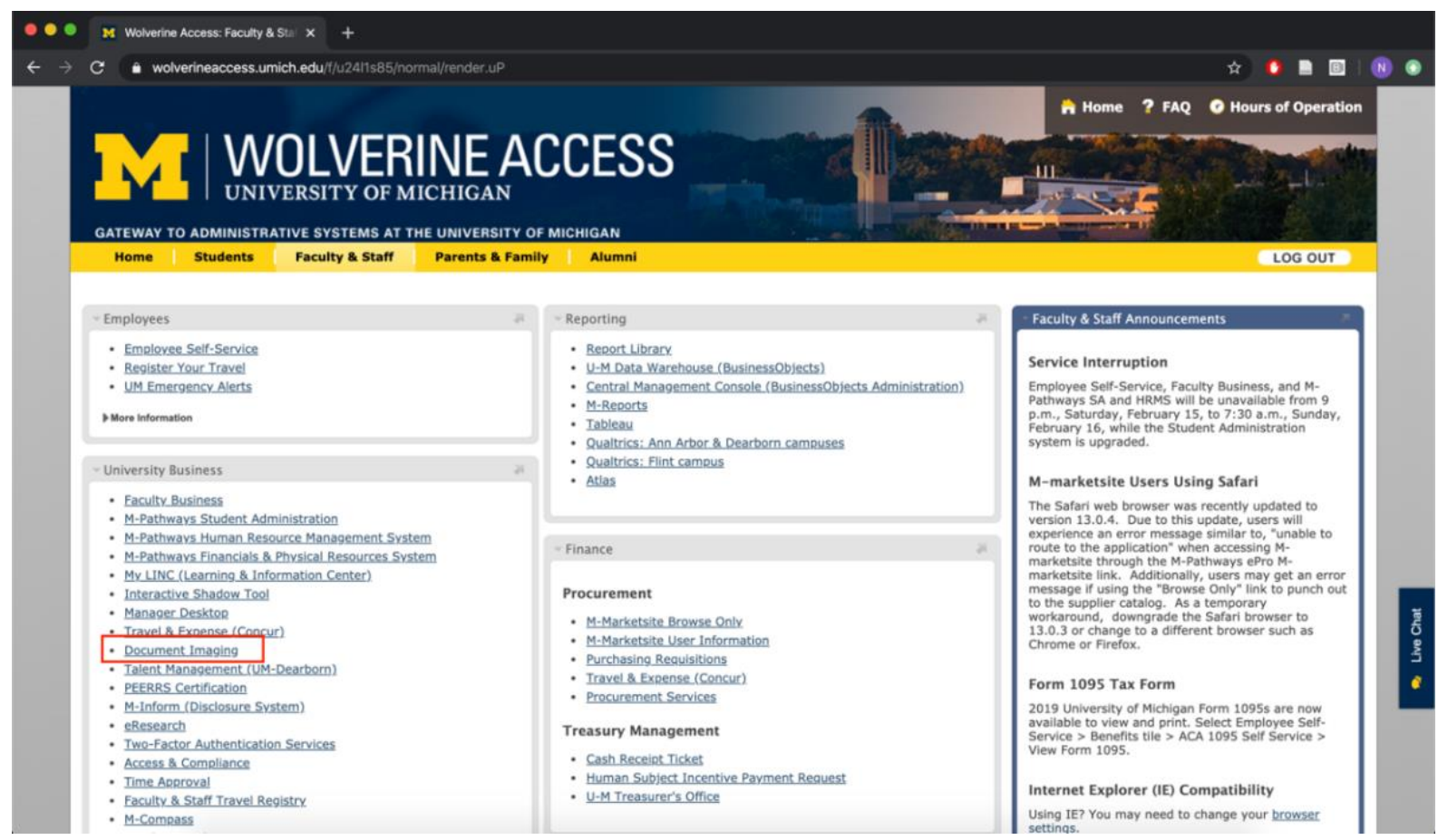

2. Log into Perceptive Content using your uniqname and password 
Appendix G, University Travel Internal Analysis Team Final Report

3. Once logged into Perceptive Content, select Documents (see image below)

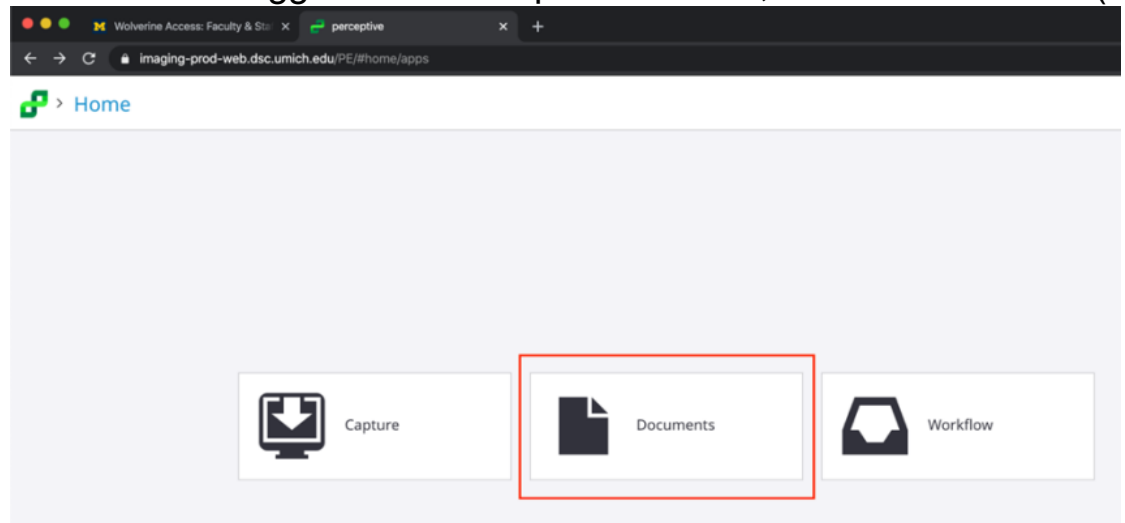

4. Once into the "Documents" functionality, select "Batch PO Search" under the "Accounts Payable Voucher" tab in the "Document Views" tab manager on the left side of the browser (see image below)

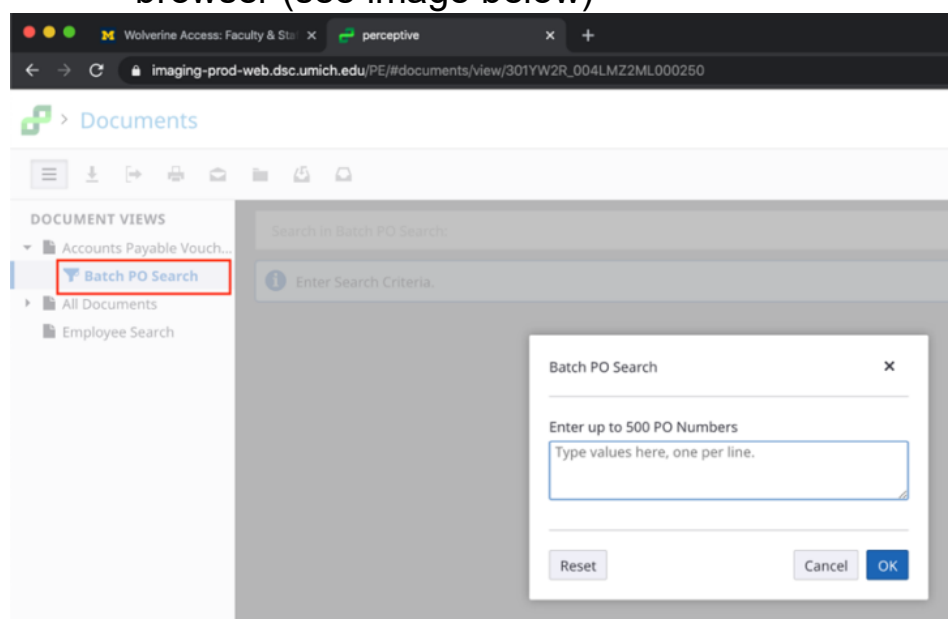

5. In the Batch PO Search pop-up, enter Voucher IDs (see image below) and hit OK
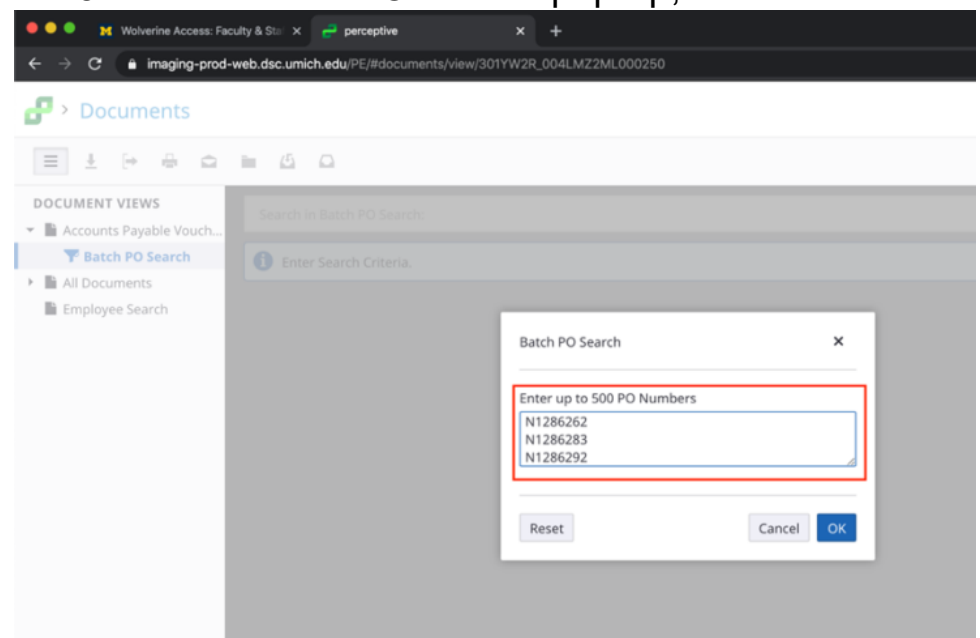

6. The Voucher IDs searched for will appear in the browser (see image on next page) and can be either viewed or exported. 
Appendix G, University Travel Internal Analysis Team Final Report

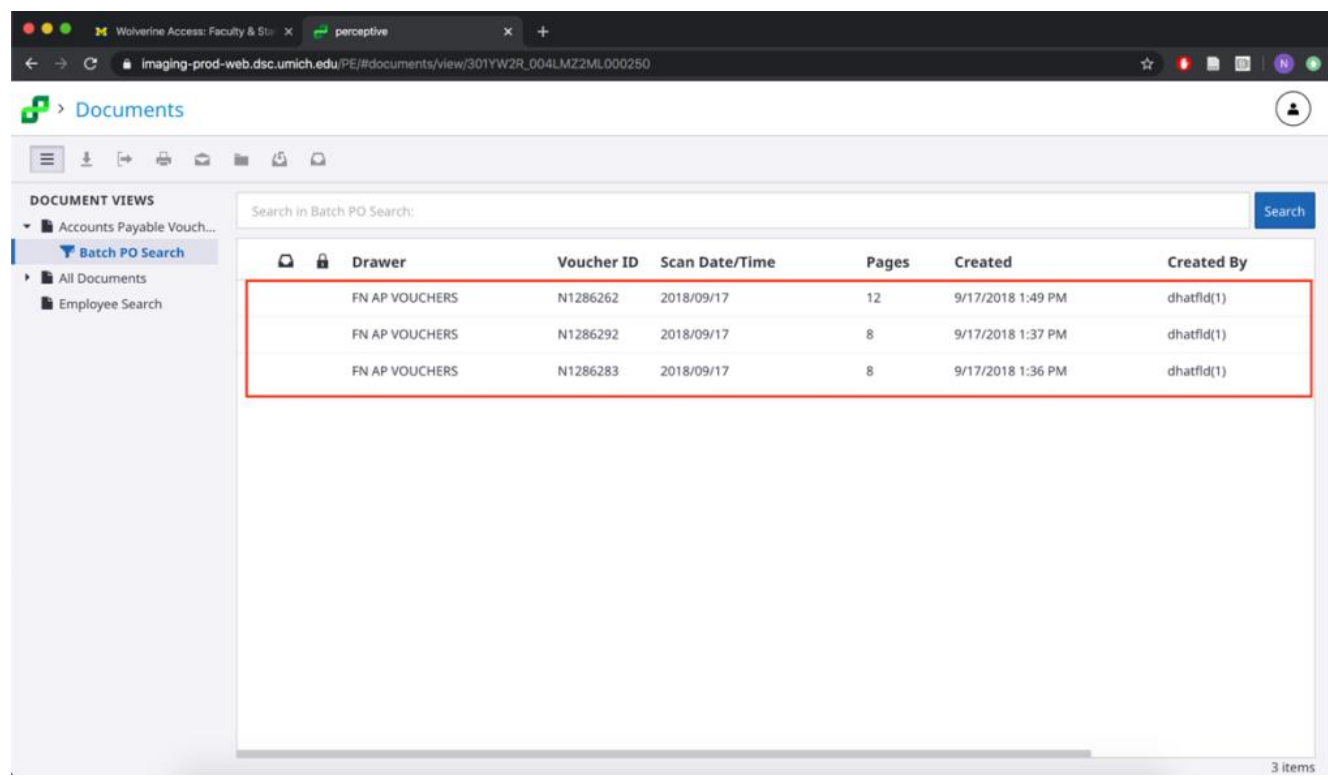

7. To export all searched for Voucher IDs, select all Voucher's and select "Export to PDFs" (see image below). This process can take quite a while.

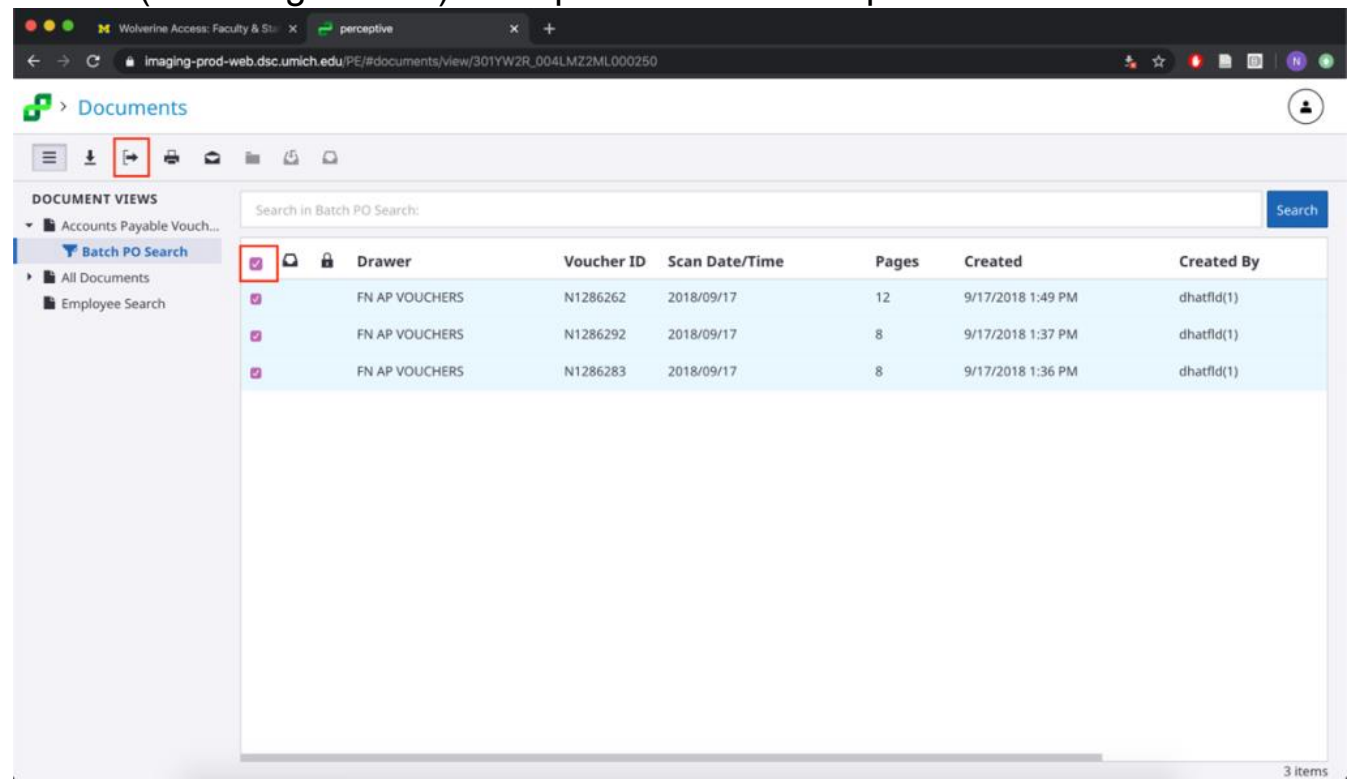

(Nate Hua, Word document email attachment, February 14, 2020) 
Appendix G, University Travel Internal Analysis Team Final Report

Alternative access procedure:

NOTE: The procedure outlined below requires the installation of the desktop client of Perceptive Content on a Windows computer. To install the desktop client, MiWorkspace and departmental IT must be contacted.

Once you have the role, you can log into Perceptive Content. To get to Perceptive Content, search for it from the Windows Search

Step 1: Log into Perceptive Content and Click on "Documents". Then go to the "Accounts Payable Voucher" area

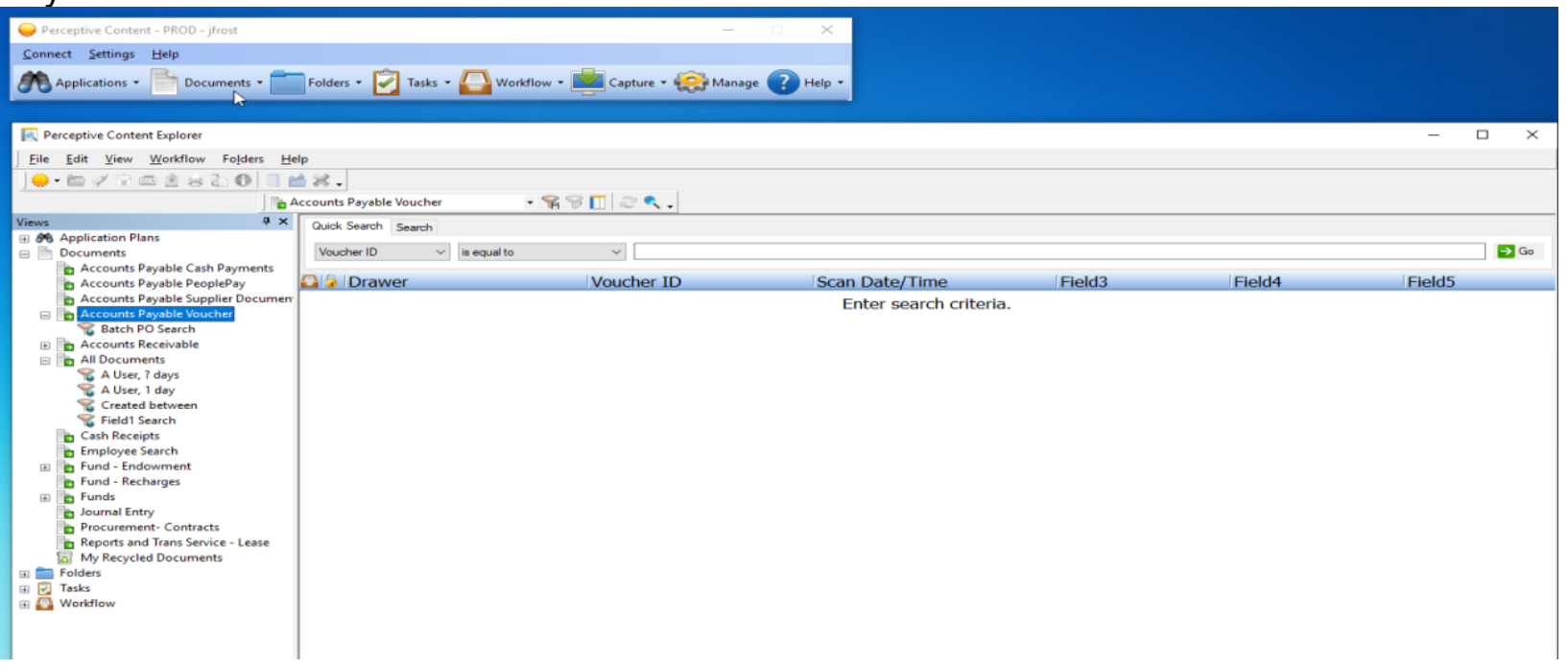

Step 2:

Click "Search" tab and then the green +

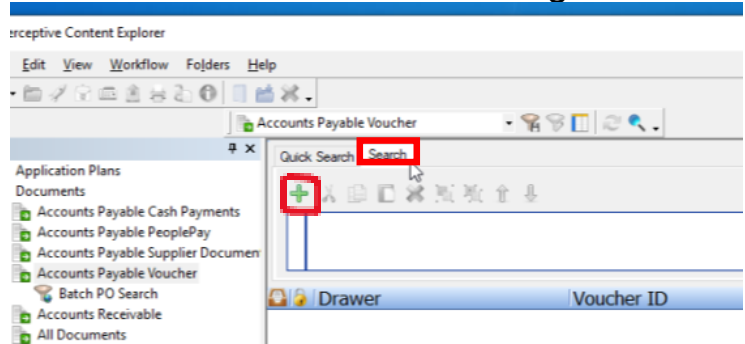

This box will pop up

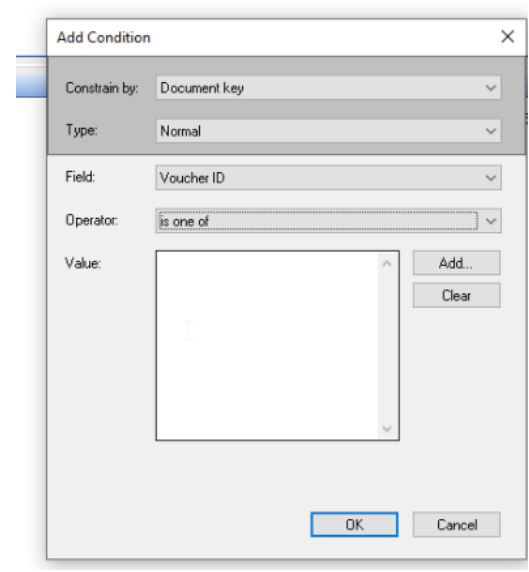


Step 3: Configure the Field, Operator and cut and paste the list of vouchers into the Value box and click OK and then click Go (far right side of screen)

Step 4: The list of images will display, select all of the lines and then right click on the mouse to "Export" the images. This will bring up another popup where you can select where to direct the image files.

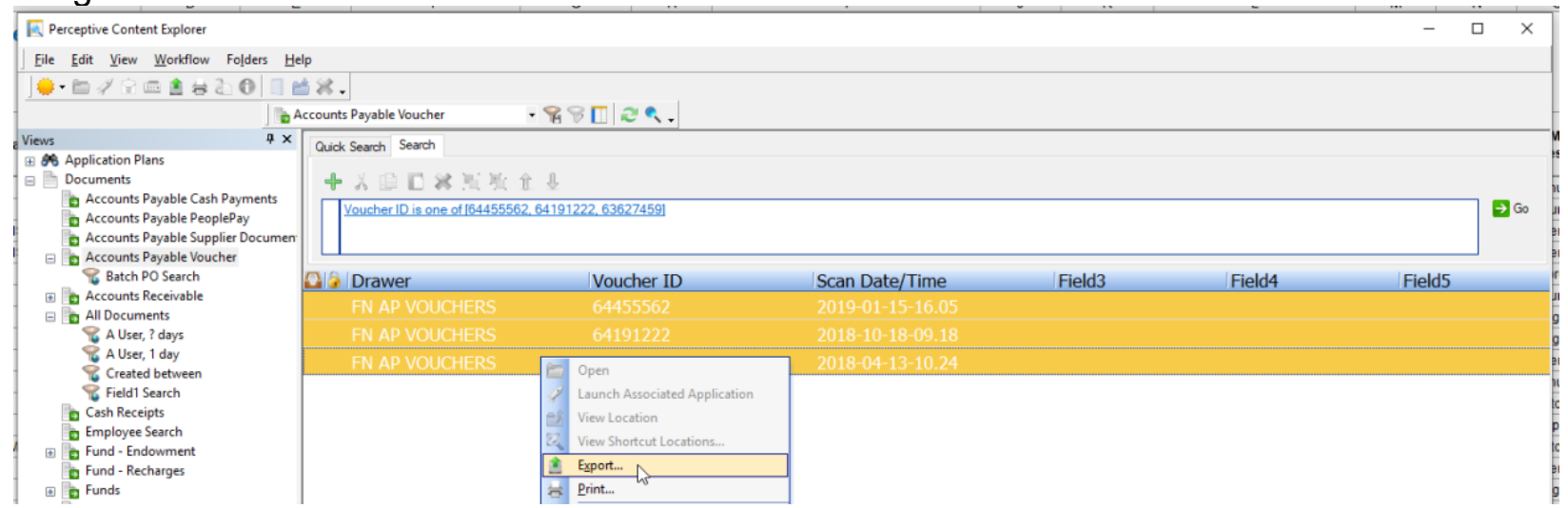

(Jeanette Frost, Word document email attachment, January 31, 2020)

Accessing Concur expense reports and receipts:

1. Log into Concur via Wolverine Access

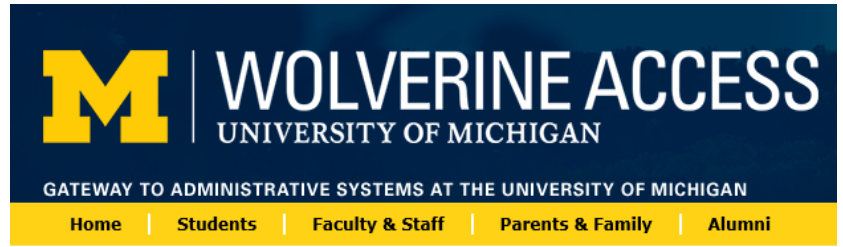

$$
\begin{aligned}
& \text { Employees } \\
& \text { - Employee Self-Service } \\
& \text { - Register Your Travel } \\
& \text { - UM Emergency Alerts }
\end{aligned}
$$

More Information

\section{University Business}

- Faculty Business

- M-Pathways Student Administration

- M-Pathways Human Resource Management System

- M-Pathways Financials \& Physical Resources System

- My LINC (Learnina \& Information Center)

- Interactive Shadow Tool

- Manager Desktop

- Travel \& Expense (Concur) A 
2. Click Expense

\section{SAP Concur $\mathbf{C}$ Travel Expense Approvals Reporting -}

\section{TRAVEL \& EXPENSE SYSTEM}

Hello, Jeanette

\section{Click Process Reports}

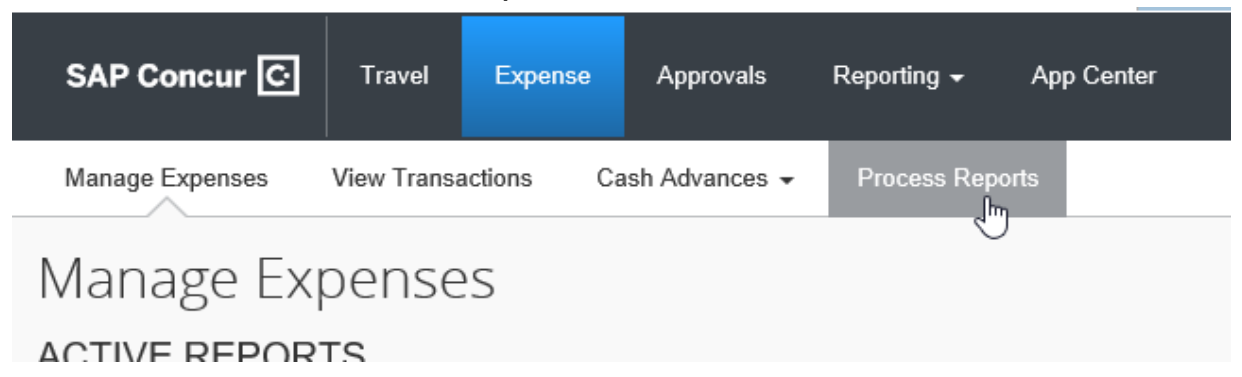

4. Change the search from Report Name to Report Key on the drop-down:

Group: Global

Run Query v Group List Settings Create/Manage Queries v

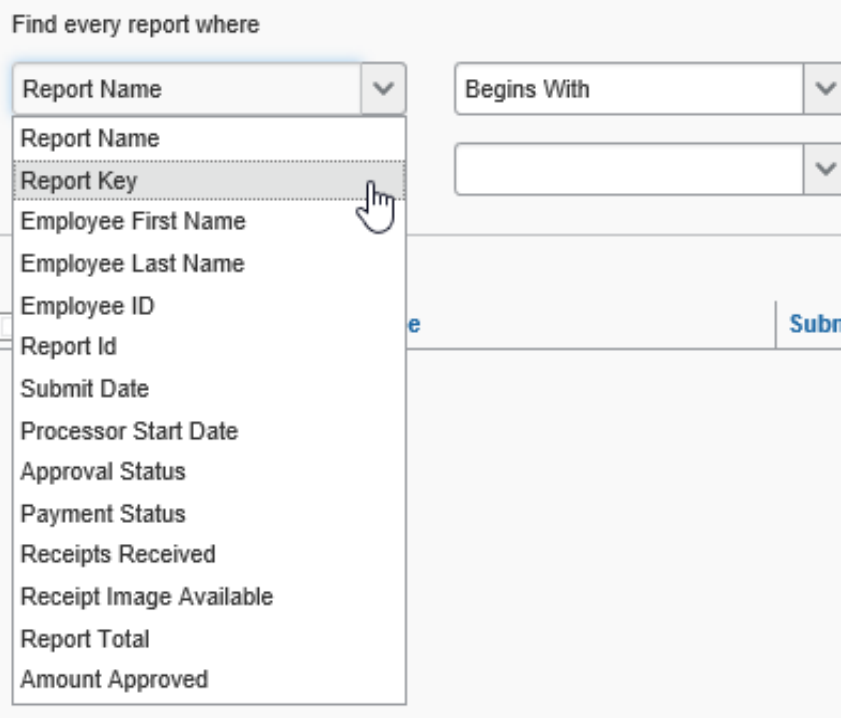


5. Enter the report key you want to pull back and click Go

Search Results

Grove Globat

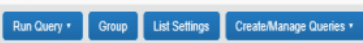

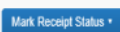

Fins every repot where

Report Key

\begin{tabular}{l|l}
\hline Equals & A 1552314 \\
\hline
\end{tabular}

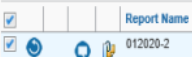

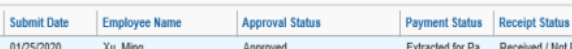

Cash Ad...

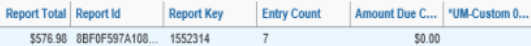

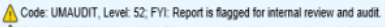

$\triangle$ Code. UMDUPCHK, Levet 53, Eppense report contains excepplon cote OUPCHECK and is being routed to Audit 3

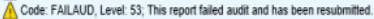

$\triangle$ This report has one or more enty level exceptions.

6. Select the report by clicking on the name of the report, once the report displays, select "Print/Email", U of M Detailed Report - By Payment/Expense Type

012020-2 [xu, Ming]

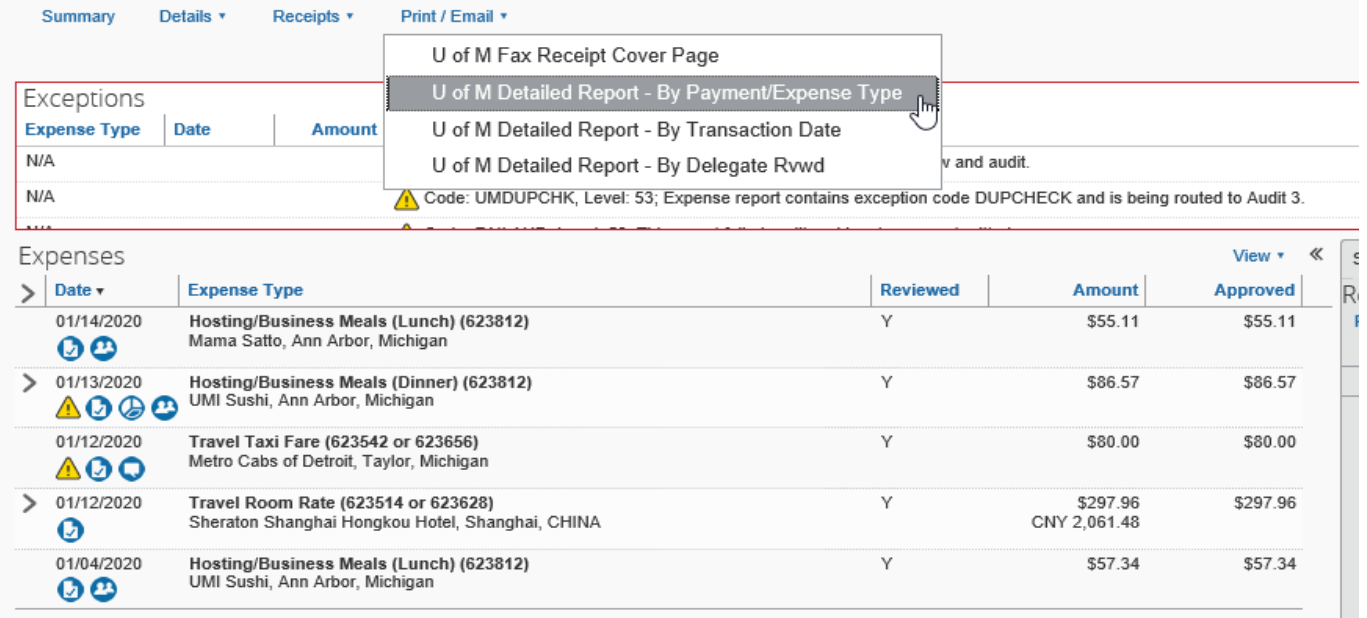

7. Click PDF if you want to create a pdf of the report and all receipts, or you can email or print the report and receipts

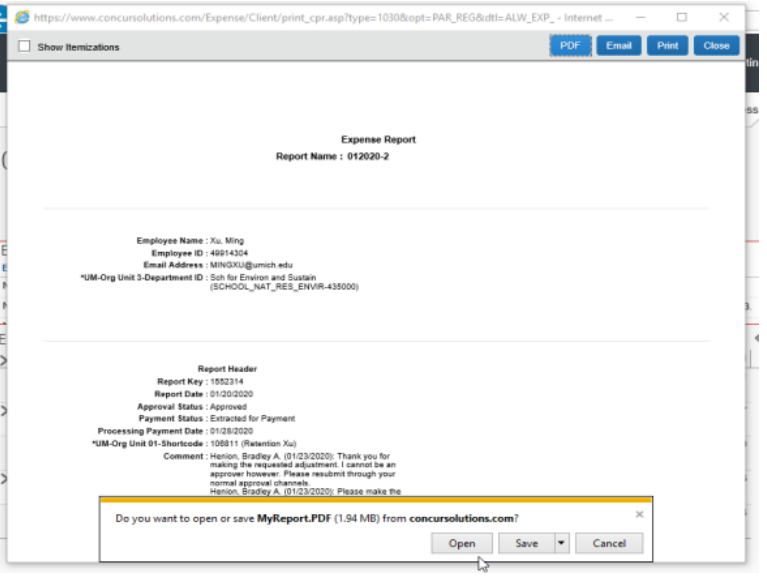

(Jeanette Frost, Word document email attachment, February 26, 2020) 
Appendix $\mathrm{H}$, University Travel Internal Analysis Team Final Report

Appendix H: Survey Comparison

\section{Comparison of the pilot and general surveys}

Subset of demographics questions that showed difference between the two surveys Q3 - What is your primary role in the University of Michigan?

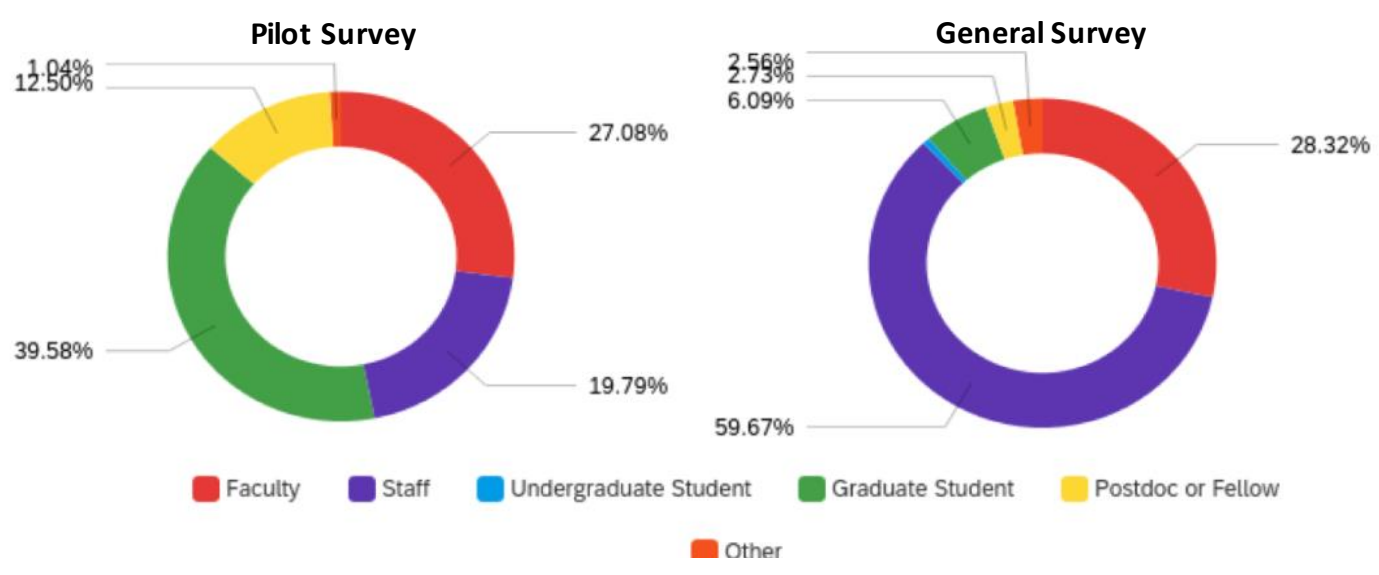

Q9 - Who paid for your university travel?

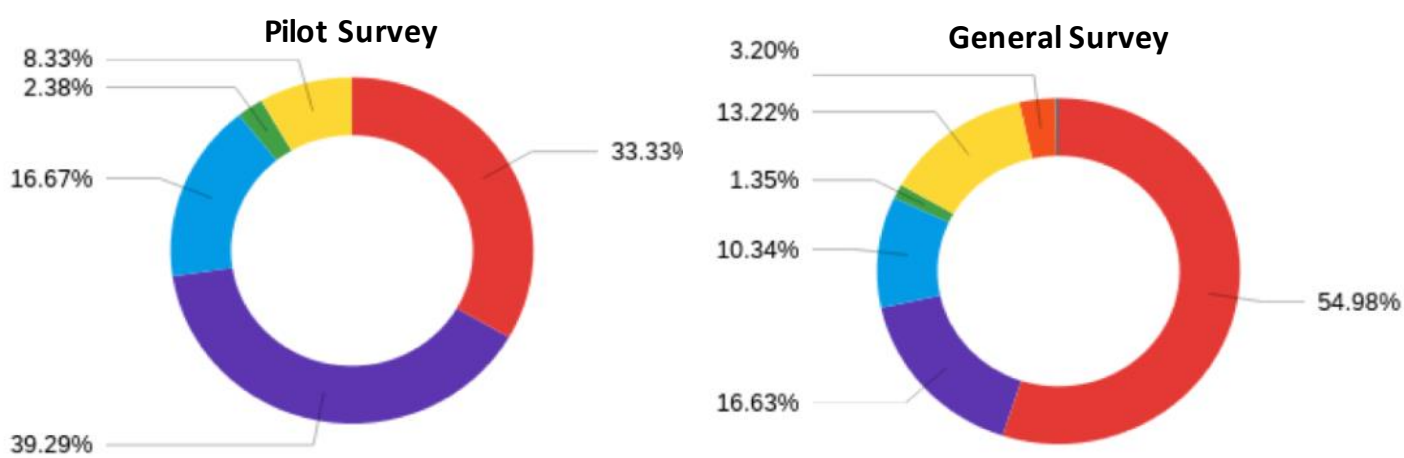

Internal university funds Grant or fellowship to the university (Such as from NIH, NSF or AHA)

Outside non-profit organization paying you directly $\quad$ For-profit business (Such as Ford, Merck)

Yourself Other, please specify Non-applicable 
Appendix $\mathrm{H}$,

University Travel Internal Analysis Team Final Report

Subset of opinion questions that showed differences between the two surveys

Q17 - How important do you think it is for the University to support air

travelfor students or fellows to attend a meeting or carrying out a project?

\section{$4.1 .55 \%$}

$19.77 \%$

Pilot Survey

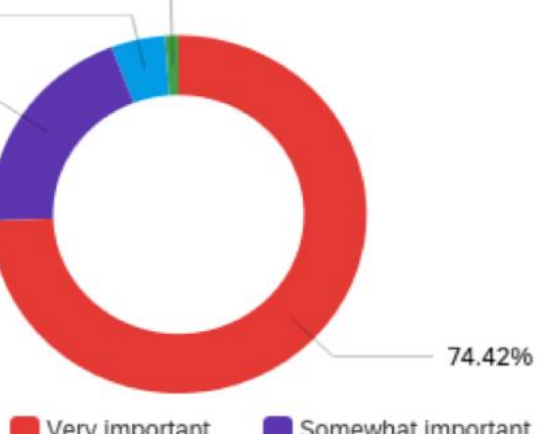

Very important

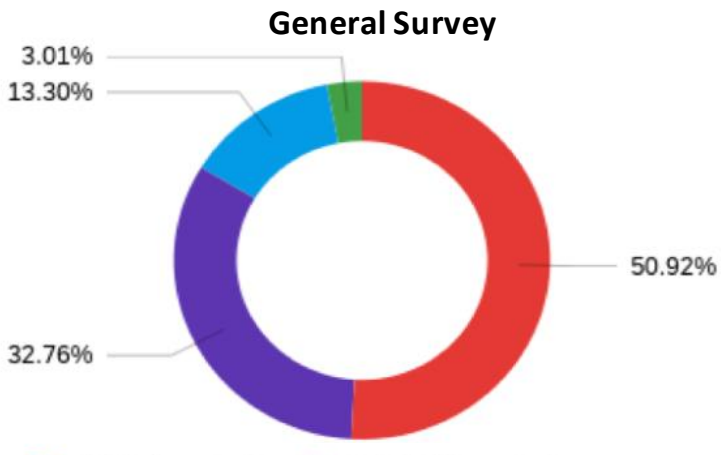

Slightly important
Not at all important

Q26 - How much would you support a travel fee if the fee were included in the increased cost of the ticket?

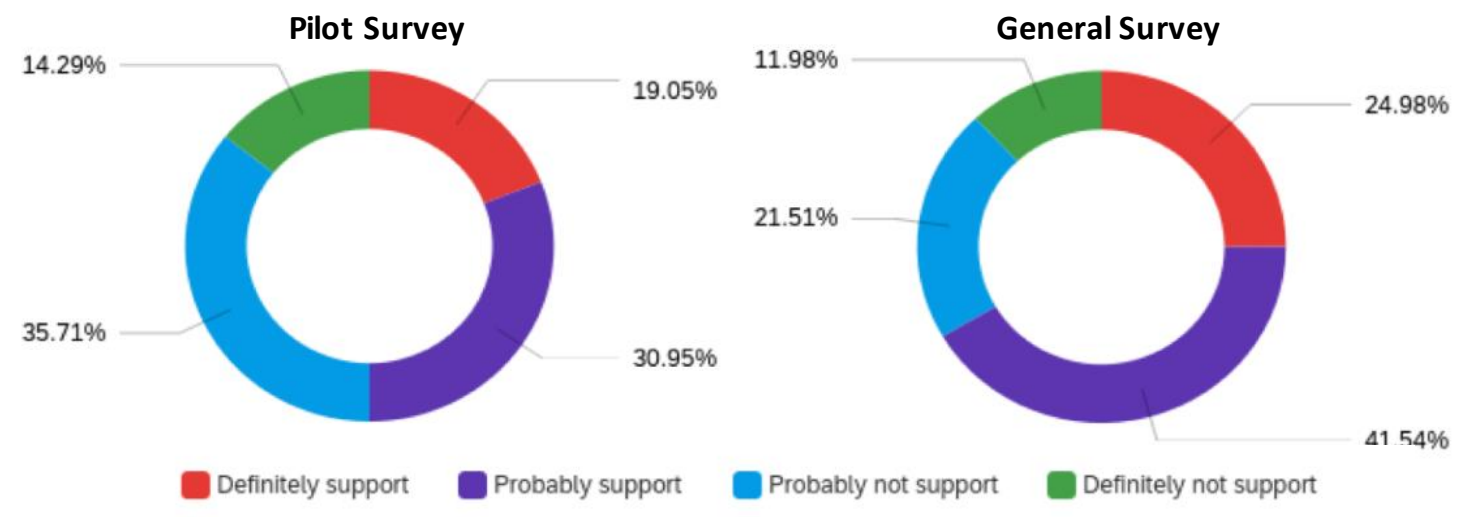

Q19 - If you were provided with videoconferencing facilities, for which of the following situations would you consider videoconferencing in place of traveling by air?

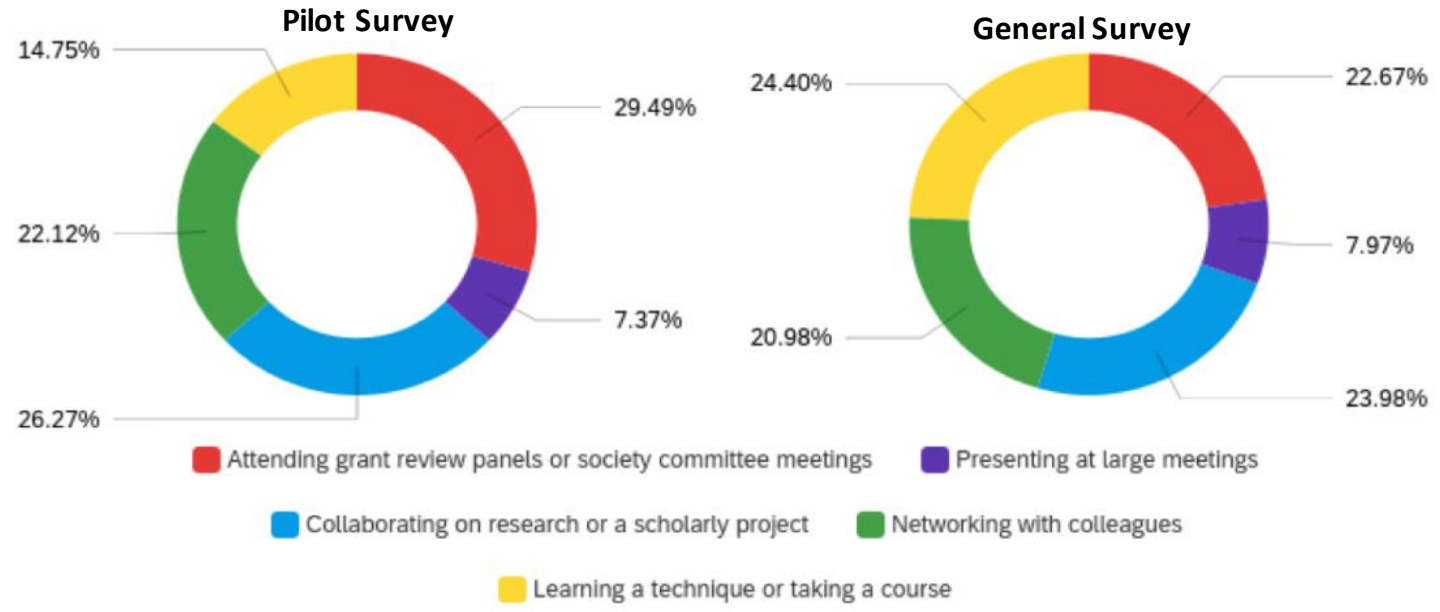


Appendix $\mathrm{H}$, University Travel Internal Analysis Team Final Report

Subset of opinion questions that were similar between the two surveys

Q22 - What is the longest distance you would be willing to use ground transportation instead of air travel to reduce greenhouse gases?
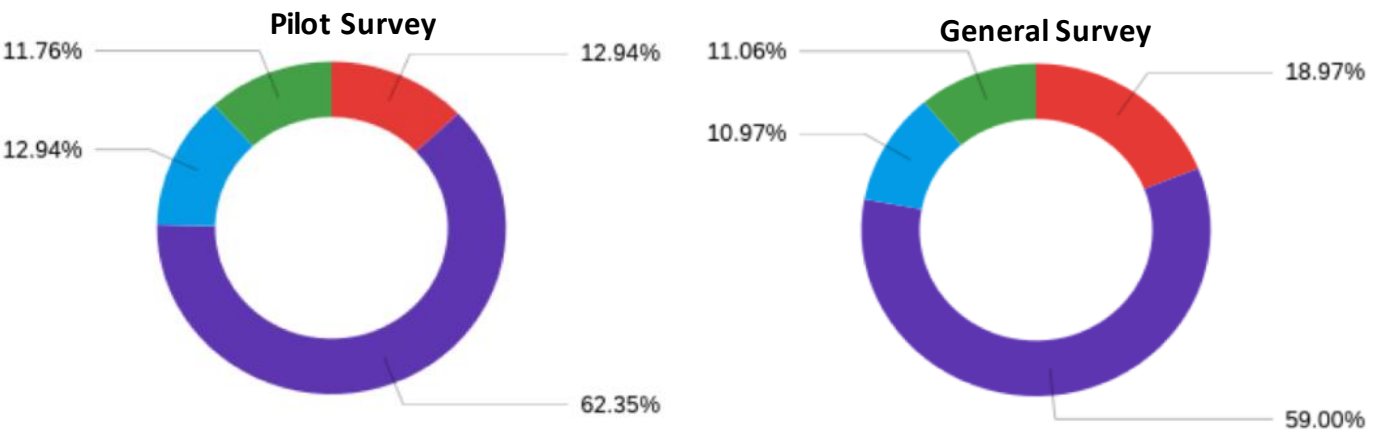

Trips under 200 miles (Detroit, Cleveland, Columbus)

Trips under 300 miles (Chicago, Indianapolis, Pittsburg, Toronto)

Trips under 400 miles (St Louis, Madison)

Trips under 500 miles (Washington DC)

Q23 - How much would you support a travel fee to mitigate the greenhouse gases produced by your travel?

Pilot Survey

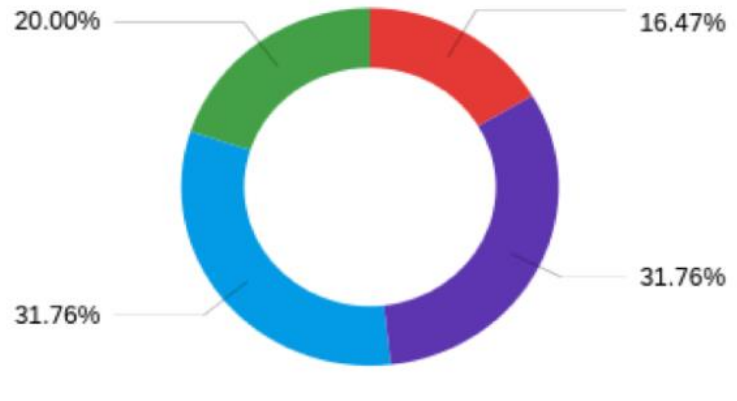

Definitely support
Probably support

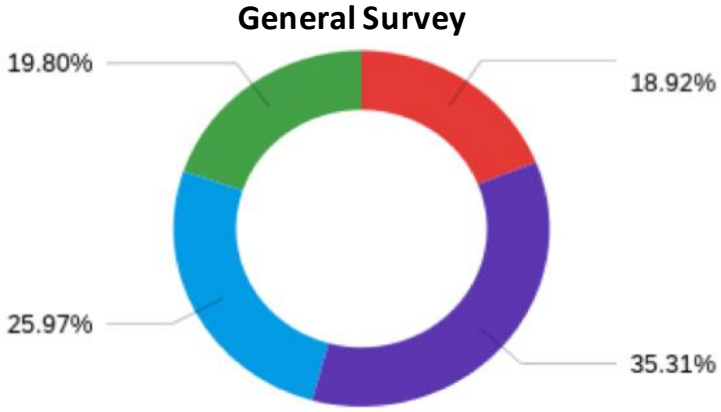

Probably not support

Definitely not support 
Appendix I, University Travel Internal Analysis Team Final Report

\section{Appendix I: Pilot Travel Survey}

Q1 - What is your gender?

\begin{tabular}{|l|r|r|r|}
\hline$\#$ & Answer & $\%$ & Count \\
\hline 1 & Male & $51.55 \%$ & 50 \\
\hline 2 & Female & $47.42 \%$ & 46 \\
\hline 3 & Other & $0.00 \%$ & 0 \\
\hline 4 & Prefer not to say & $1.03 \%$ & 1 \\
\hline & Total & $100 \%$ & 97 \\
\hline
\end{tabular}

Q2 - What is your age?

\begin{tabular}{|c|c|c|c|}
\hline \# & Answer & $\%$ & Count \\
\hline 1 & 20 years or younger & $2.08 \%$ & 2 \\
\hline 2 & 21 to 40 years & $68.75 \%$ & 66 \\
\hline 3 & 41 to 60 years & $20.83 \%$ & 20 \\
\hline \multirow[t]{2}{*}{4} & 61 years or older & $8.33 \%$ & 8 \\
\hline & Total & $100 \%$ & 96 \\
\hline
\end{tabular}

Q3 - What is your primary role in the University of Michigan?

\begin{tabular}{l|r|r|r}
\hline$\#$ & Answer & $\%$ & Count \\
\hline 1 & Faculty & $27.08 \%$ & 26 \\
\hline 2 & Staff & $19.79 \%$ & 19 \\
\hline 3 & Undergraduate Student & $0.00 \%$ & 0 \\
\hline 4 & Graduate Student & $39.58 \%$ & 38 \\
\hline 5 & Postdoc or Fellow & $12.50 \%$ & 12 \\
\hline 6 & Other & $1.04 \%$ & 1 \\
\hline & Total & $100 \%$ & 96 \\
\hline
\end{tabular}


Appendix I, University Travel Internal Analysis Team Final Report

Q4 - What is your primary school, department or unit?

\begin{tabular}{|c|c|c|c|}
\hline \# & Answer & $\%$ & Count \\
\hline 1 & Architecture \& Urban Planning & $0.00 \%$ & 0 \\
\hline 2 & Art \& Design & $1.05 \%$ & 1 \\
\hline 3 & Business & $0.00 \%$ & 0 \\
\hline 4 & Dentistry & $2.11 \%$ & 2 \\
\hline 5 & Education & $0.00 \%$ & 0 \\
\hline 6 & Engineering & $1.05 \%$ & 1 \\
\hline 7 & Environment \& Sustainability & $0.00 \%$ & 0 \\
\hline 8 & Information & $1.05 \%$ & 1 \\
\hline 9 & Kinesiology & $0.00 \%$ & 0 \\
\hline 10 & Law & $0.00 \%$ & 0 \\
\hline 11 & Literature, Science \& the Arts & $2.11 \%$ & 2 \\
\hline 12 & Medicine & $78.95 \%$ & 75 \\
\hline 13 & Music, Theatre \& Dance & $0.00 \%$ & 0 \\
\hline 14 & Nursing & $0.00 \%$ & 0 \\
\hline 15 & Pharmacy & $0.00 \%$ & 0 \\
\hline 16 & Public Health & $0.00 \%$ & 0 \\
\hline 17 & Public Policy & $0.00 \%$ & 0 \\
\hline 18 & Social Work & $0.00 \%$ & 0 \\
\hline \multirow[t]{2}{*}{19} & Other & $13.68 \%$ & 13 \\
\hline & Total & $100 \%$ & 95 \\
\hline
\end{tabular}


Appendix I, University Travel Internal Analysis Team Final Report

Q5 - We define university travel as going more than 25 miles to carry out business where you are recognized as being from the University of Michigan. Regardless of whether you were presenting, listening or participating, did you travel on university business 2018? (Pick up or drop off of guests at airport is not university travel.)

\begin{tabular}{|r|r|r|r}
\hline$\#$ & Answer & $\%$ & Count \\
\hline 1 & Yes & $65.59 \%$ & 61 \\
\hline 2 & No & $34.41 \%$ & 32 \\
\hline & Total & $100 \%$ & 93
\end{tabular}

Q6 - How many university trips did you make in $2018 ?$

\begin{tabular}{|c|c|c|c|}
\hline \# & Answer & $\%$ & Count \\
\hline 1 & $1-4$ times & $87.30 \%$ & 55 \\
\hline 2 & 5 or more times & $12.70 \%$ & 8 \\
\hline & Total & $100 \%$ & 63 \\
\hline
\end{tabular}

Q7 - For those university trips you took in 2018 (Please Enter Numbers)

\section{how many trips were \\ how many trips were how many trips were} primarily by air?

\begin{tabular}{l|l|}
\hline 6 \\
\hline 2 \\
\hline 1 \\
\hline 1 \\
\hline 0 \\
\hline 1 \\
\hline 1 \\
\hline 2 \\
\hline 0 \\
\hline 0 \\
\hline 1 \\
\hline 0 \\
\hline 1 \\
\hline
\end{tabular}
primarily by train? primarily by bus?

how many trips were primarily by car?

0

0

0

0


Appendix I, University Travel Internal Analysis Team Final Report

\begin{tabular}{|c|c|c|c|}
\hline 1 & & & 1 \\
\hline 1 & 0 & 0 & 1 \\
\hline 1 & & & 1 \\
\hline 0 & 0 & 0 & 1 \\
\hline 1 & 0 & 0 & 1 \\
\hline 0 & 0 & 0 & 1 \\
\hline 1 & & & 1 \\
\hline $\begin{array}{l}\text { how many trips were } \\
\text { primarily by air? }\end{array}$ & $\begin{array}{l}\text { how many trips were } \\
\text { primarily by train? }\end{array}$ & $\begin{array}{r}\text { how many trips were } \\
\text { primarily by bus? }\end{array}$ & $\begin{array}{r}\text { how many trips were } \\
\text { primarily by car? }\end{array}$ \\
\hline 2 & & & 1 \\
\hline 2 & & 1 & 1 \\
\hline 7 & 0 & 0 & 1 \\
\hline & & & 1 \\
\hline 1 & 0 & 0 & 0 \\
\hline 1 & 0 & 0 & 0 \\
\hline 4 & 0 & 0 & 0 \\
\hline 2 & 1 & 1 & 0 \\
\hline 3 & 0 & 0 & 0 \\
\hline 1 & 0 & 0 & 0 \\
\hline 4 & 0 & 0 & 0 \\
\hline 2 & 0 & 0 & 0 \\
\hline 4 & 0 & 0 & 0 \\
\hline 1 & 0 & 0 & 0 \\
\hline 4 & 0 & 0 & 0 \\
\hline 4 & 0 & 0 & 0 \\
\hline 1 & 0 & 0 & 0 \\
\hline 3 & 0 & 0 & 0 \\
\hline \multicolumn{4}{|l|}{8} \\
\hline 10 & & & \\
\hline
\end{tabular}


Appendix I, University Travel Internal Analysis Team Final Report

\begin{tabular}{|c|c|c|c|}
\hline 1 & & & \\
\hline 4 & 1 & & \\
\hline \multicolumn{4}{|l|}{2} \\
\hline \multicolumn{4}{|l|}{1} \\
\hline \multicolumn{4}{|l|}{1} \\
\hline \multicolumn{4}{|l|}{8} \\
\hline \multicolumn{4}{|l|}{3} \\
\hline \multicolumn{4}{|l|}{1} \\
\hline \multicolumn{4}{|l|}{1} \\
\hline $\begin{array}{l}\text { how many trips were } \\
\text { primarily by air? }\end{array}$ & $\begin{array}{l}\text { how many trips were } \\
\text { primarily by train? }\end{array}$ & $\begin{array}{r}\text { how many trips were } \\
\text { primarily by bus? }\end{array}$ & $\begin{array}{r}\text { how many trips were } \\
\text { primarily by car? }\end{array}$ \\
\hline \multicolumn{4}{|l|}{1} \\
\hline \multicolumn{4}{|l|}{4} \\
\hline \multicolumn{4}{|l|}{1} \\
\hline 2 & & & \\
\hline & & & \\
\hline & & & \\
\hline
\end{tabular}

Q8 - How many 2018 trips were international ? (Please Enter a Number)

\begin{tabular}{|r|r|r|r}
\hline$\#$ & Answer & $\%$ & Count \\
\hline 0 & 0 & $68.52 \%$ & 37 \\
\hline 1 & 1 & $24.07 \%$ & 13 \\
\hline 2 & 2 & $5.56 \%$ & 3 \\
\hline 3 & 3 & $1.85 \%$ & 1 \\
\hline & Total & $100 \%$ & 54 \\
\hline
\end{tabular}


Appendix I, University Travel Internal Analysis Team Final Report Q9 - Who paid for your university travel in 2018 ? (Check all that apply)

\begin{tabular}{|c|c|c|c|}
\hline \# & Answer & $\%$ & Count \\
\hline 1 & Internal university funds & $33.33 \%$ & 28 \\
\hline & $\begin{array}{r}\text { Grant or fellowship to the university (Such as from NIH, NSF or Am Heart } \\
\text { Assoc) }\end{array}$ & $39.29 \%$ & 33 \\
\hline 3 & Outside non-profit organization paying you directly & $16.67 \%$ & 14 \\
\hline 4 & For-profit business (Such as Ford, Merck) & $2.38 \%$ & 2 \\
\hline 5 & Other & $8.33 \%$ & 7 \\
\hline & Total & $100 \%$ & 84 \\
\hline
\end{tabular}

Q9_5_TEXT - Other

University organization

US Government NIH

Self

$\mathrm{Me}$

Self

Q10 - Were any of your university trips combined with extra time for vacation or self-enrichment in $2018 ?$

\begin{tabular}{|r|r|r|r}
\hline$\#$ & Answer & $\%$ & Count \\
\hline 1 & Yes & $55.36 \%$ & 31 \\
\hline 2 & No & $44.64 \%$ & 25 \\
\hline & Total & $100 \%$ & 56
\end{tabular}

Q11 - How much do you know about the difference in greenhouse gases produced by air travel compared to ground travel?

\begin{tabular}{l|r|r|r}
\hline$\#$ & Answer & $\%$ & Count \\
\hline 1 & A great deal & $16.07 \%$ & 9 \\
\hline 2 & Some & $33.93 \%$ & 19 \\
\hline 3 & A little & $28.57 \%$ & 16 \\
\hline 4 & Nothing at all & $21.43 \%$ & 12 \\
\hline & Total & $100 \%$ & 56
\end{tabular}


Appendix I, University Travel Internal Analysis Team Final Report

Q12 - The following questions will ask your attitudes on university travel by air for certain purposes. How important do you think it is for the University to support air travel for attending a conference or professional meeting?

\begin{tabular}{|l|r|r|r|}
\hline$\#$ & Answer & $\%$ & Count \\
\hline 1 & Very important & $73.56 \%$ & 64 \\
\hline 2 & Somewhat important & $25.29 \%$ & 22 \\
\hline 3 & Slightly important & $1.15 \%$ & 1 \\
\hline 4 & Not at all important & $0.00 \%$ & 0 \\
\hline & Total & $100 \%$ & 87 \\
\hline
\end{tabular}

Q13 - How important do you think it is for the University to support air travel for presenting a lecture, seminar, workshop or other teaching?

\begin{tabular}{|c|c|c|c|}
\hline \# & Answer & $\%$ & Count \\
\hline 1 & Very important & $69.77 \%$ & 60 \\
\hline 2 & Somewhat important & $27.91 \%$ & 24 \\
\hline 3 & Slightly important & $2.33 \%$ & 2 \\
\hline 4 & Not at all important & $0.00 \%$ & 0 \\
\hline & Total & $100 \%$ & 86 \\
\hline
\end{tabular}

Q14 - How important do you think it is for the University to support air travel for providing service to a journal or granting agency?

\begin{tabular}{|c|c|c|c|}
\hline \# & Answer & $\%$ & Count \\
\hline 1 & Very important & $30.59 \%$ & 26 \\
\hline 2 & Somewhat important & $48.24 \%$ & 41 \\
\hline 3 & Slightly important & $15.29 \%$ & 13 \\
\hline \multirow[t]{2}{*}{4} & Not at all important & $5.88 \%$ & 5 \\
\hline & Total & $100 \%$ & 85 \\
\hline
\end{tabular}

Q15 - How important do you think it is for the University to support air travel for learning a technique or taking a course?

\begin{tabular}{l|r|r|r}
$\#$ & Answer & $\%$ & Count \\
\hline 1 & Very important & $48.84 \%$ & 42 \\
\hline
\end{tabular}


Appendix I, University Travel Internal Analysis Team Final Report

\begin{tabular}{|c|c|c|c|}
\hline 2 & Somewhat important & $40.70 \%$ & 35 \\
\hline 3 & Slightly important & $8.14 \%$ & 7 \\
\hline 4 & Not at all important & $2.33 \%$ & 2 \\
\hline & Total & $100 \%$ & 8 \\
\hline
\end{tabular}

Q16 - How important do you think it is for the University to support air travel for networking with colleagues?

\begin{tabular}{|l|r|r|r}
\hline$\#$ & Answer & $\%$ & Count \\
\hline 1 & Very important & $19.77 \%$ & 17 \\
\hline 2 & Somewhat important & $45.35 \%$ & 39 \\
\hline 3 & Slightly important & $25.58 \%$ & 22 \\
\hline 4 & Not at all important & $9.30 \%$ & 8 \\
\hline & Total & $100 \%$ & 86 \\
\hline
\end{tabular}

Q17 - How important do you think it is for the University to support air travel for students or fellows to attend a meeting or carrying out a project?

\begin{tabular}{|c|c|c|c|}
\hline \# & Answer & $\%$ & Count \\
\hline 1 & Very important & $74.42 \%$ & 64 \\
\hline 2 & Somewhat important & $19.77 \%$ & 17 \\
\hline 3 & Slightly important & $4.65 \%$ & 4 \\
\hline \multirow[t]{2}{*}{4} & Not at all important & $1.16 \%$ & 1 \\
\hline & Total & $100 \%$ & 86 \\
\hline
\end{tabular}

Q18 - How important do you think it is for the University to support air travel for collaborating on research or a scholarly project?

\begin{tabular}{|c|c|c|c|}
\hline \# & Answer & $\%$ & Count \\
\hline 1 & Very important & $53.49 \%$ & 46 \\
\hline 2 & Somewhat important & $32.56 \%$ & 28 \\
\hline 3 & Slightly important & $12.79 \%$ & 11 \\
\hline \multirow[t]{2}{*}{4} & Not at all important & $1.16 \%$ & 1 \\
\hline & Total & $100 \%$ & 86 \\
\hline
\end{tabular}


Appendix I, University Travel Internal Analysis Team Final Report

Q19 - The following questions will ask your willingness to change your current practices for the purpose of reducing our carbon footprint and preventing the climate change. If you were provided with videoconferencing facilities, for which of the following situations would you consider videoconferencing in place of traveling by air? (Check all that apply)

\begin{tabular}{|r|r|r|r|}
\hline$\#$ & Answer & $\%$ & Count \\
\hline 1 & Attending grant review panels or society committee meetings & $29.49 \%$ & 64 \\
\hline 2 & Presenting at large meetings & $7.37 \%$ & 16 \\
\hline 3 & Collaborating on research or a scholarly project & $26.27 \%$ & 57 \\
\hline 4 & Networking with colleagues & $22.12 \%$ & 48 \\
\hline 5 & Learning a technique or taking a course & $14.75 \%$ & 32 \\
\hline & Total & $100 \%$ & 217 \\
\hline
\end{tabular}

Q20 - If you have used campus videoconferencing, how easy or difficult were they to use?

\begin{tabular}{|c|c|c|c|}
\hline \# & Answer & $\%$ & Count \\
\hline 1 & Very easy & $9.41 \%$ & 8 \\
\hline 2 & Moderately easy & $28.24 \%$ & 24 \\
\hline 3 & Moderately difficult & $23.53 \%$ & 20 \\
\hline 4 & Very difficult & $2.35 \%$ & 2 \\
\hline \multirow[t]{2}{*}{5} & Have not used & $36.47 \%$ & 31 \\
\hline & Total & $100 \%$ & 85 \\
\hline
\end{tabular}

Q21 - How willing would you be to use cars/trains or other ground transportation instead of flying for trips under 300 miles?

\begin{tabular}{|c|c|c|c|}
\hline \# & Answer & $\%$ & Count \\
\hline 1 & Very willing & $51.76 \%$ & 44 \\
\hline 2 & Somewhat willing & $41.18 \%$ & 35 \\
\hline 3 & Not very willing & $5.88 \%$ & 5 \\
\hline \multirow[t]{2}{*}{4} & Not at all willing & $1.18 \%$ & 1 \\
\hline & Total & $100 \%$ & 85 \\
\hline
\end{tabular}


Appendix I, University Travel Internal Analysis Team Final Report

Q22 - What is the longest distance you would be willing to use ground transportation instead of air travel to reduce greenhouse gases?

\begin{tabular}{|r|r|r|r|}
\hline$\#$ & Answer & $\%$ & Count \\
\hline 1 & Trips under 200 miles (Detroit, Cleveland, Columbus) & $12.94 \%$ & 11 \\
\hline 2 & Trips under 300 miles (Chicago, Indianapolis, Pittsburg, Toronto) & $62.35 \%$ & 53 \\
\hline 3 & Trips under 400 miles (St Louis, Madison) & $12.94 \%$ & 11 \\
\hline 4 & Trips under 500 miles (Washington DC) & $11.76 \%$ & 10 \\
\hline & Total & $100 \%$ & 85 \\
\hline
\end{tabular}

Q23 - Since much of university travel by air cannot be substituted by other modes of communication, one option would be to implement a travel fee based on the carbon footprint of your travel to cover the social and environmental cost of your travel. (The current social cost is estimated to be $\$ 50 / \mathrm{tCO}_{2} \mathrm{e}$ ) The following questions will ask your attitudes on the travel fee. How much would you support a travel fee to mitigate the greenhouse gases produced by your travel?

\begin{tabular}{|l|r|r|r|}
\hline$\#$ & Answer & $\%$ & Count \\
\hline 1 & Definitely support & $16.47 \%$ & 14 \\
\hline 2 & Probably support & $31.76 \%$ & 27 \\
\hline 3 & Probably not support & $31.76 \%$ & 27 \\
\hline 4 & Definitely not support & $20.00 \%$ & 17 \\
\hline & Total & $100 \%$ & 85 \\
\hline
\end{tabular}

Q24 - How much would you support a travel fee if it were paid for by the funds supporting the travel?

\begin{tabular}{|l|r|r|r|}
\hline$\#$ & Answer & $\%$ & Count \\
\hline 1 & Definitely support & $41.18 \%$ & 35 \\
\hline 2 & Probably support & $32.94 \%$ & 28 \\
\hline 3 & Probably not support & $20.00 \%$ & 17 \\
\hline 4 & Definitely not support & $5.88 \%$ & 5 \\
\hline & Total & $100 \%$ & 85 \\
\hline
\end{tabular}


Appendix I, University Travel Internal Analysis Team Final Report

Q25 - How much would you support a travel fee if it were paid for by the Unit or Department home of the traveler?

\begin{tabular}{|l|r|r|r|}
\hline$\#$ & Answer & $\%$ & Count \\
\hline 1 & Definitely support & $36.47 \%$ & 31 \\
\hline 2 & Probably support & $30.59 \%$ & 26 \\
\hline 3 & Probably not support & $25.88 \%$ & 22 \\
\hline 4 & Definitely not support & $7.06 \%$ & 6 \\
\hline & Total & $100 \%$ & 85 \\
\hline
\end{tabular}

Q26 - How much would you support a travel fee if the fee was included in the increased cost of the ticket?

\begin{tabular}{l|r|r|r}
\hline$\#$ & Answer & $\%$ & Count \\
\hline 1 & Definitely support & $19.05 \%$ & 16 \\
\hline 2 & Probably support & $30.95 \%$ & 26 \\
\hline 3 & Probably not support & $35.71 \%$ & 30 \\
\hline 4 & Definitely not support & $14.29 \%$ & 12 \\
\hline & Total & $100 \%$ & 84
\end{tabular}

Q27 - If an Air Travel Mitigation Fund were established to receive travel fees, which of the following would you support its use for: (Select up to 3)

\begin{tabular}{|r|r|r|r|}
\hline$\#$ & Answer & Count \\
\hline 1 & On campus projects to generate energy efficiency and renewable power & $25.00 \%$ & 55 \\
\hline 2 & Off campus projects to plant trees in Amazon river basin & $10.00 \%$ & 22 \\
\hline 3 & Off campus but local projects to assist low income organizations to \\
conserve energy or generate clean power & $22.73 \%$ & 50 \\
\hline 4 & Support sustainability projects for clean power and water worldwide & $15.45 \%$ & 34 \\
\hline 6 & Off campus but local projects to generate clean power (solar panels) & $25.45 \%$ & 56 \\
\hline 8 & Other & $1.36 \%$ & 3 \\
\hline & Total & $100 \%$ & 220 \\
\hline
\end{tabular}


Appendix I,

University Travel Internal Analysis Team Final Report

\section{Q27_8_TEXT - Other}

Promote and build infrastracture for alternative transportation. Electric train lines, local and national.

support local K-12 schools

In general, I think that supporting sustainability at the local level is the best thing any person can do to combat climate change.

Q28 - If you would like to be entered into the raffle for a $\$ 50$ Amazon gift card, please include a valid UMICH email address below. Your information will be kept strictly confidential and will not be used for any purpose other than to notify you should you win.

Q29 - If you have any comments on our survey, please put them in the text entry box below. We appreciate your feedbacks to help us improve our survey!

You need to alter your "name" page so that names with hyphens can be recognized.

Thanks for doing this!

The university could lead the nation by designing a national conference that is based on these principles to reduce carbon footprint. It takes some strategy and trial and error to find ways that work and people will still enjoy a meeting and find it effective....e.g. hub and spoke model, satellite meetings interlinked over the web. The biggest drawback of virtual meetings is opportunities for junior scientists to present their work and get feedback. There are ways this could be done but they need to be tried and explored. One highly successful meeting will become the model for meetings of the future.

Suggest a back arrow so that respondents can go back to rethink a previous question/answer

Our University would not be internationally recognized and sought after if it didn't communicate it's work to outsiders via face to face interactions. Journal papers and email just don't do it.

Good ideas!

Bear in mind that research in some departments, like Asians Languages and Cultures, requires frequent travel of 1,000+ miles. To stick the Department with extra fees because of the nature of its research would be unfair.

I care deeply about mitigating climate change, but it's hard for me to ask individuals to pay an increased cost when I'm not sure it will have much effect on the amount of CO2 produced. How might this affect a particular department's ability to pay for their students to go to conferences, etc? I would hate to see students miss out. I would like to see some incentive for choosing train/car travel when applicable - perhaps a $\$ 50$ payment to the individual who makes that choice? That makes it a positive incentive rather than a negative one.

I think being conscious of our carbon footprint via travel is very important. However, climate change is an infrastructural issue, not about personal choice of everyday people. UMich Regents actively invest in oil companies. I feel like a carbon tax is like putting a band aid on a broken arm.

I would have liked 1- a back button, 2- a non-applicable option (for example, if I am staff, I do not review grants), 3- to know about the funding options with the collected fee before I answered if I was willing to pay the fee.

I would include scenario questions: 1) you are invited to give a talk in Chicago; what would be your preferred mode of transportation? I would also add a question such as: do you consider $\mathrm{CO} 2$ emissions when choosing your mode of transportation? I think the surveys doesn't address 
Appendix I, University Travel Internal Analysis Team Final Report

yet whether or not people are already making efforts to minimize CO2 footprints. From my point of view, air travel is already minimized to a great extend; if Skype/blue jeans is an option, it's used. But these services can only replace some aspects of direct peer-2-peer interactions.

While I think that University business travel is important, some people clearly overdo it. I would support a limit on the number of sponsored trips that different people could take, based on level (e.g. 1 trip for students, 2 for postdocs, 4 for junior faculty... etc), and/or a limit on the number of invitations. None of this will matter much unless multiple universities get involved though, and making invited seminars and committee meetings etc. by video a regular thing would do a lot more to limit travel.

why 2018 and not 2019? might want to have an estimate for CO2 'tax' for travel based on actual trips (Toronto: \$50, etc.) Typo above: "feedbacks" 
Appendix J, University Travel Internal Analysis Team Final Report

\section{Appendix J: General Travel Survey}

\section{General Travel Survey Distribution Summary}

We conducted our general survey from February 10, 2020, to March 21, 2020, asking participants questions regarding their travel in 2019. There are 20,545 contacts in our population mailing list. We sampled 9,000 email addresses from the population mailing list (about $1 \%$ are invalid email addresses) and sent out our survey via Qualtrics. Due to the maximum distribution limit from Qualtrics (5,000 emails per time), we decided to send out our survey by two rounds (4,500 each), both of which were followed by three rounds of reminder. The overall general response rate is $26.5 \%$. Detailed distribution summary is as follows.

Table K. Survey Distribution Summary

\begin{tabular}{lllll}
\hline & Sent & Bounced & Started & Finished \\
\hline First Round & 4499 & 50 & 1238 & 1213 \\
Second Round & 4500 & 39 & 1193 & 1164 \\
\hline
\end{tabular}

\section{General Travel Survey Results}

\begin{tabular}{l|r|r|r|}
$\begin{array}{l}\text { Q1 - What is your gender? } \\
\#\end{array} \mid$ Answer & $\%$ & Count \\
\hline 1 & Male & $35.47 \%$ & 837 \\
\hline 2 & Female & $62.29 \%$ & 1470 \\
\hline 3 & Other & $0.47 \%$ & 11 \\
\hline 4 & Prefer not to answer & $1.78 \%$ & 42 \\
\hline & Total & $100 \%$ & 2360
\end{tabular}

Q2 - What is your age?

\begin{tabular}{|c|c|c|c|}
\hline$\#$ & Answer & $\%$ & Count \\
\hline 1 & 20 years or younger & $0.26 \%$ & 6 \\
\hline 2 & 21 to 40 years & $41.68 \%$ & 980 \\
\hline 3 & 41 to 60 years & $44.32 \%$ & 1042 \\
\hline \multirow[t]{2}{*}{4} & 61 years or older & $13.74 \%$ & 323 \\
\hline & Total & $100 \%$ & 2351 \\
\hline
\end{tabular}


Appendix J, University Travel Internal Analysis Team Final Report Q3 - What is your primary role in the University of Michigan?

\begin{tabular}{|l|r|r|r|}
\hline$\#$ & Answer & $\%$ & Count \\
\hline 1 & Faculty & $28.30 \%$ & 664 \\
\hline 2 & Staff & $59.68 \%$ & 1400 \\
\hline 3 & Undergraduate Students & $0.64 \%$ & 15 \\
\hline 4 & Graduate Student & $6.10 \%$ & 143 \\
\hline 5 & Postdoc or Fellow & $2.56 \%$ & 60 \\
\hline 6 & Other, please specify & $2.73 \%$ & 64 \\
\hline & Total & $100 \%$ & 2346
\end{tabular}

Q4 - What is your primary school, department or unit?

\begin{tabular}{|c|c|c|c|}
\hline \# & Answer & $\%$ & Count \\
\hline 1 & Architecture \& Urban Planning & $0.69 \%$ & 16 \\
\hline 2 & Art \& Design & $0.56 \%$ & 13 \\
\hline 3 & Business & $3.30 \%$ & 77 \\
\hline 4 & Dentistry & $0.99 \%$ & 23 \\
\hline 5 & Education & $1.59 \%$ & 37 \\
\hline 6 & Engineering & $7.46 \%$ & 174 \\
\hline 7 & Environment and Sustainability & $1.24 \%$ & 29 \\
\hline 8 & Information & $1.76 \%$ & 41 \\
\hline 9 & Kinesiology & $0.60 \%$ & 14 \\
\hline 10 & Law & $0.99 \%$ & 23 \\
\hline 11 & Literature, Science and the Arts & $13.30 \%$ & 310 \\
\hline 12 & Medicine & $28.44 \%$ & 663 \\
\hline 13 & Music, Theatre \& Dance & $0.69 \%$ & 16 \\
\hline 14 & Nursing & $4.33 \%$ & 101 \\
\hline 15 & Pharmacy & $1.07 \%$ & 25 \\
\hline 16 & Public Health & $3.17 \%$ & 74 \\
\hline 17 & Public Policy & $0.69 \%$ & 16 \\
\hline
\end{tabular}


Appendix J, University Travel Internal Analysis Team Final Report

\begin{tabular}{r|r|r} 
Social Work & $0.82 \%$ & 19 \\
\hline Other & $28.31 \%$ & 660 \\
\hline Total & $100 \%$ & 2331
\end{tabular}

Q5 - We define university travel as going more than 25 miles to carry out business where you are recognized as being from the University of Michigan. Regardless of whether you were presenting, listening or participating, did you travel on university business in 2019? (Pick up or drop off of guests at airport is not university travel.)

\begin{tabular}{|r|r|r|r}
\hline$\#$ & Answer & $\%$ & Count \\
\hline 1 & Yes & $83.81 \%$ & 1946 \\
\hline 2 & No & $16.19 \%$ & 376 \\
\hline & Total & $100 \%$ & 2322
\end{tabular}

Q6 - How many university trips did you make in $2019 ?$

\begin{tabular}{|c|c|c|c|}
\hline \# & Answer & $\%$ & Count \\
\hline 1 & 1-4 times & $66.39 \%$ & 1288 \\
\hline \multirow[t]{2}{*}{2} & 5 or more times & $33.61 \%$ & 652 \\
\hline & Total & $100 \%$ & 1940 \\
\hline
\end{tabular}

Q7* - For those university trips you took in 2019 (Please Enter Numbers; if you have no such experience, leave it blank or enter 0 )

\begin{tabular}{c|c|c|c|c|c} 
& Minimum & Maximum & Mean & Std Deviation & Count \\
\hline By Air & 0 & 75 & 2.36 & 3.91 & 2377 \\
\hline By Train & 0 & 6 & 0.12 & 0.44 & 2378 \\
\hline By Bus & 0 & 20 & 0.08 & 0.72 & 2378 \\
\hline By Car & 0 & 250 & 3.01 & 12.17 & 2378 \\
\hline
\end{tabular}

*We identified and deleted one outlier ("1200 times travel by air") in "By Air". 
Appendix J, University Travel Internal Analysis Team Final Report Q8 - How many trips in 2019 were international? (Please Enter a Number; if you have no such experience, leave it blank or enter 0)

\#

How many trips in 2019 were international? (Please Enter

8

a Number; if you have no such experience, leave it blank or enter 0 )

\begin{tabular}{|r|r|r|r|r|r|}
\hline Minimum & Maximum & Mean & $\begin{array}{r}\text { Std } \\
\text { Deviation }\end{array}$ & Variance & Count \\
\hline 0.00 & 25.00 & 0.60 & 1.41 & 1.99 & 1716 \\
\hline
\end{tabular}

Q9 - Who paid for your university travel in 2019 ? (Check all that apply)

\begin{tabular}{|r|r|r|r|}
\hline$\#$ & Answer & Count \\
\hline 1 & Internal university funds & $54.98 \%$ & 1546 \\
\hline 2 & Grant or fellowship to the university (Such as from NIH, NSF or AHA) & $16.61 \%$ & 467 \\
\hline 3 & Outside non-profit organization paying you directly & $10.35 \%$ & 291 \\
\hline 4 & For-profit business (Such as Ford, Merck) & $1.35 \%$ & 38 \\
\hline 5 & Yourself & $13.23 \%$ & 372 \\
\hline 6 & Other, please specify & $3.20 \%$ & 90 \\
\hline 7 & Non-applicable & $0.28 \%$ & 8 \\
\hline
\end{tabular}

Q10 - Were any of your university trips combined with extra time for vacation or self-enrichment in 2019 ?

\begin{tabular}{|r|r|r|r|}
\hline$\#$ & Answer & $\%$ & Count \\
\hline 1 & Yes & $34.36 \%$ & 650 \\
\hline 2 & No & $65.64 \%$ & 1242 \\
\hline & Total & $100 \%$ & 1892 \\
\hline
\end{tabular}


Appendix J, University Travel Internal Analysis Team Final Report

Q11 - How much do you know about the difference in greenhouse gases produced by air travel compared to ground travel?

\begin{tabular}{|c|c|c|c|}
\hline \# & Answer & $\%$ & Count \\
\hline 1 & A great deal & $10.32 \%$ & 195 \\
\hline 2 & Some & $37.41 \%$ & 707 \\
\hline 3 & A little & $30.00 \%$ & 567 \\
\hline 4 & Nothing at all & $22.28 \%$ & 421 \\
\hline & Total & $100 \%$ & 1890 \\
\hline
\end{tabular}

Q12 - The following questions will ask your opinion of the value of university travel by air for certain purposes. How important do you think it is for the University to support air travel for attending a conference or professional meeting?

\begin{tabular}{|l|r|r|r|}
\hline$\#$ & Answer & $\%$ & Count \\
\hline 1 & Very important & $75.16 \%$ & 1691 \\
\hline 2 & Somewhat important & $20.22 \%$ & 455 \\
\hline 3 & Slightly important & $3.56 \%$ & 80 \\
\hline 4 & Not at all important & $1.07 \%$ & 24 \\
\hline & Total & $100 \%$ & 2250 \\
\hline
\end{tabular}

Q13 - How important do you think it is for the University to support air travel for presenting a lecture, seminar, workshop or other teaching?

\begin{tabular}{|c|c|c|c|}
\hline \# & Answer & $\%$ & Count \\
\hline 1 & Very important & $73.03 \%$ & 1641 \\
\hline 2 & Somewhat important & $21.67 \%$ & 487 \\
\hline 3 & Slightly important & $4.27 \%$ & 96 \\
\hline 4 & Not at all important & $1.02 \%$ & 23 \\
\hline & Total & $100 \%$ & 2247 \\
\hline
\end{tabular}

Q14 - How important do you think it is for the University to support air travel for providing service to a journal or granting agency?

\begin{tabular}{l|r|r|r}
$\#$ & Answer & $\%$ & Count \\
\hline 1 & Very important & $33.21 \%$ & 737 \\
\hline 2 & Somewhat important & $39.97 \%$ & 887
\end{tabular}


Appendix J, University Travel Internal Analysis Team Final Report

Not at all important

$6.80 \%$

151

Total

$100 \%$

2219

Q15 - How important do you think it is for the University to support air travel for learning a technique or taking a course?

\begin{tabular}{|l|r|r|r|}
\hline$\#$ & Answer & $\%$ & Count \\
\hline 1 & Very important & $43.08 \%$ & 962 \\
\hline 2 & Somewhat important & $36.90 \%$ & 824 \\
\hline 3 & Slightly important & $16.48 \%$ & 368 \\
\hline 4 & Not at all important & $3.54 \%$ & 79 \\
\hline & Total & $100 \%$ & 2233 \\
\hline
\end{tabular}

Q16 - How important do you think it is for the University to support air travel for networking with colleagues?

\begin{tabular}{l|r|r|r}
\hline$\#$ & Answer & $\%$ & Count \\
\hline 1 & Very important & $20.71 \%$ & 462 \\
\hline 2 & Somewhat important & $32.32 \%$ & 721 \\
\hline 3 & Slightly important & $31.47 \%$ & 702 \\
\hline 4 & Not at all important & $15.51 \%$ & 346 \\
\hline & Total & $100 \%$ & 2231
\end{tabular}

Q17 - How important do you think it is for the University to support air travel for students or fellows to attend a meeting or carrying out a project?

\begin{tabular}{l|r|r|r}
\hline$\#$ & Answer & $\%$ & Count \\
\hline 1 & Very important & $50.90 \%$ & 1132 \\
\hline 2 & Somewhat important & $32.78 \%$ & 729 \\
\hline 3 & Slightly important & $13.31 \%$ & 296 \\
\hline 4 & Not at all important & $3.01 \%$ & 67 \\
\hline & Total & $100 \%$ & 2224 \\
\hline
\end{tabular}


Appendix J, University Travel Internal Analysis Team Final Report

Q18 - How important do you think it is for the University to support air travel for collaborating on research or a scholarly project?

\begin{tabular}{|l|r|r|r|}
\hline$\#$ & Answer & $\%$ & Count \\
\hline 1 & Very important & $47.79 \%$ & 1061 \\
\hline 2 & Somewhat important & $35.00 \%$ & 777 \\
\hline 3 & Slightly important & $14.01 \%$ & 311 \\
\hline 4 & Not at all important & $3.20 \%$ & 71 \\
\hline & Total & $100 \%$ & 2220 \\
\hline
\end{tabular}

Q19 - The following questions will ask your willingness to change your current practices for the purpose of reducing your carbon footprint and preventing the climate change. If you were provided with videoconferencing facilities, for which of the following situations would you consider videoconferencing in place of traveling by air? (Check all that apply)

\begin{tabular}{|r|r|r|r|}
\hline$\#$ & Answer & $\%$ & Count \\
\hline 1 & Attending grant review panels or society committee meetings & $22.67 \%$ & 1365 \\
\hline 2 & Presenting at large meetings & $7.97 \%$ & 480 \\
\hline 3 & Collaborating on research or a scholarly project & $23.99 \%$ & 1444 \\
\hline 4 & Networking with colleagues & $20.98 \%$ & 1263 \\
\hline 5 & Learning a technique or taking a course & $24.39 \%$ & 1468 \\
\hline & Total & $100 \%$ & 6020 \\
\hline
\end{tabular}

Q20 - If you have used campus videoconferencing, how easy or difficult were they to use?

\begin{tabular}{|c|c|c|c|}
\hline \# & Answer & $\%$ & Count \\
\hline 1 & Very easy & $14.07 \%$ & 309 \\
\hline 2 & Moderately easy & $43.81 \%$ & 962 \\
\hline 3 & Moderately difficult & $19.54 \%$ & 429 \\
\hline 4 & Very difficult & $3.37 \%$ & 74 \\
\hline \multirow[t]{2}{*}{5} & Have not used & $19.22 \%$ & 422 \\
\hline & Total & $100 \%$ & 2196 \\
\hline
\end{tabular}


Appendix J, University Travel Internal Analysis Team Final Report

Q21 - How willing would you be to use cars/trains or other ground transportation to replace flying for trips under 300 miles?

\begin{tabular}{|c|c|c|c|}
\hline \# & Answer & $\%$ & Count \\
\hline 1 & Very willing & $51.07 \%$ & 1120 \\
\hline 2 & Somewhat willing & $38.35 \%$ & 841 \\
\hline 3 & Not very willing & $8.03 \%$ & 176 \\
\hline 4 & Not at all willing & $2.55 \%$ & 56 \\
\hline & Total & $100 \%$ & 2193 \\
\hline
\end{tabular}

Q22 - What is the longest distance you would be willing to use ground transportation instead of air travel to reduce greenhouse gases?

\begin{tabular}{|r|r|r|r|}
\hline$\#$ & Answer & $\%$ & Count \\
\hline 1 & Trips under 200 miles (Detroit, Cleveland, Columbus) & $18.98 \%$ & 415 \\
\hline 2 & Trips under 300 miles (Chicago, Indianapolis, Pittsburg, Toronto) & $58.98 \%$ & 1290 \\
\hline 3 & Trips under 400 miles (St Louis, Madison) & $10.97 \%$ & 240 \\
\hline 4 & Trips under 500 miles (Washington DC) & $11.07 \%$ & 242 \\
\hline & Total & $100 \%$ & 2187 \\
\hline
\end{tabular}

Q23 - Since much of university travel by air cannot be substituted by other modes of communication, one option would be to implement a travel fee based on the carbon footprint of your travel to cover the social (environmental) cost of your travel. For example, economy round trip air travel from Detroit to Boston yields $0.43 \mathrm{tCO}_{2} \mathrm{e}$, from DTW to Los Angeles $1.1 \mathrm{tCO}_{2} \mathrm{e}$ and from Detroit to Paris France $2.1 \mathrm{tCO}_{2} \mathrm{e}$. The current social cost is estimated to be $\$ 50 / \mathrm{tCO}_{2} \mathrm{e}$.The following questions will ask your opinion of a carbon mitigation travel fee. How much would you support a travel fee to mitigate the greenhouse gases produced by your travel?

\begin{tabular}{|l|r|r|r|}
\hline$\#$ & Answer & $\%$ & Count \\
\hline 1 & Definitely support & $18.93 \%$ & 411 \\
\hline 2 & Probably support & $35.33 \%$ & 767 \\
\hline 3 & Probably not support & $25.93 \%$ & 563 \\
\hline 4 & Definitely not support & $19.81 \%$ & 430 \\
\hline & Total & $100 \%$ & 2171 \\
\hline
\end{tabular}

Q24 - How much would you support a travel fee if it were paid for by the funds supporting the travel? 
Appendix J, University Travel Internal Analysis Team Final Report

\begin{tabular}{|l|r|r|r|}
\hline$\#$ & Answer & $\%$ & Count \\
\hline 1 & Definitely support & $39.02 \%$ & 849 \\
\hline 2 & Probably support & $33.78 \%$ & 735 \\
\hline 3 & Probably not support & $16.91 \%$ & 368 \\
\hline 4 & Definitely not support & $10.29 \%$ & 224 \\
\hline & Total & $100 \%$ & 2176 \\
\hline
\end{tabular}

Q25 - How much would you support a travel fee if it were paid for by the Unit or Department home of the traveler?

\begin{tabular}{|l|r|r|r|}
\hline$\#$ & Answer & $\%$ & Count \\
\hline 1 & Definitely support & $32.40 \%$ & 703 \\
\hline 2 & Probably support & $34.75 \%$ & 754 \\
\hline 3 & Probably not support & $20.97 \%$ & 455 \\
\hline 4 & Definitely not support & $11.89 \%$ & 258 \\
\hline & Total & $100 \%$ & 2170 \\
\hline
\end{tabular}

Q26 - How much would you support a travel fee if the fee were included in the increased cost of the ticket?

\begin{tabular}{r|r|r|r}
$\#$ & Answer & $\%$ & Count \\
\hline 1 & Definitely support & $24.99 \%$ & 540 \\
\hline 2 & Probably support & $41.55 \%$ & 898 \\
\hline 3 & Probably not support & $21.47 \%$ & 464 \\
\hline 4 & Definitely not support & $11.99 \%$ & 259 \\
\hline & Total & $100 \%$ & 2161
\end{tabular}

Q27 - If an Air Travel Mitigation Fund were established to receive travel fees, which of the following would you consider appropriate for its use: (Select up to 3 )

\begin{tabular}{|r|r|r|r|}
\hline$\#$ & Answer & Count \\
\hline 1 & On campus projects to generate energy efficiency and renewable power & $27.04 \%$ & 1368 \\
\hline 2 & Off campus projects to plant trees in the Amazon river basin & $8.50 \%$ & 430 \\
\hline 3 & Off campus but local projects to generate clean power (solar panels) & $23.29 \%$ & 1178 \\
\hline
\end{tabular}


Appendix J,

University Travel Internal Analysis Team Final Report

4

5

6
Off campus but local projects to assist low income organizations to conserve energy or generate clean power

Support sustainability projects for clean power and water worldwide
$19.87 \%$

$19.65 \%$

$$
\begin{array}{r|r}
\text { Other, please specify } & 1.66 \% \\
\hline \text { Total } & 100 \%
\end{array}
$$

1005

994

5059

Q27_6_TEXT - Other, please specify

On campus and in-state projects to foster green energy efficiency, green practices, renewable power plus subsidies to develop more undergrad students in this vein. Support for in-state communities striving to be more efficient. As successful efforts can be made "best practice" and scaled, extend reach/contribution to others in urgent need. Also, create offsetting impact by facilitating local and regional travel using ride sharing or other more energy efficient approaches (perhaps making all van share and university vehicles electric and/or installing more solar or wind production..... But since we are a university, our offsetting contribution could always involve "educating/training" more communities, industries that need it, student populations. Consider benefiting the student population of older workers who need retraining from outdated industry!

The above choices are all good suggestions; but I don't agree air travel is the main issue to increase the greenhouse effect. The important thing to decrease the environmental pollution is to increase the forest area and stop destroying and wasting the nature sources. Without other tool to improve the travel experience, the air fly still be the necessary for us to save the travelling time.

Provide 'scholarships' for individuals who would like to take advantage of virtual training/networking opportunities but do not have department financial support to do so Need to offset the cost of additional days of travel: per diem and hotel cost; dept budgets won't likely go up to pay for extra cost of non-air travel

It seems to me that the important issue is that the $\$$ invested actually offsets the emissions. I would prioritize the project that reliably reduces or sequesters the most carbon emissions, whatever and wherever that is. I wonder about an internal travel emission cap and trade program?

I would want it to support real, additional, verifiable, enforceable, and permanent offsets.

What about local (off-campus) reforestation programs?

public transportation

Thorium reactor development

Donations to various causes

Support Great Lakes restoration

Projects to promote more Nuclear Power

Other projects that would directly consume or sequester $\mathrm{CO} 2$

fund local research on sustainability

Support efforts at the University to lead conference alternatives that require less travel (ie, perhaps regional meetings that are networked) 
Projects to improve shared travel options for daily commuters driving to and from the University to decrease the carbon footprint by staff, faculty, and students. Such options would also reduce the burden on the University to expand parking lots/structures.

Fossil fuel divestment

Commumity education on the importance of reducing wasteful practices

Return to units for research support

Shift University power use toward clean power and water on all campuses

Need to see research showing effectiveness

This could be a dangerous "slush fund" to support efforts that do NOT reduce or capture carbon.

Plant trees in Michigan and the Midwest

Flint still has no water.

Washington DC lobbying efforts to promote clean energy over fossil fuels

Projects to improve video conference capabilities for faculty to reduce the need for travel.

Support policies to make legislative change surrounding clean power action planning

On campus projects to reduce the amount of traffic congestion and idling emissions due to pedestrians that are a huge problem here.

Community projects that respond to actual community needs as identified by the community members themselves.

research to improve alternative energy sources

Increase public transportation options in the local area

Support and promote 'work-from-remote-locations' aka 'work from home' policies.

Projects implemented to address and improve the large carbon foot print animal agriculture has on our environment. We need a decrease in the use of animal products in Ann Arbor and at the University.

Help/encourage airplane industries to find alternative clean power solution. Imposing fees is not and will not be effective. It is just going to increase the already high prices of airfare tickets due to current fees being collected. As a recent example, automotive industries never thought about making cars that are more efficient and generates less emission till they were incentivized/challenged to do so.

Support UM units who are not wealthy enough to pay these fees. While this structure may be great for bio or engineering schools of wealth, other units will be cut off from travel because we cannot afford it.

solar project PPA for lower cost projects in sunnier locations

Plant trees within 50 mile radius of campus

Reliable and viable alternative transportation methods 
On or off campus projects to generate energy efficiency and zero carbon power

On campus projects to improve sustainability of transportation and transit options available to students and staff.

Local project but NOT solar panels (c'mon, it's Michigan, we don't have enough sunshine)

lobby to stop the cut of trees in the Amazon

Off campus projects specifically focused on combatting environmental racism

Not sure - would want more information about administration and efficacy of program

on campus sustainability training programs for faculty/staff/students

I don't see elsewhere that I can put comments, but I think at the begining of the study, you should provide a general comparison of the carbon footprints for general activities (utilities, transportation, etc.) Is the air travel carbon the dominanting factor? Is it significantly larger than other activities, given it is much less frequent than human activities?

RESEARCH! These funds would be better wasted by academics rather than a bunch of idiots with solar panels.

off campus animal protection due to climate change, water pollution, etc.

Lobbying for better rail/bus infrastructure

local transportation

\section{REPLACEMENT OF LEAF BLOWERS ON CAMPUS}

Would want to know the dollars are actually being used appropriately and that they are having an impact

\section{Support the Consumers Energy Clean Energy Plan}

It should go towards carbon sequestration research and activities. --- It is a carbon tax, so I think it would be appropriate to take the problem head on. Another option would be research on alternative fuels for air travel... Reduce the air travel impact as well.

support funding for buildings to be brought up to energy and sustainable ON CAMPUS

For campus and city conservation purposes

university research and development for clean energy and clean energy promotion

Support sustainability projects for clean power and water locally.

Incentivize uze of bicyles in town, electric vehicles in and out of town

Projects known to have best ROI

Anything outside of university of Michigan entities. Cannot just be paid back to the university. Otherwise this is just the $U$ trying to save money on travel and pay itself to improve its finances. Only trustworthy if it's paid to a non UM cause.

how about plant tress on campus!? UM has a terrible attitude to its own campus I would prefer to select projects that have the biggest worldwide effect for the future of our planet as well as local projects that would put pressure on places where change might not easily 
be explored unless there was a mandate.

Not having students pay fee to be apart of an intramural team.

Commute at the medical campus is a disaster. No parking space. Cars are emitting CO2 for nothing in searching for a parking spot. The $U$ should invest more in daily commute by reenforcing bus system, which is very primitive, does not arrive on time and rarely serviced.

Whatever gives the highest return on the investment

I feel strongly that first-world countries that contributed the most to global warming must not place the blame, or foist the burden of fixing the problem, on low income countries or communities. Whatever solutions we come up with should recognize this.

Not sure - depends on effectiveness of these alternatives, about which I am not well incormed

UNIVERSITY OF MICHIGAN MUST DIVEST FROM ALL FOSSIL FUEL INVESTMENTS 


\section{Appendix K: Group Comparison}

We care more about those who had more university travels in 2019 and those who self-reported who knew more about the difference in greenhouse gases (GHG) produced by air travel compared to ground travel. We define two groups: frequent travelers and people with good knowledge on GHG. Frequent travelers are respondents who had 5-or-more-time university travels in 2019. People with good knowledge on greenhouse gas are those who reported that they knew "a great deal" or "some" about the difference in greenhouse gases produced by air travel compared to ground travel. Note that we excluded responses which finished less than $75 \%$ of our survey when doing this analysis.

Q1 Who are the frequent travelers and who know more about greenhouse gas emission by different travel modes?

\begin{tabular}{llll}
\hline & Faculty & Students/Postdoc & Staff \\
\hline Frequent travelers & 300 & 38 & 278 \\
Non-frequent travelers & 334 & 165 & 1002 \\
\hline
\end{tabular}

\begin{tabular}{llll}
\hline & Faculty & Students/Postdoc & Staff \\
\hline Know more about GHG & 368 & 95 & 401 \\
Know less about GHG & 236 & 91 & 616 \\
\hline
\end{tabular}

We tabulate the primary roles and the results are illustrated above. As we can see, about $50 \%$ faculty members in our survey are frequent travelers. Besides, almost half of respondents are self-identified as "know more about GHG" and half self-identified as "know less".

Q2 What is the difference of attitudes among frequent travelers and non-frequent travelers?

\begin{tabular}{llll}
\hline & Videoconference & Travel Fees & Ground Transportation Miles \\
\hline Non-Frequent travelers & 2.23 & 2.55 & 315.15 \\
Frequent travelers & 2.48 & 2.49 & 311.91 \\
T-test p-value & 0.001 & 0.233 & 0.403 \\
\hline
\end{tabular}

We pay more attention to alternatives to air travel (videoconference and ground transportation) and the supportiveness of setting up travel fees. Therefore, we scale the supportiveness of videoconference and travel fees from 1 to 4.1 stands for "very difficult (to use)" and 4 stands for "very easy (to use)" regarding videoconference. Similarly, in terms of travel fees, 1 indicates "definitely not support," and 4 indicates "definitely support". Additionally, the longest distance people would be willing to use ground transportation instead of traveling by air ranges from 200 miles to 500 miles.

The average mean of each variable is reported above. Only the difference of attitude on videoconference is statistically significant. Frequent travelers think videoconferencing is easier to use than non-frequent travelers. Also, frequent travelers are less willing to support the travel fee although the statistical test result is not significant. 
Q3 What is the difference of attitudes among people who know more about GHG and who don't?

\begin{tabular}{llll}
\hline & Videoconference & Travel Fees & Ground Transportation Miles \\
\hline Know less about GHG & 2.22 & 2.44 & 306.73 \\
Know more about GHG & 2.42 & 2.61 & 322.90 \\
T-test p-value & 0.001 & 0.000 & 0.000 \\
\hline
\end{tabular}

The table given above illustrates different attitudes on alternatives to air travel and supportiveness of travel fees. We have a clear result that there is a significantly different attitude among people who know more about GHG and who know less. As expected, people who know more about GHG tend to accept alternatives to air travel and also, they are more willing to support the travel fee. 
Appendix L,

University Travel Internal Analysis Team Final Report

\section{Appendix L: Internet-Assisted Virtual Meetings}

Virtual meetings can be divided into three sizes, which require different hardware, software and communications strategies. The first is 1-to-1 communication carried out with Skype, Zoom, or BlueJeans most often using a laptop computer or iPad as these include a camera microphone and speakers. A desktop computer can be used with an added camera and microphone but is more apt to give problems as the components are not as well integrated. Cost for this communication is low as most academicians and scientists already have the equipment.

The second type is small group meetings. The original format was for two groups each sitting around a conference table to be in real time communication. This requires a conference room equipped with a large TV screen (55 to 75 inches) and a camera microphone that can record from a larger area and at higher resolution than a laptop. Many centers/units have such a facility, but a new one can be set up for $\$ 4,000$ to $\$ 10,000$ depending mainly on the size of the screen and whether it is put together by an IT department. Such facilities can also be used for small to medium sized in-house meetings where it is desired for all present to be able to see the material. This may require a larger screen. A newer and more common small group meeting model is where each person (up to $\sim 8-12$ ) is in a different physical location and uses their own laptop. The organizer sends out a link using Zoom, BlueJeans, or Go to Meeting software Professional Grade. As long as everyone has a standard professional quality laptop or iPad and a good high-speed internet connection, the limitations relate to the skill and experience of the moderator. All participants can be seen by each other and can present material they have on their computer by the share screen functions. Participants can also send public or private messages to each other by the Chat function. Such meetings can be used for Committee business or Grant Review panels. When such meetings involve international participants without high speed internet connections, the functioning of the meeting definitely suffers.

The third type is the larger meeting with 30 to 1,000 participants. This physically overlaps with what is used for teaching large virtual classes and is characterized by asymmetric equipment with a classroom or auditorium with high quality video, multiple cameras, and a technical manager on one end, as well as a large number of participants/students using a laptop or desktop that can send in questions electronically but mainly watches and listens. With so many people, there is usually no attempt to put individual pictures on the screen, but this could be done for a preselected panel of discussants. Breakout groups can also be used, similar to small group meetings. For large meetings, the organizers need to decide if they want communication to be synchronous or asynchronous. The latter allows participants from different time zones and more thought out responses but can extend the meeting to as much as one or two weeks. Posters can be put up on Twitter to facilitate responses and questions.

\section{Virtual Meetings Bibliography}

Reshef, Orad, Igor Aharonovich, Andrea Armani, Sylvain Gigan, Rachel Grange, Mikhail A. Kats, and Riccardo Sapienza. "How to Organize an Online Conference." Nature Reviews Materials 5 (April 2020): 253-256. https://doi.org/10.1038/s41578-020-0194-0.

An online-only worldwide conference focused on innovations in optics (Photonics Online Meetup or POM) held in January 2020 is described. It consisted of three 1.5 hour sessions hosted on WebEx Events which can connect hundreds of participants globally with additional features such as audience muting and delocalized presenters. About 100 abstracts were submitted and presented as Posters on Twitter with some reaching 4,000 views. Advertisement of the meeting which was not sponsored by a Society was by Twitter. Creation of local viewing groups termed 
Appendix L, University Travel Internal Analysis Team Final Report

POM-Hubs was encouraged and 66 were formed. The Hubs were like mini in-person meetings. The successes and difficulties of the meeting were discussed.

Warkentin, Merrill E., Lutfus Sayeed, and Ross Hightower. "Virtual Teams versus Face-toFace Teams: An Exploratory Study of a Web-based Conference System." Decision Sciences 28, no. 24 (1997): 975-996.

An exploratory study of a World Wide Web-based asynchronous computer conference system known as MeetingWeb is presented and discussed. The computer-mediated communication system could not outperform traditional face-to-face teams under otherwise comparable circumstances. The paper presents suggestions on how to improve the interaction experience of virtual teams.

Levine, Caroline, et al. "Reducing the Carbon Footprint of Academic Travel." Inside Higher Ed, April 18, 2019. https://www.insidehighered.com/views/2019/04/18/12-scholars-share-ideasreducing-carbon-emissions-academic-travel-opinion.

Twelve scholars share ideas to limit GHG production from academic travel. Focuses on large inperson meetings and how to reduce their climate effects.

Frisch, Bob, and Cary Greene. "What It Takes to Run a Great Virtual Meeting." Harvard Business Review, March 5, 2020. https://hbr.org/2020/03/what-it-takes-to-run-a-great-virtualmeeting.

Twelve steps that can make a virtual meeting more effective.

Janisch, Tscherina, and Lorenz Hilty. "Changing University Culture Towards Reduced Air Travel-Background Report for the 2017 Virtual Conference on University Air Miles Reduction." ETH Zurich University, August 2017. https://ethz.ch/content/dam/ethz/main/ethzurich/nachhaltigkeit/Bildmaterial/virtualconference/Janisch\%20et\%20al\%202017 Changing\%2 Ouniversity\%20culture\%20towards\%20reduced\%20air\%20travel Background\%20Report\%20Vi rtual\%20Conference.pdf. 
Appendix L,

University Travel Internal Analysis Team Final Report

\section{Appendix M: Air Travel Offsets Established by Other Universities}

Several universities have already instituted various forms of a travel fee; Arizona State University, Creighton, UCLA, and Yale all maintain travel mitigation funds: ASU collects \$10 per each trip, UCLA \$9 domestic and \$25 international, Creighton \$10 domestic and \$25 international, and Yale Divinity School \$50 domestic and \$100 international. The University of Maryland states that they offset all university travel. Other universities are studying or planning for carbon offsets for university travel including Cornell, Pennsylvania, Illinois, and University of Washington. Most of these funds are used to reduce external energy needs in the surrounding area or on campus. Most often their costs are low possibly to generate acceptance and some exempt certain types of travel such as student, athletic, or sometimes grant-funded travel. The most successful programs have oversight by a Sustainability Office and either use the funds on campus to reduce GHG production or in the community, such as the Yale Community Carbon Fund. 
Appendix N,

University Travel Internal Analysis Team Final Report

\section{Appendix N: Team Biographies}

\section{John A. Williams, MD, PhD}

Dr. Williams graduated from the University of Washington in 1968 with an MD (honors) and a $\mathrm{PhD}$ in Physiology and Biophysics. Following postdoctoral work and 15 years on the faculty at the University of California, San Francisco, Dr. Williams has been at Michigan for 32 years as Professor of Physiology and Internal Medicine and served 20 years as Chair of the Department of Molecular and Integrative Physiology. He is currently the Active Emeritus Horace W.

Davenport Professor of Physiology. At Michigan, he has also participated as a Core Leader and Associate Director in the Gastrointestinal Center and in the Michigan Diabetes Center. He remains active in teaching gastrointestinal science to first-year medical students. He is the author of over 400 publications, most of which deal with the pancreas and its regulation by gastrointestinal hormones. He has mentored over 70 trainees at all educational levels. Many former trainees are professors, division chiefs, and departmental chairs around the world. He served on two NIH study sections and chaired one. He has been Editor or Associate Editor of five prominent journals, including American Journal of Physiology, The Journal of Clinical Investigation, Gastroenterology, and Annual Review of Physiology; he is the founding Editor of Pancreapedia, an open access electronic knowledge base for the Exocrine pancreas. He has also served as President of two scientific societies, the American Physiological Society and the American Pancreatic Association. He is the recipient of a number of awards, including selection as a Fellow of AAAS, a Lifetime Achievement Award from the American Pancreatic Association, and the Distinguished Achievement Award from the American Gastroenterological Association.

\section{Ming Xu, PhD}

Dr. Xu is an Associate Professor and Director of China Programs in School for Environment and Sustainability and an Associate Professor in Department of Civil and Environmental Engineering at the University of Michigan, Ann Arbor. He earned his BS and MS from Tsinghua University, China, and $\mathrm{PhD}$ from Arizona State University, all in environmental engineering. His research focuses on environmental impacts of industrial systems. At the University of Michigan, he is a core faculty member in the Center for Sustainable Systems and co-directs the Graduate Certificate Program in Industrial Ecology. He was awarded the Robert A. Laudise Medal from International Society for Industrial Ecology for "outstanding achievement in industrial ecology by a researcher under the age of 36" in 2015. He received the National Science Foundation Faculty Early Career Development (CAREER) Award in 2016. In 2017, he received the Nanova/CAPEES Frontier Research Award from Chinese-American Professors in Environmental Engineering and Science for his "recognized research leadership and pioneered an innovative research area" in environmental science and engineering. In 2019, he was selected by Environmental Science \& Technology and Environmental Science \& Technology Letters to be featured in the "Early Career Scientists Virtual Issue" for the "critical role that early career investigators play in discovering new phenomena and pioneering new approaches for solving old problems" in the environmental science and technology field. Currently, he serves as the Editor-in-Chief of the journal Resources, Conservation \& Recycling. He was elected to Chair the 2022 Gordon Research Conference on Industrial Ecology.

Hyo Sub Choi is a PhD candidate in the Department of Molecular and Integrative Physiology at the University of Michigan. He holds a Bachelor of Science in Biochemistry from Boston College. Hyo serves as a member of the Sustainability Committee in Rackham Student Government. He currently lives in Ann Arbor, MI. 
William Chown is currently finishing a Data Science major at the University of Michigan College of LSA, as well as minors in Mathematics and Physics. He enjoys the outdoors and wants to make the world a better place through the ethical use of data. He currently lives in Ann Arbor, MI.

Jiangzhou Fu is a first-year master's student majoring in Survey Methodology. He holds bachelor's and master's degrees in Political Science. He currently works as a research assistant at the Institute for Social Research, University of Michigan.

Nate Hua is a graduating master's student in the School for Environment and Sustainability (SEAS). He holds a bachelor's degree in Chemistry from the University of lowa, and before coming to the University of Michigan, he traveled extensively across the Eastern Hemisphere of the globe, inspiring his pursuit of sustainability analysis for travel. Additionally, Nate has focused his studies at SEAS in energy systems and worked as a researcher in the Center for Sustainable Systems analyzing material flows of automotive metals.

Cathy Lyu is a Master of Applied Statistics degree candidate at the University of Michigan. She holds a Bachelor of Science in Mathematics and Economics from University of WisconsinMadison. She has contributed to projects for MDP Autonomous Truck and Michigan Institute for Data Science. She currently lives in Ann Arbor, MI, working remotely.

Monica Yen is a Master of Applied Data Science degree candidate at the University of Michigan School of Information. She holds a Bachelor of Science in Environmental Studies and Sustainability from Michigan State University. She has contributed to projects for Schoolcraft College, the City of Ann Arbor, and Harris Nature Center. She currently lives in Canton, MI, working remotely. 


\section{ENDNOTES}

1. Hardisty, David J., Alec T. Beall, Ruben Lubowski, Annie Petsonk, and Rainer Romero-Canyas. "A Carbon Price by Another Name May Seem Sweeter: Consumers Prefer Upstream Offsets to Downstream Taxes." Journal of Environmental Psychology 66 (2019): 101342. https://www.sauder.ubc.ca/sites/default/files/2019-09/A Carbon Price by Another Name.pdf.

2. Anderson, Kevin. "The Inconvenient Truth of Carbon Offsets." Nature 484 (April 2012): 7. https://doi.org/10.1038/484007a.

3. U.S. Environmental Protection Agency. "Emission Factors for Greenhouse Gas Inventories." EPA Center for Corporate Climate Leadership, March 9, 2018. https://www.epa.gov/sites/production/files/2018-03/documents/emissionfactors mar 2018 0.pdf.

4. UNH Sustainability Institute. "Carbon References. Sustainability Indicator Management \& Analysis Platform." The Sustainability Institute at the University of New Hampshire, n.d. https://unhsimap.org/cmap/resources/carbon-references.

5. International Civil Aviation Organization. "ICAO Carbon Emissions Calculator Methodology Version 10." ICAO Environment, 2017. https://www.icao.int/environmentalprotection/CarbonOffset/Documents/Methodology\%20ICAO\%20Carbon\%20Calculator v102017.pdf.

6. "The myclimate Flight Emission Calculator." myclimate, August 13, 2019. https://www.myclimate.org/fileadmin/user upload/myclimate home/01 Information/01 About myclimate/09 Calculation principles/Documents/myclimateflight-calculator-documentation EN.pdf.

7. McDermott, Mat. "What the Heck Is Radiative Forcing \& Why Should My Aviation Carbon Offset Include It?” Treehugger, May 15, 2009.

8. University of Michigan. "Work Plan Overview." President's Commission on Carbon Neutrality, May 1, 2019. http://sustainability.umich.edu/media/files/PCCN-Work-PlanOverview-050119.pdf.

9. Mickelson, Brian, Gretchen Thuesen, Nicholas Waldo, Alison Cullen, and Elise Glassman. "University of Washington Air Travel: A Sustainable Path Forward." Report, UW Sustainability Office, March 18, 2016. https://green.uw.edu/sites/default/files/docs/final-reportuw-air-travel.pdf.

10. Ciers, Joachim, Aleksandra Mandic, Laszlo D. Toth, and Giel O. Veld. "Carbon Footprint of Academic Air Travel: A Case Study in Switzerland." Sustainability 11, no. 1 (2018): 80. https://doi.org/10.3390/su11010080. 
11. Larsen, Hogne N., Johan Pettersen, Christian Solli, and Edgar G Hertwich. "Investigating the Carbon Footprint of a University - the Case of NTNU." Journal of Cleaner Production 48 (2013): 39-47. https://doi.org/10.1016/j.jclepro.2011.10.007.

12. Arsenault, Julien, Julie Talbot, Lama Boustani, Rodolphe Gonzalès, and Kevin Manaugh. "The Environmental Footprint of Academic and Student Mobility in a Large ResearchOriented University." Environmental Research Letters 14, no. 9 (2019): 95001. https://doi.org/10.1088/1748-9326/ab33e6.

13. Genter, Katie. "Everything You Need to Know about Carbon Offsetting for Your Flights." The Points Guy, November 21, 2019. https://thepointsguy.com/guide/everything-youneed-to-know-carbon-offsetting-flights/.

14. Graver, Brandon, Kevin Zhang, and Dan Rutherford. " $\mathrm{CO}_{2}$ Emissions from Commercial Aviation, 2018." International Council on Clean Transportation Working paper 2019-16. https://theicct.org/sites/default/files/publications/ICCT CO2-commercl-aviation2018 20190918.pdf. 